\title{
MASSACHUSETTS INSTITUTE OF TECHNOLOGY
}

\author{
Laboratory for Nuclear Science
}

\section{PROGRESS REPORT}

February 29, 1956 


\section{DISCLAIMER}

This report was prepared as an account of work sponsored by an agency of the United States Government. Neither the United States Government nor any agency Thereof, nor any of their employees, makes any warranty, express or implied, or assumes any legal liability or responsibility for the accuracy, completeness, or usefulness of any information, apparatus, product, or process disclosed, or represents that its use would not infringe privately owned rights. Reference herein to any specific commercial product, process, or service by trade name, trademark, manufacturer, or otherwise does not necessarily constitute or imply its endorsement, recommendation, or favoring by the United States Government or any agency thereof. The views and opinions of authors expressed herein do not necessarily state or reflect those of the United States Government or any agency thereof. 


\section{DISCLAIMER}

Portions of this document may be illegible in electronic image products. Images are produced from the best available original document. 


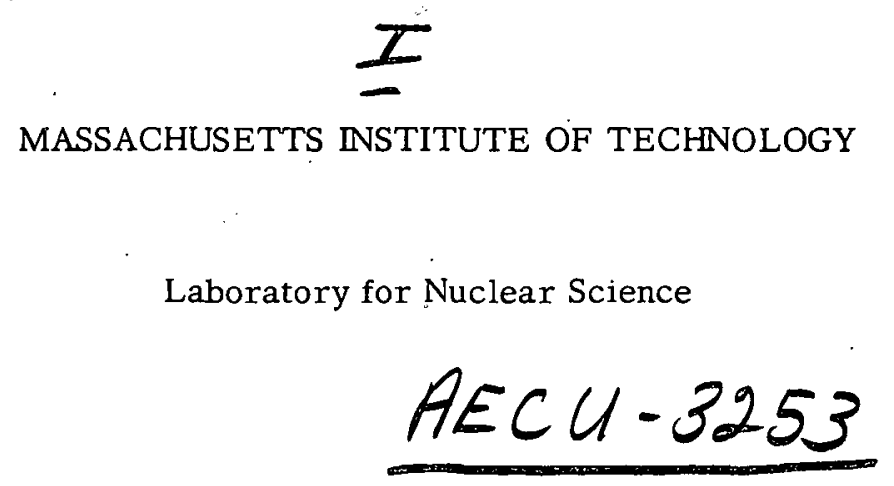

- PROGRESS REPORT

February 29, 1956

\begin{abstract}
Reproduction in whole or in part is permitted for any purpose by the U. S. Government. The data and the results which are presented in this report should not otherwise be published without prior consultation with the Laboratory for Nuclear Science.
\end{abstract}

\footnotetext{
Researches herein reported by the Chemistry Groups have been supported by the Atomic Energy Commission under Contract No. AT(30-1)-905; the work of the remaining groups has been supported by the joint program of the Office of Naval Research and the Atomic Energy Commission under Task Contract N5ori-07806.
} 


\section{II}

This is the fortieth progress report of the Laboratory for Nuclear Science at the Massachusetts Institute of Technology. Progress during the period of December 1, 1955 through February 29, 1956 is reported.

\section{TABLE OF CONTENTS}

Chemistry of the Fission Elements Group . . . . . . . . . . . . 1

Nuclear Chemistry (Inorganic) Group . . . . . . . . . . . . . 10

Nuclear Chemistry (Organic) Group . . . . . . . . . . . . . 21

Cosmic Ray Group . . . . . . . . . . . . . . . . . . . 25

Elementary Particle Scattering Group . . . . . . . . . . . . 32

Rockefeller Generator Group . . . . . . . . . . . . . . . . 39

ONR Generator Group . . . . . . . . . . . . . . . . . . 41

Radioactivity Group . . . . . . . . . . . . . . . . . . . 47

Cyclotron Group . . . . . . . . . . . . . . . . . . . . 51

Synchrotron Group . . . . . . . . . . . . . . . . . . 54

Theoretical Group: . . . . . . . . . . . . . . . . . . . 64

Cambridge Accelerator Project Group . . . . . . . . . . . . . 68

Personnel Listing . . . . . . . . . . . . . . . . . . . 74

Reprints of published papers listed herein are available in limited numbers upon request from the Laboratory for Nuclear Science. 


\section{COMPLEX IONS OF THE FISSION ELEMENTS}

\section{A. Analytical Chemistry of Indium}

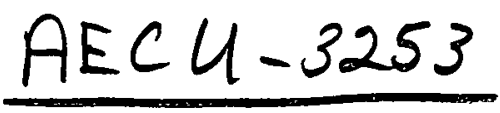

The ultraviolet spectrophotometric study of indium bromide complexes in aqueous solution has been concluded. Treatment of data obtained previously and recently by some of the methods outlined by Rossotti and Rossotti ${ }^{1}$ has revealed the value of the stability constant for the reaction $\mathrm{InBr}_{2}{ }^{+}+\mathrm{Br}^{-}=\mathrm{InBr}_{3}$ at an ionic strength of 4.00 to be 3.4. A summary of an average of the "step-wise" stability constants obtained by different methods of treatment of the data give the values of $120,19,3.4$ and 6.8 for the mono-, di-, tri-, and tctra-bromo complexes at an ionic strength of 4.00 .

The spectra of indium in the presence of excess bromide were examined again, this time with the use of $0.100 \mathrm{~cm}$. silica cells in order that spectra at wavelengths lower than $230 \mathrm{~m} \mu$ could be obtained. The observation of an absorption peak at $235 \mathrm{~m} \mu$ was confirmed. A previously suspected increase of absorbancy with ionic strength was confirmed.

Studies on the lower oxidation states of indium have yet to give evidence of the formation of these states. More work on this phase of the analytical chemistry of indium is currently being carried out. (E. A. Burns)

B. Interfacial Tension and Complex Ion Formation

Work on the method of Kazi and Desai ${ }^{2}$ on the effect of complex ion formation on the interfacial tension of aqueous solutions against certain polar organic solvents continues. It has been recently found, in this laboratory, that interfacial tension maxima of the type obtained by Kazi and Desai ${ }^{2}$ can be obtained by employing the ring method of DuNouy for the measurement. By measuring the change in interfacial tension of a series of aqueous solutions (containing a constant amount of potassium chloride but varying amounts of mercuric chloride) against $\underline{n}$-butyl acetate, a maximum interfacial tension was noted at the point corresponding to the formation of the $\mathrm{HgCl}_{4}{ }^{--}$ ion. Another series of aqueous solutions containing the same amount of potassium chloride as before, but substituting mercuric nitrate for the mercuric chloride yielded a similar maximum at the point corresponding to the formation of undissociated $\mathrm{HgCl}_{2}$. Similar results were obtained when the surface tension (i.e., the interfacial tension versus air) of the two series of solutions was determincd, although the maxima in both cases were not as well defined as in the interfacial tension measurements.

Even though the results are somewhat analogous to those of Kazi and Desai in respect to the position of some of the maxima, this laboratory fails to note the relatively large differences

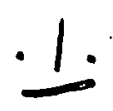


in interfacial tension between the minimum and maximum values obtained by the original investigators, our range being about one-tenth of theirs; that is, $3-4$ dynes $/ \mathrm{cm}$. versus $0.35 \mathrm{dyne} / \mathrm{cm}$. At present the work in this laboratory is being directed towards an investigation of the feasibility of this method as a titration procedure for the detection of end points in complexometric processes. (E. A. Heintz)

C. Acetato Complexes of Lead in Aqueous Solution

The existence of three complex ions, $\mathrm{Pb}(\mathrm{OAc})^{+}, \mathrm{Pb}(\mathrm{OAc})_{2}$, and $\mathrm{Pb}(\mathrm{OAc})_{3}-$ has been found in perchlorate solutions of lead containing excess sodium acetate. By the use of polarographic, potentiometric, and solubility techniques successive "uver-all" stability constants have been evaluated at an ionic. strength of 1.98. The average values of the "over-all" formation constants obtained by the three techniques for the mono-, di-, and tri-acetato complexes are 145, 810, and 2950 , respectively. The existence of anionic species was confirmed by an anion exchange technique. (E. A. Burns)

\section{FLAME PHOTOMETRY OF THE ALKALI METALS}

Work has been initiated on a study to determine and evaluate interferences with flame intensities arising from mutual interactions among lithium, sodium and potassium ions. The information is to be obtained by applying the analysis of variance to the results of suitably designed factorial experiments. (W. E. Ohnesorge)

\section{THERMOMETRIC TITRATIONS}

\section{A. Acetic Acid as a Solvent}

The anhydrous acetic acid prepared as described in the previous report was found to be unsuitable as a solvent when using the thermometric end point. The technique of adding calculated amounts of acetic anhydride to react with the water present (as determined by Karl Fischer titration) and heating without catalyst for several days resulted in a water content of $<0.10 \%$. However, the reaction proved to be incomplete despite the lcngth of time it was held at an elevated temperature (ca. $100^{\circ} \mathrm{C}$ ), and small amounts of acetic anhydride remained unreacted. Upon addition of the perchloric acid titrant, in the absence of any strong base, the reaction was catalyzed, and a kinetic temperature effect was noted which had a deleterious effect upon the normal thermometric titration curve after the end point. It was estimated that the amount of unreacted acetic anhydride could not have been greater than $0.1 \%$.

Anhydrous acetic acid was finally prepared in the presence of a trace of perchloric acid $(0.001 \underline{M})$ to act as catalyst. By adding the calculated amount of acetic anhydride, and allowing the reaction to proceed overnight, it was found that the water content of the acetic acid had been 
- reduced to $<0.01 \%$ without excess acetic anhydride remaining. A small blank must be used in conjunction with this solvent.

Using this solvent to make solutions of several bases, together with the $0.5 \mathrm{M}$ perchloric acid prepared as described in the last report, thermometric titrations were performed in an essentially anhydrous acetic acid solvent system ( $<0.01 \%$ water). The heat of dilution of the perchloric acid solution was negligibly small in the absence of water.

Equation (1) related the slope of a thermometric titration curve to: (a) the isothermal heat of reaction $\left(\Delta \mathrm{H}_{\mathrm{T}}\right)$ in $\mathrm{Kcal} / \mathrm{mole}$ (where $\mathrm{T}$ is the initial temperature of the solution); (b) the molarity of the titrant $(M)$; and $(c)$ the heat capacity $\left(C_{p}\right)$ in cal/deg of the product solution plus the calorimeter. The initial slope,

$$
\frac{\mathrm{dT}}{\mathrm{dV}}=-\frac{\Delta \mathrm{H}_{\mathrm{T}} \mathrm{M}}{\mathrm{C}_{\mathrm{p}}}
$$

provides the most advantageous point for the calculation. Thus one titration curve can be used to calculate the purity of the substance being titrated and its heat of reaction with the titrant. Table 1.I shows the results of three titrations of reagent-grade anhydrous sodium acetate with $0.5 \mathrm{M}$ perchloric acid in anhydrous acetic acid.

TABLE 1.I

\begin{tabular}{cccc} 
Curve & Analysis & $\frac{-\Delta \mathrm{H} \text { in }}{\text { Kcal/mole }}$ & $\begin{array}{c}\text { Temp. in } \\
\text { degrees C. }\end{array}$ \\
\cline { 2 - 3 } 1 & $99.3 \%$ & 5.6 & 23.2 \\
2 & $99.6 \%$ & 5.9 & 22.2 \\
3 & $99.9 \%$ & 5.7 & 22.6 \\
ave & $99.6 \%$ & 5.7 & \\
Std Dev & 0.30 & 0.16 &
\end{tabular}

The concentration of the sodium acetate solutions was of the order of $0.05 \underline{\mathrm{M}}$. The heat capacity of the Dewar flasks had been previously determined, and the specific heat of the sodium acetate solutions was found to be essentially the same as that of pure acetic acid. The value of the heat of reaction represented by equation (2)

$$
\mathrm{NaAc}+\mathrm{HClO}_{4}=\mathrm{NaClO}_{4}+\mathrm{HAC}
$$

agrees excellently with the measurements made by Jolly ${ }^{3}$ who reported it at $-5.7 \mathrm{Kcal} / \mathrm{mole}$ $\left(25^{\circ} \mathrm{C}\right)$.

Work is being continued on the titration of other acetates, amines, and inorganic salts in anhydrous acetic acid. (H. J. Keily) 
B. Acetonitrile as $\underline{\text { a Solvent }}$

Organic bases and soluble inorganic salts have been titrated automatically with $0.5 \mathrm{M}$ perchloric acid in acetonitrile, using a thermistor as the temperature sensitive indicator.

Titrations of Organic Bases: The initial slopes $\mathrm{dT} / \mathrm{dV}$ of the titration curves for bases fall into two distinct groups, indicating widely differing heats of reaction. The heats for aliphatic bases generally appear to be much greater than those for aromatic bases. Pyridine appears to be intermediate between the two groups. Small differences in heats of reaction appear to exist within each group for each individual compound, although experimental conditions were such that the reality of these differences cannot be proven unequivocally at this time. The roundness of the end point appears to be correlated with the strength of the base titrated. Bases as weak as o-chloroaniline ( $\mathrm{pK}_{\mathrm{b}}$ in $\mathrm{H}_{2} \mathrm{O} 10^{-12}$ ) give curves that appear to be amenable to extrapolation to quantitatively useful end points.

Titrations of Inorganic Salts: As preliminary to titration studies, the solubilities of a total of 47 salts, mostly the $\mathrm{Li}, \mathrm{Na}, \mathrm{K}$, and $\mathrm{NH}_{4}$ salts of common acids, were determined. Many of the salts are virtually insoluble in acetonitrile. The thiocyanates, iodides, and perchlorates were generally quite soluble. Lithium salts seem to be more soluble than those of the other alkali cations. All the titrations with perchloric acid gave endothermic reactions in contrast to the exothermic titrations observed with organic bases. A study is being made to see if the apparent small differences in heats of reaction are real, and if they relate to other properties." (E. J. Forman)

\section{COULOMETRY}

\section{A. Coulometric Titrations with Electrically Generated Mercury (I and II)}

In earlier reports it has been shown that the substitution of mercury for silver in the titration of halides was advantageous because the smaller solubility products permitted correspondingly smaller amounts of the halides to be determined. During the past quarter, the study has been extended to cyanide with the result that $5 \mu \mathrm{g}$ of cyanide in a $50 \mathrm{ml}$. sample can be determined with an accuracy and precision of better than $1 \%$.

At the present time optimum conditions are being sought for the determination of sulfide.

\section{(E. P. Przybylowicz)}

B. Coulometric Generation of Reagents for Studies of Indicator "Blanks" in Titrations

In titrations of submicrogram amounts of substances in $10-100 \mathrm{ml}$. of solution, the amount of reagent that must be added to effect a change in the indicator becomes a significant, or even predominant, factor in the titration. In attempting to study potentiometric indication in the bromine-bromide system, polarization of the electrodes appeared to be the limiting factor when commercially available vacuum-tube voltmeters and potentiometers were employed. In order to 
minimize polarization effects, a vibrating-reed electrometer was obtained. Mechanical and electrical difficulties encountered when the unit was put into service have just been eliminated. As a result, experiments are now being started in which polarization should play an insignificant role. (J. K. Lee)

\section{PRECIPITATION OF METAL SULFIDES WITH THIOACETAMIDE}

A quantitative investigation of the effect of substituting thioacetamide for hydrogen sulfide in a conventional qualitative system of analysis has been undertaken. A preliminary study was made on the precipitation of the sulfides of the hydrogen-sulfide group elements and the ammoniumsulfide group elements as a function of acidity and temperature. The results of this study indicated that precipitation occurred faster at higher temperatures, that the rate of precipitation as a function of acidity was also a function of the element under consideration, and that uncommon colors were obtained during precipitation.

A study of the completeness of precipitation of the hydrogen-sulfide group elements and coprecipitation of the ammonium-sulfide group elements is being initiated. A factorial investigation of the completeness of precipitation of cadmium as a function of acidity, ratio of thioacetamide concentration to cadmium concentration, and time of heating at $90^{\circ} \mathrm{C}$ is currently being performed. (E. A. Burns)

\section{VOLUMETRIC DETERMINATION OF SULFATE IN MIXTURES WITH WEAK ACID ANIONS}

An ion-exchange method for the determination of sulfate in the presence of halides has been developed by Whiteker and Swift and independently by Futterknecht. In this method a sulfate-halide mixture is passed through a cation exchanger in the hydrogen form. The resultant mixture of acids is first titrated to determine the total acidity and then to determine the halide content. The equivalents of sulfate are calculated from the difference between the total equivalents of acid and the equivalents of halide.

The present investigation concerns the extension of this method to include a determination of sulfate. in the presence of weak acid anions such as arsenate and phosphate. As before, the' mixture is passed through a cation exchanger and the total acidity determined. If this titration is made with a pH meter, the total acidity may be broken up into that due to strong acids and that due to weak acids. The $\mathrm{pH}$ of the titrated solution is then adjusted to 1.0 and the halides titrated argentometrically. The equivalents of sulfate can readily be determined by subtracting the equivalents of halide and the equivalents of weak acids from the total acidity.

In order to keep this method simple, a Beckman Model $\mathrm{G}$ pH Meter is to be used with a glass electrode and a silver electrode serving as the electrode pair for both titrations. In the acidimetric 
titration the glass electrode is the indicating electrode and the silver electrode is the reference electrode. During the argentometric titration the roles of the electrodes are reversed.

Statistical studies will be performed on the ion-exchange method in order to determine the optimum flow rate, column height, and amount of wash solution. (R. C. DeGeiso)

\section{ION-EXCHANGE MEMBRANE ELECTRODES}

An investigation of the nature of the potential developed across an ion-exchange membrane placed between solutions of different activity in the same or different components has been initiated. The apparatus necessary for such a study has been constructed, and preliminary measurements have been made.

Two problems have been chosen for investigation. The first is a study of the factors affecting the potential at sub millimolar concentrations. Published data indicate that at low concentrations the potentials obtained are no longer those of a simple concentration cell but tend to be of somewhat lesser magnitude. These deviations from ideal behavior have been attributed to hydrolysis by some authors and by others to rate of diffusion processes. It is hoped that this situation may be clarified by a comparison of the membrane potentials obtained with sodium chloride and hydrochloric acid, or with other systems in which a solution containing a "sink" of one of the mobile ions is used.

Also of interest is the use of ion-exchange membrane electrodes in potentiometric titrations. Relatively little work has been done in this field, but it appears that these electrodes might prove to be of value in systems where at present no indicating electrode is available, as for example with the alkali and alkaline earth metal ions. (R. B. Hanselman)

\section{THE ELECTRODEPOSITION BEHAVIOR OF TRACE AMOUNTS OF ELEMENTS}

\section{A. Nickel}

During the past quarter, effort has been devoted exclusively to the instrumental aspects of the problem. In the first place, most of the potentiostats were found to be erratic in performance, thereby necessitating a complete overhaul. More important, new apparatus has been built and tested including counting rate meters, a power supply, and an amplifier. Finally, equipment for gamma-ray spectroscopy has been received and is in the process of being tested and calibrated.

In preparation for the electrolyses, several glass cups of different sizes have been prepared for use as mercury reservoirs (and electrodes). These will be used for both polarographic determinations and electrolytic separations. It is expected that preliminary runs using millimolar solutions of nickel will be made following which more dilute solutions will be explored using radioactivity. (C. F. Morrison) 


\section{B. Copper}

Deposition curves showing the percentage deposited as a function of the potential on the platinum gauze electrode have been obtained in a number of media using millimolar copper (II) in . $0.1 \mathrm{M}$ supporting electrolyte. In general, the curves agreed with the comparable polarographic ones within $10 \mathrm{mv}$. A single run using $10^{-4} \mathrm{M}$ copper in perchlorate medium has indicated through the presence of a small plateau at potentials more noble than the regular wave, the definite possibility of "pre-deposition" of the first layer of copper atoms as hoped for on the basis of analogy with silver.

In anticipation of following the behavior in very dilute solutions, two preparations of radioactive $\mathrm{Cu}^{64}$ by deuteron bombardment of zinc have been made in order to compare various methods for the separation of the resulting mixture of zinc, gallium and copper. Ion exchange, solvent extraction, precipitation and electrolysis have each been explored briefly. Interestingly enough, it appears at this time that electro-deposition may be the most suitable method. (R. C. DeGeiso)

\section{Manganese}

The anodic co-deposition of $\mathrm{Mn}^{52}$ with lead dioxide, is being revived after a lapse of several years. In concentrations below $10^{-6} \mathrm{M}$, manganese has been found not to deposit as the oxide unless substantial amounts of another oxide, such as lead dioxide, were deposited. Thus, an opportunity is available for studying the important factors in electrolytic coprecipitation and to compare them with those encountered in the classical studies. On the basis of the earlier study, it is expected that electrolytic coprecipitation, like homogeneous precipitation, will lead to better reproducibility. In addition, it appears that control of the electrode potential will result in increased selectivity. (E. A. Heintz)

\section{RATES OF ELECTROCHEMICAL REACTIONS}

\section{A. Solid Electrodes}

Preparations for oscillographic studies of reaction rates at platinum electrodes have nearly been completed. Appropriate power supplies, amplifiers and AC bridge circuits have been designed and assembled. These will permit qualitative studies of the type.proposed by Heyrovsky as well as quantitative ones, patterned after Randles, to be made. At the present time, minor difficulties are being eliminated from the apparatus following which attempts will be made to reproduce some of the results obtained by Heyrovský and by Randles before going on to other systems. (R. F: Breese)

\section{B. Mercury Electrodes}

The present study is designed to explore quantitatively the effect of supposedly inert electrolytes on the electron-transfer process. From a study of the published polarographic literature, 
Chemistry of the Fission Elements Group

as well as from a survey of several other systems that has just been completed, it appears that a surprising number of inorganic reactions will be susceptible to such a study. Anomalous shifts of polarographic waves for arsenic (III), heretofore unreported, are now under investigation.

(W. H. Reinmuth).

\section{FLUORESCENCE OF METAL CHELATES}

An investigation has been begun to determine the effect of the structure of organo-metallic compounds on their fluorescence spectra and on the extent of the conversion of exciting radiation into fluorescent radiation. A number of qualitative studies have been reported in the literature but the only exhaustive quantitative study appears to have dealt only with the chlorophylls. However, no systematic study of the effect of changing the metal ion has been discovered. Studies have been initiated at room temperature while awaiting the delivery of apparatus that will permit measurements of absorption, excitation and fluorescence spectra at temperatures down to $77^{\circ} \mathrm{K}$. It is expected that phosphorescence will appear at low temperatures.

\section{A. 8-Quinolinol (Oxine)}

Reported differences in the absorption spectra for the oxinates of aluminum, gallium and indium have been confirmed. Corresponding, but larger, differences have been found in the fluorescence spectra of chloroform solutions. At the same time, the intensity of the fluorescence decreased markedly in going from aluminum to gallium while that for indium was not much different from gallium. Studies are also being made in solutions of $95 \%$ ethanol. At the same time, oxinates of a series of divalent metals are being prepared and analyzed so that they can be examined in the same way. (W. E. Ohnesorge)

B. Other Systems

At the present time, derivatives of 8-quinolinol as well as those of 1- and 2-naphthol are being purified by fractional recrystallization and by chromatography. Spectra of some of the pure organic compounds have already been recorded. As soon as the selected group of compounds has been surveyed, one of the systems will be selected for study in a way comparable to that described above for 8-quinolinol. (D. M. Hercules)

\section{REFERENCES}

1. Acta Chem. Scand. 9, 1166 (1955).

2. J. Indian Chem. Soc., 30, (1953 to present).

3. W. L. Jolly, J. Am. Chem. Soc., 74, 6199 (1952). 


\section{ADDRESSES}

D. N. Hume, "Photometric Titrations", Analytical Group, Northeastern Section, American Chemical Sociery, Cambridge, Mass., December 14, 1955.

D. N. Hume, "Photometric Titrations", Analytical Symposium, Louisiana State University, Baton Rouge, Louisiana, February 1, 2 and 3, 1956.

\section{PUBLICATIONS}

L. B. Rogers, "Electrodeposition Studies Involving Dilute Solutions", Record of Chemical Progress, Vol. 16, No. 3, (1955).

W. C. Purdy, E. A. Burns, and L. B. Rogers, "Sensitivity of Bromine-Bromide Potentiometric End Point", Anal. Chem. 27, 1988 (1955).

D. N. Hume

L. B. Rogers 
Nuclear Chemistry (Inorganic) Group

\section{SOLVENT EXTRACTION AND PHYSICO-CHEMICAL STUDIES}

A. Solvent Extraction Studies in Hydrochloric Acid- $\beta, \beta^{\prime}$-dichlorodiethyl Ether Systems

In the interpretation of distribution data, it is usually necessary to correct the raw data for phase volume changes due to the mutual solubility of both phases ${ }^{1}$. $\beta, \beta^{\prime}$-dichlorodiethyl ether was originally chosen as the organic phase for this series of studies partially on the basis of low mutual solubility with aqueous hydrochloric acids. However, recent work has shown that the phase volume changes at high acid concentrations, although small by comparison to similar systems, are, nevertheless, significant ${ }^{1,2}$.

These volume changes have been measured directly by equilibration in graduated volumetric vessels. However this technique is subject, not only to the usual difficulties common to the precise measurement of small differences, but to problems peculiar to the equilibration and subsequent separation of two liquid phases of similar density. These difficulties have been avoided to a large degree by the determination of the acid concentration of the aqueous phase before and after equilibration with a known volume of the ether, the difference in concentration being due in part to the partition of the acid, but to a larger extent to the increase of the aqueous phase volume through dissolution of the ether.

The fractional volume change of the aqueous phase, $\frac{\Delta V}{V_{O}}$, is given by the following stoichiometric equation:

$$
\frac{\Delta V}{V_{o}}=\frac{N_{o}-N_{E}}{N_{E}}-\frac{V_{\beta} N_{\beta}}{V_{o} N_{E}}
$$

where: $\Delta V=$ the volume change of aqueous phase,

$\mathrm{V}_{\mathrm{O}}=$ the initial volume of aqueous phase $(25 \mathrm{ml})$,

$\mathrm{V}_{\beta}=$ the initial volume of organic phase $(25 \mathrm{ml})$,

$\mathrm{N}_{\mathrm{O}}=$ the initial concentration of acid in aqueous phase,

$\mathrm{N}_{\mathrm{E}}=$ the equilibrium concentration of acid in aqueous phase, and

$\mathrm{N}_{\beta}=$ the equilibrium concentration of acid in organic phase.

Equation (1) is subject to the conditions that the sum of the phase volumes be constant and that the ether be initially acid-free; both conditions were verified experimentally in these studies.

The second term on the right of equation (1) contains the correction for the partition of the acid and must be evaluated by approximate methods, taking $\frac{N_{0}-N_{E}}{N_{E}}$ as a first approximation to 
$\frac{\Delta \mathrm{V}}{\mathrm{V}_{\mathrm{o}}}$. In practice the value for $\mathrm{N}_{\beta}$ for $\mathrm{HCl}$ was taken from the work of Plank ${ }^{2}$. The values reported for $\mathrm{HBr}$ have not been corrected in this manner since $\mathrm{N}_{\beta}$ for $\mathrm{HBr}$ is not known. Preliminary experiments of a semi-quantitative nature have indicated that the correction for the $\mathrm{HBr}$ partition is quite small and of marginal significance.

Data obtained to date indicate that the fractional aqueous phase volume change $\frac{\Delta V}{V}$ for $\mathrm{HCl}$ is approximately a linear function of initial $\mathrm{HCl}$ concentration in the aqueous phase, reaching from less than 0.001 at $7 \underline{\mathrm{M} \mathrm{HCl}}$ to .05 at $11.5 \mathrm{M} \mathrm{HCl}$; at concentrations above $11.5 \mathrm{M}, \frac{\Delta \mathrm{V}}{\mathrm{V}}$ begins to increase rapidly and above 0.07 at $12.0 \mathrm{M}$ initial $\mathrm{HCl}$. Preliminary information on the $\mathrm{HBr}-\beta, \beta^{\prime}-$ dichlorodiethyl ether system indicates similar behavior except that $\mathrm{HBr}$ is about twice as effective in producing volume change as $\mathrm{HCl}$; that is, $\mathrm{HBr}$ produces roughly the same volume change as twice the concentration of HCl. (R. J. Dietz, Jr., and J. W. Irvine, Jr.)

B. Extraction of Hydrochloric Acid from Water into $\beta, \beta^{\prime}$-dichlorodiethyl Ether

The experiments on the distribution of $\mathrm{HCl}$ between water and $\beta, \beta^{\prime}$-dichlorodiethyl ether. discussed in the last report ${ }^{3}$ were continued. Assuming the absence of appreciable ionization of $\mathrm{HCl}$ in ether, at low acid concentrations the pertinent reaction in this system is

$$
\mathrm{H}_{\mathrm{W}}{ }^{+}+\mathrm{Cl}_{\mathrm{W}}-=\mathrm{HCl}_{\mathrm{O}}
$$

the subscript $w$ referring to the water, and o the organic layer. As the concentration of $\mathrm{HCl}$ in the ethereal phase in the range investigated is low $\left(\sim 10^{-4} \underline{\mathrm{M}}\right)$, the equation

$$
\left(\mathrm{HCl}_{\mathrm{O}}\right) /\left(\mathrm{H}^{+}\right)\left(\mathrm{Cl}^{-}{\gamma_{ \pm}}^{2}=\mathrm{K}\right.
$$

should be valid, and a plot of. $\mathrm{HCl}_{\mathrm{O}}$ against $\mathrm{c}^{2}{\gamma_{ \pm}}^{2}$, where $\mathrm{c}$ is the concentration of aqueous acid in moles per liter and $\gamma_{ \pm}$the mean activity coefficient for the $\mathrm{HCl}_{\mathrm{W}}$, should, at sufficiently low concentrations, yield a straight line passing through the origin.

For initial aqueous acid concentrations of 1 to $6 \underline{\mathrm{M}}$, Henry's Law was found to hold within the limits of experimental error. At $22^{\circ} \mathrm{C}$ the slope of the line is $2.0 \times 10^{-6} \underline{\mathrm{M}}^{-1}$. As earlier attempts $^{2,4}$ to determine this constant relied heavily on extrapolations of the determinations of the extraction coefficient made at higher concentrations where Henry's Law is no longer valid, the agreement with these results is poor. Plank ${ }^{2}$ using a determination made at an initial aqueous acid concentration of $8.17 \mathrm{M}$ found the slope to be approximately $8 \times 10^{-7} \underline{\mathrm{M}}^{-1}$. However, this new value is in reasonable agreement with the experimental data of these previous studies ${ }^{2,4}$.

At initial aqueous acid concentrations greater than $6 \mathrm{M}$, there is a large deviation from ideality. The radiochemical determinations of the extraction coefficient at these higher concentrations are in good agreement with those previously obtained by titration methods. Further studies of the deviation in the more concentrated solutions are to be made. (C. E. Gleit, C. D. Coryell, and J. W. Irvine, Jr. ) 
C. Preparation of $\underline{\mathrm{HCl}}^{38} \mathrm{O}_{4}$

As described in the L.N.S. Quarterly Progress Report, November 30, 1955, an excellent yield of $\mathrm{HCl}^{38}$ can be obtained by the reaction $\mathrm{Cl}^{37}(\mathrm{~d}, \mathrm{p}) \mathrm{Cl}^{38}$ using $\mathrm{LiCl}$ as the target in the M. I. T. cyclotron.

An attempt was made to prepare $\mathrm{HCl}^{38} \mathrm{O}_{4}$ by bombarding $\mathrm{LiClO}_{4}$ with deuterons and preparing $\mathrm{HClO}_{4}$ from this by passing the lithium salt through a column of Dowex-50 in the acid form. This was found to be unsuccessful. The radioactive acid produced by this procedure was nearly pure $\mathrm{HCl}^{38}$. Presumably, an appreciable part of the destruction of the perchlorate is a secondary effect of the interaction of deuterons with the lithium ions. In order to avoid such reactions the $\mathrm{LiClO}_{4}$ was replaced by $\mathrm{RbClO}_{4}$. Recent experiments indicate that a substantial yield of $\mathrm{HCl}^{38} \mathrm{O}_{4}$ can be obtained by such a process. (C. E. Gleit, C. D. Coryell, and J. W. Irvine, Jr. )

\section{Solvent Extraction of Metal Halide-Halogen Acid Complexes}

A theor $y^{5}$ to explain the solvent extraction of metal halide-halogen acid complexes by $\beta, \beta^{\prime}-$ dichlorodiethyl ether has been proposed which postulates acid ionization of the complex in the ether. In order to test this theory, an analysis has been carried out of some distribution data obtained by Golden ${ }^{6}$ on the $\mathrm{Au}(\mathrm{III})$ - $\mathrm{HCl}$ system. The data exhibited poor reproducibility so that only points obtained in triplicate were used. Activity coefficients were estimated by the Debye-Huickel theory. The following values were calculated for the thermodynamic ionization constant of $\mathrm{HAuCl}_{4}$ in $\beta, \beta^{\prime}$ dichlorodiethyl ether:

$\begin{array}{cc}\frac{\mathrm{N}_{\mathrm{HCl}}}{3.0} & \frac{\mathrm{K} \times 10^{-3}}{2.7} \\ 4.2 & 3.7 \\ 6.0 & 3.0 \\ 7.8 & 5.2 \\ 9.0 & 4.4\end{array}$

If the theory is correct, $\mathrm{K}$ should be a constant. The data were not accurate enough to attempt a calcularion of $\mathrm{K}_{\mathrm{HCl}}$. The extraction coefficients for this system will be remeasured with the aim of obtaining an accuracy of 10 percent over the entire region. (A. M. Poskanzer and C. D. Coryell).

E. The Dissociation of Hydrochloric Acid in $\underline{\beta, \beta^{*} \text {-dichloroaiethyl Ether }}$

Preparations are being made for an investigation of the $\beta, \beta^{\prime}$-dichlorodiethyl ether $-\mathrm{HCl}-\mathrm{H}_{2} \cdot \mathrm{O}$ system. The first probiem is the determination of the dissociation constant of $\mathrm{HCl}$ in the dry ether. This involves measurements of the equivalent conductance and vapor pressure of $\mathrm{HCl}$ in the ether * and of the dielectric constant, viscosity, and density of the solution. Since the system is sensitive to oxygen arid moisture, all operations have to be carried out under nitrogen. The experimerital preparations can be divided into the following groups: 


\section{Nuclear Chemistry (Inorganic) Group}

\section{Purification of Solvents}

a) $\beta, \beta^{\prime}$-dichloroethyl ether was purified by washing successively with dilute acid and base and running through a column of "molecular sieves" to remove the moisture. After fractional distillation through a $90 \mathrm{~cm}$ packed column at $50-60 \mathrm{~mm}$, the middle fraction had a specific conductance of less than $10^{-7}$ mho.

b) Water with a specific conductance of $2 \times 10^{-7}$ mho was obtained by passing distilled $\mathrm{H}_{2} \mathrm{O}$ through a mixed bed deionizer using polyethylene apparatus.

\section{Standard Solutions and Titrations}

The required precision of 0.001 in $0.01 \mathrm{~N}$ acid-base titration can be achieved by overtitrating, using methyl red and backtitrating from a micro-burette, determining end point conductometrically. The primary $\mathrm{HCl}$ standard was determined gravimetrically (as $\mathrm{AgCl}$ ).

\section{Conductance Bridge and Cells}

The bridge consists of a General Radio Type 1604-B comparison bridge, Type 1432 decade resistor of $1,111,100 \Omega$ total in $10 \Omega$ steps, a $140 \mu \mu \mathrm{f}$ variable capacitor, and a cell. The Type 1604-B bridge is a unit containing two ratio arms $(25,000 \Omega$ each), an oscillator delivering $0.4,1$, and $5 \mathrm{Kc}$, and a cathode-ray-tube indicator. The decade resistor serves as standard and the capacitor to balance out cell capacitance. Various cells of cell constants ranging from 0.005 to 45 have been designed and prepared. Preliminary measurements on dilute $\mathrm{KCl}$ solutions have indicated that impedance measurements can be made with a precision of at least 0.001 .

Plans for the immediate future include $\mathrm{HCl}$ vapor-pressure measurements over the ether by the gas-saturation method with subsequent conductometrical and analytical determinations of absorbed $\mathrm{HCl}$ in water. This should give information on the activity of undissociated $\mathrm{HCl}$ in $\beta, \beta^{\prime}-$ dichlorodiethyl ether and also some indication of the accuracy of conductance measurements. (E. Rudzitis and J. W. Irvine, Jr.)

\section{ION EXCHANGE RESIN AND COMPLEX ION FORMATION STUDIES}

\section{A. X-ray Absorption Edges of Metals in Complexes}

Previously a theoretical approach and its application to complexes of $\mathrm{Cu}(\mathrm{II})$ were reported $3,7 \mathrm{a}, 7 \mathrm{~b}$. Work has now been extended to some complexes of $\mathrm{Zn}$ (II), $\mathrm{Ni}$ (II) and $\mathrm{Co}$ (III). These studies are still in progress, but indicate that the simple crystal-field theory approach may

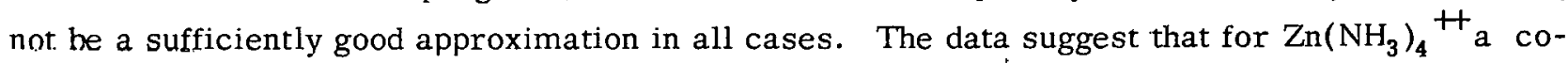
planar configuration may occur, rather than the generally assumed tetrahedral one. In this work the cooperation of Professor H. P. Hanson of the University of Texas is acknowledged. It is possible that some observed splittings are characteristic of the ammonia ligands rather than the symmetry of the complexes as postulated in the crystal-field analysis. Certain complexes of $\mathrm{Zn}$ (II) 
Nuclear Chemistry (Inorganic) Group

now under examination should provide an unambiguous solution to the problem. (F. A. Cotton)

B. Thermodynamic Properties of Complex Ions

Previously studies ${ }^{8}$ of the temperature dependence of the equilibrium constants as measured potentiometrically have been reported and used to calculate $\Delta H^{\circ}$ and $\Delta S^{\circ}$ for the formation of fiveand six-membered diamine rings with several metals. Studies of the thermodynamics of such systems - which are regarded as simple prototype chelate systems - are being extended. At present, apparatus for making very accurate measurements of heats of solution, reaction and vaporization is being designed and constructed. (F. A. Cotton, R. D. Francis, H. Frumkin, and E. W. Stone)

\section{Anion Exchange Resin Phase Studies}

In the studies of chemical specificities of certain anion pairs on strong base anion exchange resins, results have been reported 3,9 which explain the great variation in selectivity coefficient with resin composition. A thermodynamic evaluation of this variation indicates that for certain resin composition ranges, two phases of different composition are formed.

At the present time work is in progress to determine experimentally the composition of these phases by allowing separated resins of different composition to equilibrate with the same electrolyte solution. A determination in this manner of phases of different composition requires that the resin be of high chemical homogeneity.

Upon examining the Dowex-2-X8 system with chloride and thiocyanate, a method of determining the two ions potentiometrically was developed. The ions in the resin are displaced with $\mathrm{NaClO}_{4}$. The solution is made $0.2 \mathrm{M}$ with $\mathrm{HClO}_{4}$ and titrated against a silver electrode with $0.1 \mathrm{M}$ $\mathrm{AgNO}_{3}$. Just after the AgNCS endpoint (which comes before the AgCl endpoint) the solution is neutralized and titrated to the combined chloride and thiocyanate equivalence point. This method was. found to be accurate to approximately 0.5 percent. (D. H. Freeman)

D. Anion Exchange Resin Studies of the Halide Complexes of Thallium(III) and (I)

Kraus, Nelson, and Smith ${ }^{10}$ have studied the absorption of $\mathrm{Tl}$ (III) on the anion-exchange resin Dowex-1 over a 2 to $12 \mathrm{M}$ HCl range. The present experiments are concerned with the absorption of trace amounts of carrier-free $12 \mathrm{~d} \mathrm{Tl}^{202}$ (III) on 8 percent cross-linked, 50-100-mesh Dowex-1 (in chloride form) in the concentration range $10^{-4}$ to $3 \mathrm{M}$ in halide ion at $25.0 \pm 0.5^{\circ} \mathrm{C}$, and have yielded the following results and conclusions:

(1) Saturating the solution with $\mathrm{Cl}_{2}$ to prevent the reduction of $\mathrm{Tl}$ (III) to $\mathrm{Tl}(\mathrm{I})^{11}$ results in the production of additional chloride ions of concentration not negligible compared to that of initially added chloride ion and thus is an unsatisfactory method of preventing reduction under the present conditions.

(2) The presence of 1 to $2 \mathrm{M} \mathrm{HClO}_{4}$ greatly depresses the absorption of $\mathrm{Tl}$ (III) on the resin, possibly, since $\mathrm{ClO}_{4}-$ absorbs on anion exchange resins ${ }^{11,9}$ and the $\mathrm{CiO}_{4}-$ concentration is 
comparatively large, by a competitive effect, and thus $\mathrm{HClO}_{4}$ is not suited for maintaining constant acidity and ionic strength.

(3) In the absence of $\mathrm{Cl}_{2}$ and $\mathrm{HClO}_{4}$, two sets of points are obtained (see Figure 2.1. The

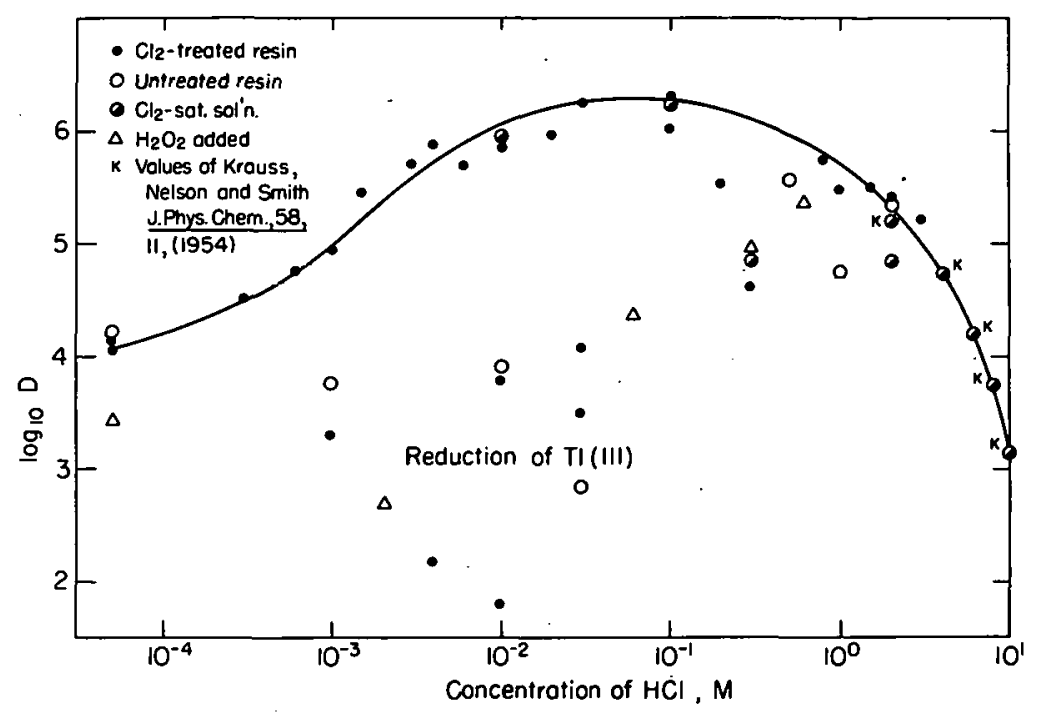

Figure 2.1

Absorption of thallium(III) on Dowex -1 at $25^{\circ} \mathrm{C}$.

distribution coefficient, $\mathrm{D} \equiv$ (amount of $\mathrm{Tl}$ per gram resin/amount per $\mathrm{ml}$ solution)) even when resin, especially pretreated with $\mathrm{Cl}_{2}$ under acid conditions in order to avoid Hofmann degradation, is used. The higher set of values describes a fairly presentable absorption curvel while the lower. set probably results from sporadic reduction, a conclusion supported by the fact that the effect lessens as the halide concentration is increased due to greater stability of the Tl(III) species with greater complexing. The presence of a considexable concentration of $\mathrm{H}_{2} \mathrm{O}_{2}$ (ca. $0.1 \underline{\mathrm{M}}$ ) does not appreciably reduce the effect. The absorption curve (see Figure 2.1) shows a small slope unan-

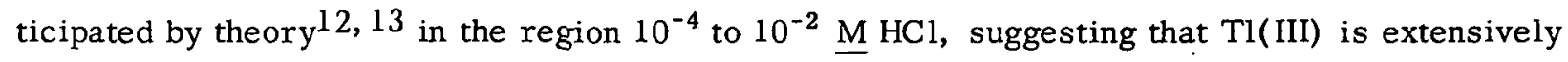
hydrolyzed at low acidities 14,15 . The general features of this curve are congruent with analogous features of curves obtained with Amberlites IR-120(H), IR-4B, and IRA-400 16 . Interpreting this absorption curve in terms of the ideas of Irving and Rossotti ${ }^{17}$ and Marcus and Coryel1 12,13 one obtains

$$
\begin{aligned}
& \mathrm{K}_{3} \equiv\left(\mathrm{TlCl}_{3}\right) /\left(\mathrm{TlCl}_{2}^{+}\right)\left(\mathrm{Cl}^{-}\right)=143 \underline{\mathrm{M}}^{-1}\left(\mu=\underline{\mathrm{ca}} \cdot 10^{-2}\right) \\
& \mathrm{K}_{4} \equiv\left(\mathrm{TlCl}_{4}^{-}\right) /\left(\mathrm{TlCl}_{3}\right)\left(\mathrm{Cl}^{-}\right)=\text {ca. } \cdot 2 \underline{\mathrm{M}^{-1}} \cdot(\mu=\underline{\text { ca. }} 1) .
\end{aligned}
$$


This value of $\mathrm{K}_{3}$ is in quite good agreement with the value quoted by Benoit ${ }^{18}, \mathrm{~K}_{3}^{\circ}=160\left(18^{\circ} \mathrm{C}\right.$ ? ), and the ratio $\mathrm{K}_{3} / \mathrm{K}_{4}=70$ is in fair agreement with the ratio he quotes for the corresponding bromide complexes, $\mathrm{K}_{3}^{\mathrm{O}} / \mathrm{K}_{4}^{\mathrm{O}}=80$, thus lending support to the theory of Marcus and Coryell and the experiments of Benoit.

Exploratory experiments on the absorption of carrier-free $\mathrm{Tl}^{202}(\mathrm{I})$ on Dowex-1 in chloride form indicate that $\mathrm{D}$ is small ${ }^{10}$ and that the curve (not shown) is $U$-shaped, decreasing with increasing $\mathrm{HCl}$ concentration at low acidities (ca. $10^{-4} \underline{\mathrm{M}}$ ) and increasing at higher acidities (ca. $1 \underline{\mathrm{M}}$ ); the former again suggests hydrolysis ${ }^{19}$ and the latter is compatible with the available estimates of the dissociation constant of $\mathrm{TlCl}^{20,21}$ (ca. 4 ).

The absorption of $\mathrm{Tl}(\mathrm{III})$ on the chloride form of Dowex-1 in $10^{-3}$ to $1 \mathrm{M} \mathrm{HBr}$ is large $\left(\mathrm{D}>10^{5}\right)$.

The following studies are planned tentatively: extension of the above experiments to $\mathrm{HBr}$ media and to different temperatures in order to evaluate the heats of association of the halide complexes of $\mathrm{Tl}(\mathrm{III})$ and possibly $\mathrm{Tl}(\mathrm{I})$, and further studies of abnormalities exhibited by the absorption of 'l'l( 1 ) on Dowex-1.' (R. A. Horne)

E. Anion-Exchange-Resin Studies of the Chloride Complexes of Tellurium(IV) and VI)

In the last progress report ${ }^{3}$, studies on the absorbability of tracer amounts of $\mathrm{Te}(\mathrm{IV})$ chloro complexes in $\mathrm{HCl}$ on the arion exchange resin (Dowex-1, 10 percent cross linked) were mentioned. These experiments have been extended to include the study of the systems $\mathrm{Te}$ (IV) - $\mathrm{LiCl}-\mathrm{HCl} \mathrm{mix}$ tures, anion-exchange resins, and $\mathrm{Te}(\mathrm{VI})-\mathrm{LiCl}$ or $\mathrm{HCl}$-anion-exchange resins.

The absorption of the chloro complexes of $\mathrm{Te}$ (IV) can be explained ${ }^{12}$ by the following reaction:

$$
\mathrm{TeCl}_{4}+\mathrm{RCl} \rightarrow \mathrm{RTeCl}_{5}
$$

(where $R$ is one equivalent of the polymeric cation of the anion-exchange resin). This means the neutral chloro complex is absorbed. This complex is formed in about $8 \mathrm{M} \mathrm{HCl}$ by the following reaction:

$$
\mathrm{Te}(\mathrm{OH})_{\mathrm{n}}(4-\mathrm{n})^{+}+4 \mathrm{Cl}^{-} \rightleftharpoons \mathrm{TeCl}_{4}+\mathrm{nOH}^{-}
$$

In $8 \underline{\mathrm{M}} \mathrm{HCl}$ the distribution coefficient of $\mathrm{Te}(\mathrm{IV})$ is about $3 \times 10^{4}$. In $8 \underline{\mathrm{M}} \mathrm{LiCl}$ solution the distribution coefficient DTe is only about 10 because the equilibrium (7) lies to the left. Increasing the $\mathrm{LiCl}$ concencration favors the formation of the neutral complex and the distribution coefficient increases $(\mathrm{D} \sim 600$ in $11 \mathrm{M} \mathrm{LiCl})$. The reproducibility of the measurements in pure $\mathrm{LiCl}$ solutions is very poor, because small amounts of acids shift the equilibrium (7) to the right.

Therefore, by adding $\mathrm{HCl}$ to the $\mathrm{LiCl}$ solutions the distribution coefficient is increased very rapidly and finally exceeds the distribution coefficient for pure $\mathrm{HCl}$ of the same $\mathrm{Cl}^{-}$concentration. In $\mathrm{LiCl}$ concentrations higher than $8 \underline{\mathrm{M}}$ : $\mathrm{D}_{\mathrm{Te}} \sim 70$ in $\underline{9 \mathrm{M} \mathrm{LiCl}}, 10^{5}$ in $8.9 \underline{\mathrm{M} \mathrm{LiCl}}+0.1 \underline{\mathrm{M} \mathrm{HCl}}, 2 \times 10^{5}$ 
in $8 \mathrm{M} \mathrm{LiCl}+1 \mathrm{M} \mathrm{HCl}$. In $9 \mathrm{M} \mathrm{HCl}, \mathrm{D}$ is only $2.5 \times 10^{4}$. This $\mathrm{LiCl}$ effect (higher distribution coefficient in $\overline{\mathrm{LiCl}}$ solution than in $\mathrm{HCl}$ ) has been observed previously by Kraus and co-workers ${ }^{22}$ for many metals but its physical interpretation is not yet clear.

$\mathrm{Te}$ (VI) which is obtained by oxidation of $\mathrm{Te}$ (IV) with chlorine gas is only slightly absorbed by an anion exchanger in $\mathrm{HCl}$ concentrations of less than $7 \underline{\mathrm{M}}$. Above $10 \mathrm{M} \mathrm{HCl}, \mathrm{D}$ increases to $15 \times 10^{3}$ without going through a maximum. In pure $\mathrm{LiCl}$ solutions the distribution coefficients of $\mathrm{Te}(\mathrm{VI})$ were found to be smaller than 10.

The different behavior of Te(IV) and TE(VI) on anion exchangers allows an easy separation of both these oxidation states in $2-4 \underline{\mathrm{M}} \mathrm{HCl}$. (U. L. Schindewolf)

F. Preparation of an Aliphatic Anion-Exchange Resin

In order to investigate whether the aromatic groups in the ion exchange resin have any influence on the absorbability of the chloro complexes of the transition metals, an aliphatic anionexchange resin containing no aromatic groups was prepared by the polymerization at $60-80^{\circ} \mathrm{C}$ of a mixture of equivalent amounts of tetraethylenepentamine and epichlorohydrin in methanol. After grinding the polymerization product (Ulex-2), it was converted to the $\mathrm{OH}^{-}$form and then treated with dimethylsulfate to insure that all the amino groups had become quaternary. This ion exchange resin in the $\mathrm{Cl}^{-}$form may have the following structure:

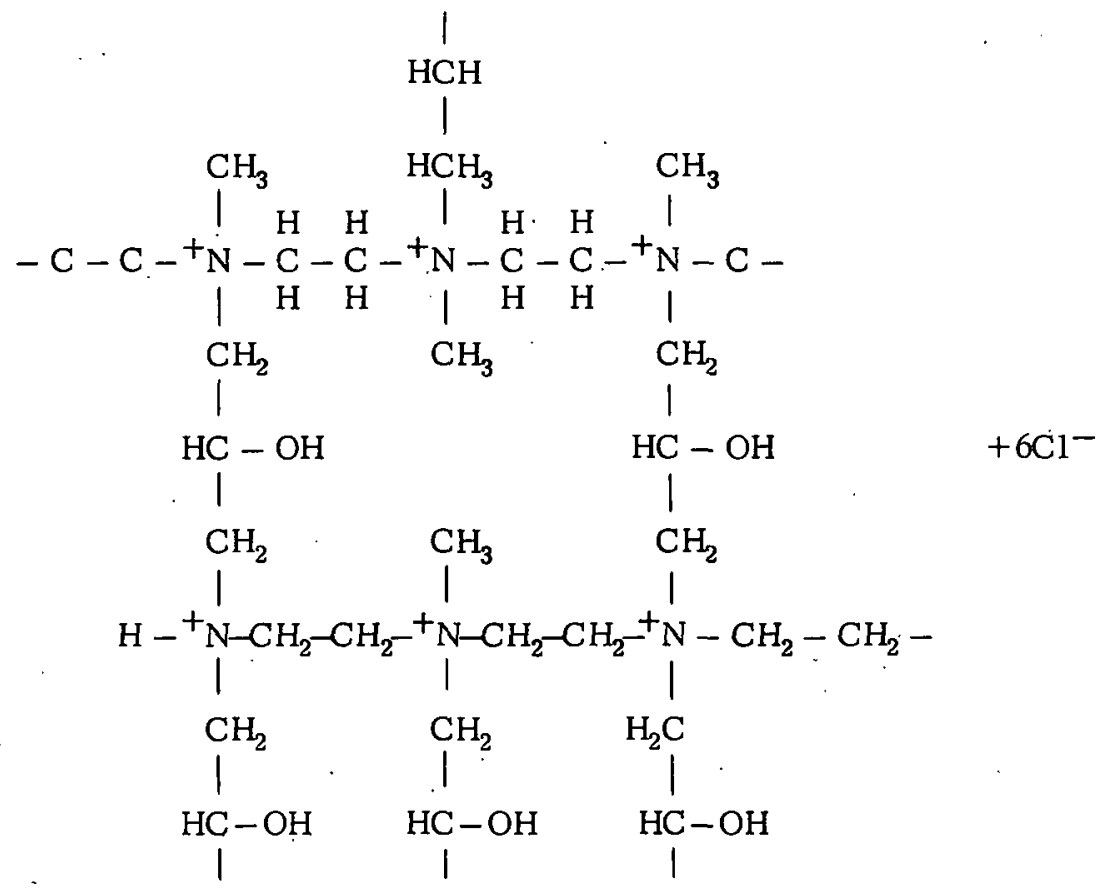

Experiments with this resin with tracer amourts of $\mathrm{Ag}^{105}$ and $\mathrm{Zn}^{65}$ are in progress. (U. L. Schindewolf) 


\section{NUCLEAR CHEMISTRY}

\section{A. Fission Yields and Decay Properties of Neutron-rich Silver Nuclides}

The decay properties of silver-111, 112, 113, and 115 have been measured in anticipation of obtaining yields in thermal neutron fission of $\mathrm{U}^{235}, 15-, 12-$, and 8-Mev deuteron fission of $\mathrm{U}^{238}$, and low energy fission of $\mathrm{Bi}$ or other low $\mathrm{Z}$ nuclides. The fission yields, F. Y., of natural uranium by $14-\mathrm{Mev}$ deuterons have been measured and found reproducible; the thermal neutron yields, however, reproduce very poorly. The former measurements were made on uranium metal wrapped in aluminum foil, dissolved in boiling concentrated nitric acid and a little mercuric nitrate. The latter irradiations were made on uranyl nitrate solutions ( $50 \mathrm{gms}$ in $250 \mathrm{ml}$ ) which were shaken before aliquots were taken. Table No. 2.I gives the results of the measurements to date.

Table 2.I

\begin{tabular}{|c|c|c|c|c|}
\hline & $t_{1 / 2}$ & $\mathrm{E}_{\beta} \mathrm{Mev}$ & $\underline{\mathrm{E}_{\gamma} \mathrm{Mev}}$ & F.Y. $(14 \mathrm{Mev}$ d $)$ \\
\hline $\mathrm{Ag}^{111}$ & $7.4 \pm 0.1 \mathrm{~d}$ & $1.1 \pm 0.1$ & - & $0.367 \pm 0.025$ \\
\hline $\mathrm{Ag}^{112}$ & $3.2 \mathrm{~h}$ & - & - & $0.347 \pm 0.033$ \\
\hline $\mathrm{Ag}^{113}$ & $5.3 \pm 0.1 \mathrm{~h}$ & $2.2 \pm 0.1$ & $.240 \pm 0.002$ & $0.246 \pm 0.014$ \\
\hline $\mathrm{Ag}^{115}$ & $21.1 \pm 0.5 \mathrm{~m}$ & $2.9 \pm 0.1$ & $.290 \pm 0.002$ & $0.181 \pm 0.013$ \\
\hline
\end{tabular}

The half-lives agree with those previously reported; the $\beta$ energies of $\mathrm{Ag}^{111}$ and $\mathrm{Ag}^{113}$ also are in agreement with other determinations. The $\beta$ energy of $\mathrm{Ag}^{115}$ was previously reported as $\sim 3 \mathrm{Mev}$ while no $\gamma$ rays were reported ${ }^{23}$ for $\mathrm{Ag}^{113}$ and $\mathrm{Ag}^{115}$. The fission yields are relative to $\mathrm{Ba}^{140}$, and may not represent the total chain yields in $\mathrm{Ag}^{113}$ and $\mathrm{Ag}^{115}$ due to isomerism and charge distribution which has not been conclusively determined as yet. . (J. M. Alexander)

\section{B. The Decay Energy of Cesium 139}

The $\beta$-ray energy of $9.7 \mathrm{~m} \mathrm{Cs}^{139}$ was measured as $4.3 \pm 0.2 \mathrm{Mev}$, and $\sim 0.25 \mathrm{Mev}$ of $\gamma$ radiation (average) was found from isochronous absorption curves 24 . An unsuccessful attempt has been made to verify the presence of $\gamma$ radiation due to $\mathrm{Cs}^{139}$. It is felt that any $\mathrm{Cs}^{139} \gamma$ ray with an energy less than $2 \mathrm{Mev}$ and with an abundance greater than 10 percent could have been observed.

The $\dot{\gamma}$ rays from two different samples of cesium separated from fission were studied by means of a $\mathrm{NaI}(\mathrm{Tl})$ scintillation counter. The pulses from the linear amplifier were displayed on the face of an oscilloscope and were photographed with a Polaroid Land camera at various intervals. No lines corresponding to a half-life different from that of $32 \mathrm{~m} \mathrm{Cs}^{138}$ were observed.

The $0.46,1.010$, and $1.426 \mathrm{Mev}$ lines ${ }^{25}$ of $\mathrm{Cs}^{138}$ were prominent. The abundances of the above lines are 26 percent, 25 percent, and 73 percent respectively ${ }^{25}$. Previous experiments have shown that the activity of $\mathrm{Cs}^{139}$ is between one and two times that of $\mathrm{Cs}^{138}$ at a time after bombardment corresponding to the time of observation of the $\gamma$ rays. This means any $\mathrm{Cs}^{139} \gamma$ ray with an 
abundance greater than approximately 20 jercent shoüld have been prominent. A $\gamma$ ray of $>10$ percent abundance could most probably have been seen unless its energy coincided with one of the previously cited $\mathrm{Cs}^{138} \gamma$-ray energies. (R. C. Fix)

\section{REFERENCES}

1. Irving, Rossotti, and Williams, J. Chem. Soc., 906 (1955).

2. H. F. Plank, Ph.D. Thesis, Department of Chemistry, Massachusetts Institute of Technology, June 1950.

3. Laboratory for Nuclear Science Progress Report, November 30, 1955.

4. J. Axelrod and E. H. Swift, J. Am. Chem. Soc., 62, 33 (1940).

5. J. Saldick, Paper 78, Division of Physical and Inorganic Chemistry, Am. Chem. Soc., September $12-18,1954$, New York, N.Y.

6. G. S. Golden, S. B. Thesis, Department of Chemistry, Massachusetts Institute of Technology, May 1954.

7. a. F. A. Cotton and C. J. Ballhausen, J. Chem. Phys. (submitted).

b. F. A. Cotton and H. P. Hanson, J. Chem. Phys. (submitted).

8. F. A. Cotton and F. E. Harris, J. Phys. Chem., 59, 1203 (1955).

9. Gregor, Belle, and Marcus, J. Am. Chem. Soc., 77, 2713 (1955).

10. Kraus, Nelson, and Smith, J. Phys. Chem., 58, 11 (1954).

11. Gregor, Belle, and Marcus, J. Am. Chem. Soc., 76, 1984 (1954).

12. C. D. Coryell and Y. Marcus, Bull. Res. Council Israel, $\underline{4}, 7$ (1954).

13. Y. Marcus, private communication to C. D. Coryell, 1955.

Coryell, Irvine, Herber, Rudzitis, and Poskanzer, Laboratory for Nuclear Science Annual Progress Report, p. 20, May 1955.

14. C. Johnson, J. Am. Chem. Soc., 74, 959 (1952).

15. R. W. Dodson, ibid., 75, 1795 (1953).

16. R: A. Horne, unpublished work performed at Brookhaven National Laboratory, 1955.

17. H. Irving and F. J. C. Rossotti, J. Chem. Soc., 3397 (1953).

18. R. Benoit, Bull. soc. chim. France, 16, 518 (1949).

19. R. P. Bell and J. H. B. George, Trans. Faraday Soc., 49, 619 (1953).

20. G. Harbottle and R. W. Dodson, J. Am. Chem. Soc., 73, 2442 (1951).

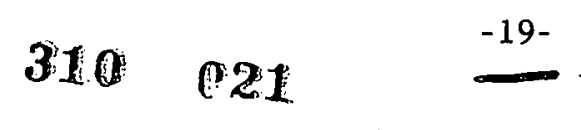


21. K. H. Hu and A. B. Scott, ibid., 77, 1380 (1955)

22. K. A. Kraus and F. Nelson, Paper UN-837, Collected Papers of the Geneva Conference on Atomic Energy, 1955.

23. Hollander, Perlman, and Seaborg, Rev. Mod. Phys., 25, 469 (1953).

24. R. C. Fix and J. W. Irvine, Jr., Laboratory for Nuclear Science Progress Report, November $30,1955$.

25. Duffield, Bunker, Mize, and Stainer, Phys. Rev. 100, 1236A (1955).

\section{ADDRESSES}

C. D. Coryell, "Atomic Energy and National Affairs", Wheaton College Science Club, Norton, Massachusetts; February 28, 1956.

C. D. Coryell, "Education and Science in the Middle East", Boston Technton Society, January 9, 1956.

C. D. Coryell, "Basic. Science and Engineering of Radioactivè Decay. I. Uninuclear Reactions", Westinghouse Atomic Power Division, Bettis Station, Pittsburgh, Pennsylvania, January 25, 1956.

C. D. Coryell, "Basic Science and Engineering of Cation-Anion Resins in Nuclear Science", Westinghouse Atomic Power Division, Bettis Station, Pittsburgh, Pennsylvania, January 27, 1956.

C. D. Coryell, "Neutron and Proton Shell Numbers in the Cosmic Abundance of the Elements", Harvard-M. I. T. Physics Seminar, Harvard University, February 16, 1956.

\section{PUBLICATIONS}

U. Schindewolf, "Review of Recent Applications of Ion Exchangers in Analytical Chemistry", Laboratory for Nuclear Science Technical Report No. 68, December 15, 1955.
C. D. Coryell
J. W. Irvine, Jr. 
Nuclear Chemistry (Organic) Group

\section{THERMAL DECOMPOSITION OF BENZOYL PEROXIDE}

The product yields from a decomposition of $0.003 \mathrm{M}$. benzoyl peroxide in cyclohexane at $91^{\circ}$ containing $0.015 \mathrm{M}$. styrene were measured and compared with an earlier decomposition ${ }^{1}$ using more styrene (see Table 3.I). All products except benzene were isolated as described earlier.

TABLE 3.I

Moles of Product from 100 Moles of 0.003 M. Benzoyl Peroxide in Styrene-inhibited Cyclohexane Solution at $91^{\circ}$

\begin{tabular}{|l|c|c|}
\hline \multirow{2}{*}{ Product } & Yield \\
\cline { 2 - 3 } & 0.015 M. Styrene & 0.12 M. Styrene \\
\hline Benzene & 145 & not determined \\
Benzoic acid & 47.8 & 39.5 \\
Diphenyl & 0.14 & 0.10 \\
Phenyl benzoate & 1.8 & 1.6 \\
\hline
\end{tabular}

The diphenyl is not yet pure. After complete purification its yield will probably agree with that of the earlier run.

It appears, then, that benzoyl peroxide forms $0.1 \%$ diphenyl and $1.5-2.0 \%$ phenyl benzoate in a cage reaction.

It is not yet possible to say whether or not the benzoic acid and benzene are formed in a cage reaction.

The isolation of benzene continues to give trouble. 'It was reported earlier that benzene can be isolated by distilling it with the solvent cyclohexane from the remainder of the reaction mixture, then nitrating the distillate and isolating the benzene as $\mathrm{m}$-dinitrobenzene. However, when this was tried with a run containing styrene, only a dark oil was obtained. It appears that some styrene distills over with the benzene and cyclohexane and interferes with the nitration. . The modification shown on the following page gave pure $\mathrm{m}$-dinitrobenzene.

A sample containing benzene of known activity treated in this way gave dinitrobenzene with 0.528 the original activity. Had there been no exchange, the dinitrobenzene should have had 0.667 the original activity. This experiment will be repeated several times. If the amount of exchange . is the same each time, the method can be used to determine the benzene yield. 


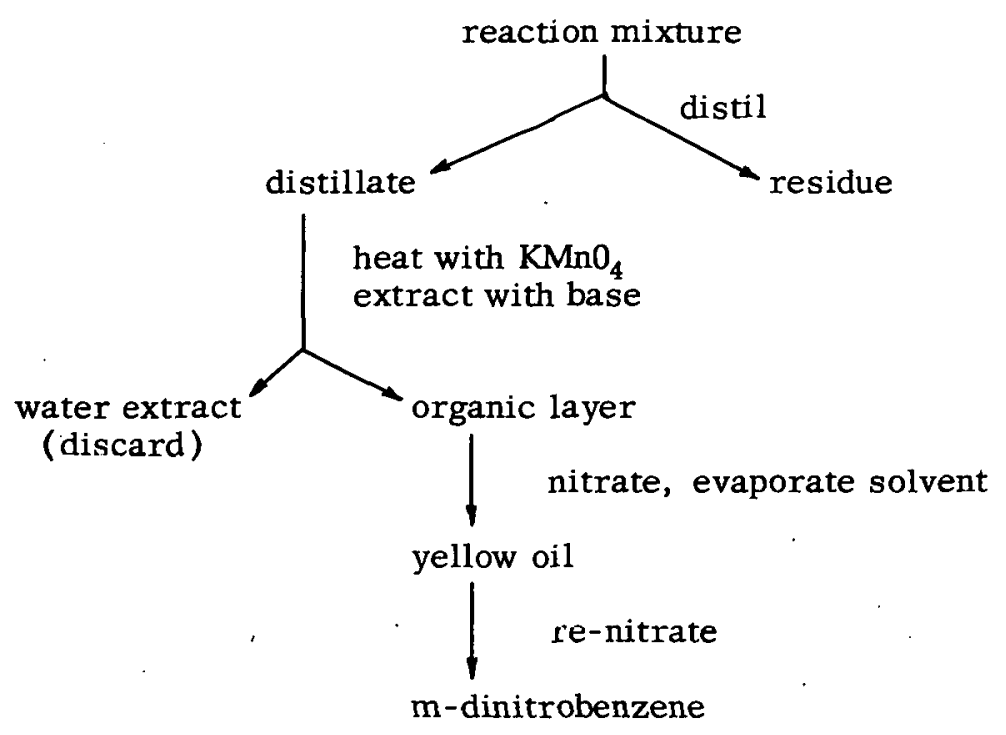

The yield of benzene given in the preceding diagram was calculated assuming that the amount of exchange in the isolation run was the same as that in the trial run with benzene of known activity (if there was no exchange, the yield of benzene is 105 moles). (L. J. Schaad)

\section{COMPARISON OF HYDROXIDE ION AND DEUTEROXIDE ION ISOTOPE EFFECTS}

The isotope effect noted in solvolysis reactions employing the deuteroxide ion in heavy water and the hydroxide ion in light water may be attributed to two causes. First, the deuteroxide and hydroxide ions possess different zero point energies and would therefore be expected to undergo reaction at different rates. Second, part of the isotope effect will be due to the fact that the two bases are solvated to different extents by the light and heavy waters. Data have been published which state that large free energy changes are encountered in the transfer of a mole of solute from one solvent to the other.

It is of interest, then, to determine whether the isotope effect in these cases is due to the greater freedom of the deuteroxide ion in heavy water as opposed to that of the hydroxide ion in light water, or whether the effect may be attributed principally to the difference in zero point energies which exists between the two bases.

The most direct manner of assessing the importance of the two effects is to perform the solvolysis reactions in a common, inert medium. The present work is directed upon these lines. (R. F. W. Bader)

\section{PROTON TRANSFERS BETWEEN THE HYDROXYL GROUPS OF ALCOHOLS}

A re-evaluation of the flow method used previously in this investigation ${ }^{2}$ has revealed that one of the assumptions on which the method is based is invalid. Flash distillation in the original 
apparatus does not quench proton transfer: separation of reactants is not quantitative because it is not sufficiently rapid.

Table 3.II describes the results of five such flash distillations in terms of percent $t$-butanol separated. $t$-Butanol was determined volumetrically both in distillate and in residue by using a standard solution of lithium aluminum hydride with $\underline{N}$-phenyl-p-aminoazobenzene indicator. ${ }^{3}$ It was found that use of a dry nitrogen atmosphere throughout the determination permitted direct titration of the alcohol and that back titration of an excess of hydride with standard butanol solution was not necessary.

TABLE 3.II

Separation of $t$-Butanol from Solvent in Flash Distillation

\begin{tabular}{|c|c|c|c|c|c|c|}
\hline $\begin{array}{l}\text { Exp't } \\
\text { No. }\end{array}$ & Solvent & $\begin{array}{c}\mathrm{t}-\mathrm{BuOH} \\
\mathrm{M} . \\
\end{array}$ & $\begin{array}{c}\text { Contact Time } \\
(\text { sec. })\end{array}$ & $\begin{array}{l}\text { Distill'n } \\
\text { Time (sec.) }\end{array}$ & $\begin{array}{l}\% \text { t- } \mathrm{BuOH} \\
\text { Separated }\end{array}$ & $\begin{array}{l}\text { Total \% } \\
\text { Isolated } \\
\end{array}$ \\
\hline 1 & Toluene & 0.10 & 0.49 & 25 & 57 & 97 \\
\hline 2 & Toluene & .10 & .50 & 55 & 66 & 97 \\
\hline 3 & Toluene & .025 & .54 & 30 & 42 & 94 \\
\hline 4 & Tetralin & .10 & - & 40 & 64 & 98 \\
\hline 5 & $\begin{array}{l}20 \% \text { by vol. } \\
\text { Ethyl Ether } \\
\text { in Tetralin }\end{array}$ & .10 & .96 & 55 & 59 & 100 \\
\hline
\end{tabular}

Roughly one-half of the $\underline{t}$-butanol used was separated. Experiment No. 2 shows, furthermore, that what is separated is not removed instantaneously upon introduction into the vaporization chamber, but that some distillation of $t$-butanol from the liquid remaining behind also occurs. This means that contact time as calculated in the usual manner from the dimensions of the flow tube is not a true measure of reaction time. Reaction time here is, in fact, not constant during each experiment but rather varies over the considerable range from "contact time" to total time of the experiment (distillation time). Calculation of reaction time under these circumstances is prohibitively difficult.

The relative insensitivity of percent separation to changes in alcohol concentration and changes in solvent seems to indicate that here the physical dimensions of the vaporization apparatus are the limiting factor. Apparatus dimensions could control the rate of separation in two ways: by limiting the rate of vaporization through control of the amount of distilland surface exposed, or by impeding the flow of vapor to the cold trap. Rates of vaporization under conditions of dynamic equilibrium are difficult to calculate directly, but an estimation of the rate at which molecules leave the surface of the distilland ${ }^{4}$ shows that vaporization is probably not ratecontrolling in this case. The rate at which vapor must flow to the cold trap, on the other hand, is much greater than the system under investigation can handle. 5 Work is now underway, 
therefore, on the construction of a system offering less impedance to vapor flow. (A. J. Kresge)

\section{STUDY OF ION PAIR FORMATION IN THE DECOMPOSITION OF ALKYL CHLOROSULFITES}

This problem has proceeded with the preparation of both primary and secondary alkyl chlorosulfites. The $\mathrm{n}$-butyl chlorosulfite, b. p. $83.0-84.0^{\circ}(16 \mathrm{~mm}$.), was prepared in a $60 \%$ yield, Anal. Calcd. for $\mathrm{C}_{4} \mathrm{H}_{9} \mathrm{O}_{2} \mathrm{Cl} \mathrm{S}: \mathrm{C}, 30.67 ; \mathrm{H}, 5.79 ; \mathrm{Cl}, 22.64 ; \mathrm{S}, 20.47$. Found: C, 30.87; H, 5.69; $\mathrm{Cl}, 22.51 ; \mathrm{S}, 20.29$. The n-octyl chlorosulfite, b. p. 104.0-105.0 $0^{\circ}$ (.07-.08 mm.), was prepared in a $58 \%$ yield. The sec-butyl chlorosulfite, b. p. $49.0^{\circ}$ (12 mm.), was prepared in a $55 \%$ yield, Anal. Calcd. for $\mathrm{C}_{4} \mathrm{H}_{9} \mathrm{O}_{2} \mathrm{Cl} \mathrm{S}: \mathrm{C}, 30.67 ; \mathrm{H}, 5.79 ; \mathrm{Cl}, 22.64 ; \mathrm{S}, 20.47$. Found: C, 31.00; H, 5.85; C1, 22.74; S, 20.40 .

Work is now in progress on the isolation and identification of the decomposition products of sec-butyl and sec-octyl chlorosulfites in toluene. (Paul M. Zanet)

\section{REFERENCES}

1. L. J. Schaad, Laboratory for Nuclear Science Quarterly Progress Report, November 30, 1955.

2. M. M. Halmann, Laboratory for Nuclear Science Annual Progress Report, May 31, 1955.

3. T. Higuchi and D. A. Zuck, J. Am. Chem. Soc.; 73, 2676 (1951).

4. E. S. Perry in A. Weissberger's "Technique of Organic Chemistry", Vol. IV, Interscience Publishers, Inc., New York, N. Y., 1951, p. 500.

5. J. C. Hecker, ibid., p. 540 .

J. C. Sheehan

C. J. Swain 
Cosmic Ray Group

\section{OPERATION OF THE MULTIPLATE CHAMBER AT ECHO LAKE}

Approximately 5,000.pictures have been taken with the temperature control system described in the November 30, 1955 L.N.S. Quarterly Progress Report. For this series of pictures a uniform vertical temperature gradient was imposed such that the top of the chamber was $0.5^{\circ} \mathrm{C}$ hotter than the bottom. The temperature over any horizontal plane was constant to better than $0.1^{\circ} \mathrm{C}$.

For the above series of pictures, two detection systems were employed. These have been previously described in the August 31, 1955 L. N.S. Quarterly Progress Report. Detector A selected nuclear interactions which occurred inside the cloud chamber and detector B selected $\mu$ mesons the ionization of which was close to the minimum value. During operation the chamber was controlled by detector A for about 20 frames, after which the selection switched over to detector $B$ for two or three frames. In this manner, one has available absolute calibration tracks for ionization measurements over the entire run.

Evaluation of this data is in progress.

Operation of the chamber is being discontinued February 15, 1956. (H. S. Bridge, R. A. Hewitt)

\section{PHOTOMETRIC IONIZATION MEASUREMENTS}

The development of a method for determining photometrically the ionization of cloud chamber tracks has essentially been completed. The method, and some results of its use on pictures taken with the Colorado multiplate cloud chamber, were reported at the Los Angeles meeting of the American Physical Society.

One reason for making ionization measurements is to determine the range of a particle which is seen to go into, but not come out of, a plate in the cloud chamber. Such residual ranges were determined for stopped secondaries from four $K_{\mu 2}$ and three $K_{\pi 2}$ heavy mesons. Since it is known that $\mathrm{K}_{\mu 2} \rightarrow \mu+\nu$, and $\mathrm{K}_{\pi 2} \rightarrow \pi+\pi^{\mathrm{o}}$, measuring the ranges of the $\mu$ and $\pi$, respectively, determines the masses of the $K_{\mu 2}$ and $K_{\pi_{2}}$. The results, which remove previous discrepancies, are compatible with those from range measurements in emulsions.

Another reason for making ionization measurements is to determine directly the mass of a particle; if its residual range is known. Such mass determinations were made for a particle which stops and gives rise to three electronic cascades, having a total energy of at least $1630 \mathrm{Mev}^{1}$. The mass value obtained is $1610 \pm 300 \mathrm{~m}_{\mathrm{e}}$, which is compatible with the protonic mass $\left(1836 \mathrm{~m}_{\mathrm{e}}\right)$, and 
confirms that this event was the annihilation of an antiproton. (D. O. Caldwell and Y. Pal)

\section{OPERATION OF THE LARGE MULTIPLATE CLOUD CHAMBER} AT THE BROOKHAVEN NATIONAL LABORATORY

During the last Cosmotron running period the cloud chamber was in operation with the 2-Bev $\pi$-beam for more than 200 hours. Excellent pictures were obtained for part of this time. However, the preliminary scanning of the film is not yet complete and we do not know what fraction of the pictures is suitable for detailed analysis.

Some technical problems concerning the chamber remain, and we are attempting to solve these before the next period of Cosmotron operation. The two most important are temperature control and control of background fog. Although the chamber appears to operate well on a 2.5 or 3.0 minute cycle, a large vertical temperature gradient is established after several hours continuous operation and the expansion ratio must be continuously increased to compensate for this effect. It is probable that the quality of the pictures decreases as the temperature difference becomes larger; in any event the readjustment of the expansion ratio is undesirable. We think that the heat: ing temperature of the chamber results from the lamps, and water-cooling and heat-absorbing glass is being installed to reduce this effect.

A further difficulty associated with the large expansion ratio is that the increased piston travel apparently produces local overexpansion at the edges of the piston and necessitates a longer cleaning cycle. During the present shutdown period several changes in the piston design are being tried in an effort to eliminate possible local overexpansion.

During the next running period we plan to continue operation using mostly 3 -Bev protons in order to compare the production of unstable particles by $\pi^{-}$-mesons and protons.

Analysis of the $\pi^{-}$-meson data has been started, and during the next quarter the emphasis will be on this phase of the program. We expect however to continue operation of the chamber and to divide the time between the $\pi^{-}$- and proton-beams as may be indicated by results of the analysis program. (H. Blumenfeld, H. S. Bridge, E. Boldt, L. Jauneau, and B. Rossi - M. I. T. in collaboration with C. Leavitt - B. N. L.)

\section{SOUTHERN HEMISPHERE AIR SHOWER MONITOR}

The recording of the rate of arrival of high-energy cosmic-ray events $\left(\sim 10^{15} \mathrm{ev}\right)$ at the Chacaltaya Laboratory is continuing on a regular basis. (R. W. Williams in collaboration with I. Escobar and R. Palmeira of the Laboratorio de Fisica Cosmica of Bolivia) 


\section{HIGH-COUNNTING-RATE TELESCOPE}

Work on a large-area plastic scintillation counter which would be sensitive mainly to the meson component (at sea level) has begun. The plan is to obtain counting rates of about 1000 $\mathrm{c} / \mathrm{sec}$, so that the standard resolution will be good enough to study in detail the rapid timefluctuations of cosmic rays. It is expected that the apparatus should be operating by the end of the year when the solar activity (which causes the most interesting of the variations) will be increas ing. (R. D' Arcy and R. W. Williams)

\section{HIGH-ENERGY CROSS SECTIONS}

The analysis of the dali collected during the summer of 1955 , with the equipment described in the November 30, 1955 L.N.S. Quarterly Progress Report has been completed. The energy discriminator, which in this experiment utilizes the large high pressure rectangular ionization chamber, described in the 1955 L. N.S. Annual Progress Report has been calibrated. Four energy channels are distinguished. They are:

$$
\begin{aligned}
60 & <\mathrm{E}_{1}<120 \mathrm{Bev} \\
120 & <\mathrm{E}_{2}<250 \\
250 & <\mathrm{E}_{3}<525 \\
525 & <\mathrm{E}_{4}
\end{aligned}
$$

These are claculated on the basis of no elasticity in the cascade initiating nucleon-nucleon collision in the iron producing layer. Also it is assumed that one-third of the energy is carried off by $\pi^{\circ}$ mesons.

The major correction required in the reduction of the data was the effective absorber correction, due to the finite acceptance angle of the apparatus. This amounted to an increase of 12 percent in the thickness of the absorber.

The corrected collision mean-free path for protons in iron in the energy range $60<\mathrm{E}<120$ Bev is:

$$
\lambda_{60-120}=151 \pm 19 \mathrm{gm} / \mathrm{cm}^{2},
$$

and for $\mathrm{E}>120 \mathrm{Bev}$ it is:

$$
\lambda_{>120}=127 \pm 25 \mathrm{gm} / \mathrm{cm}^{2} \text {. }
$$

The errors here are standard deviations.

In order to improve the statistics, it is planned to put the equipment back into operation this spring. It is planned to have a somewhat lower triggering bias than previously, so that it will be easier to monitor the counting rate. (R. W. Williams, A. J. Morency, A. E. Brenner) 


\section{LARGE AIR SHOWER EXPERIMENT}

Extensive modifications have been completed on eleven out of the twenty scintillation detectors. The purpose of the modifications is to eliminate the fire hazard arising from the use of toluene as the scintillation fluid. In order to reduce expense and effort, only eleven counters have been modified so that the first measurements will be made with only five of the distant detectors (D ring), all of the middle detectors ( $M$ ring), and the center detector. Eventually all the liquid detectors will be replaced by plastic scintillation detectors at which time full operation will be resumed with twenty detectors.

The above modifications have included the following:

(1) glass window seals over the photomultiplier wells,

(2) retaining ring around the base of the detector with sand fill to confine spilled toluene,

(3) smothering cans supported over the detectors by fusible alloy fixtures,

(4) over-all fire-proof sheet metal house,

(5) cleared area 25 feet in diameter around each detector,

(6) fire alarm system.

The present arrangement of the eleven modified counters is shown in Figure 4.1. A new

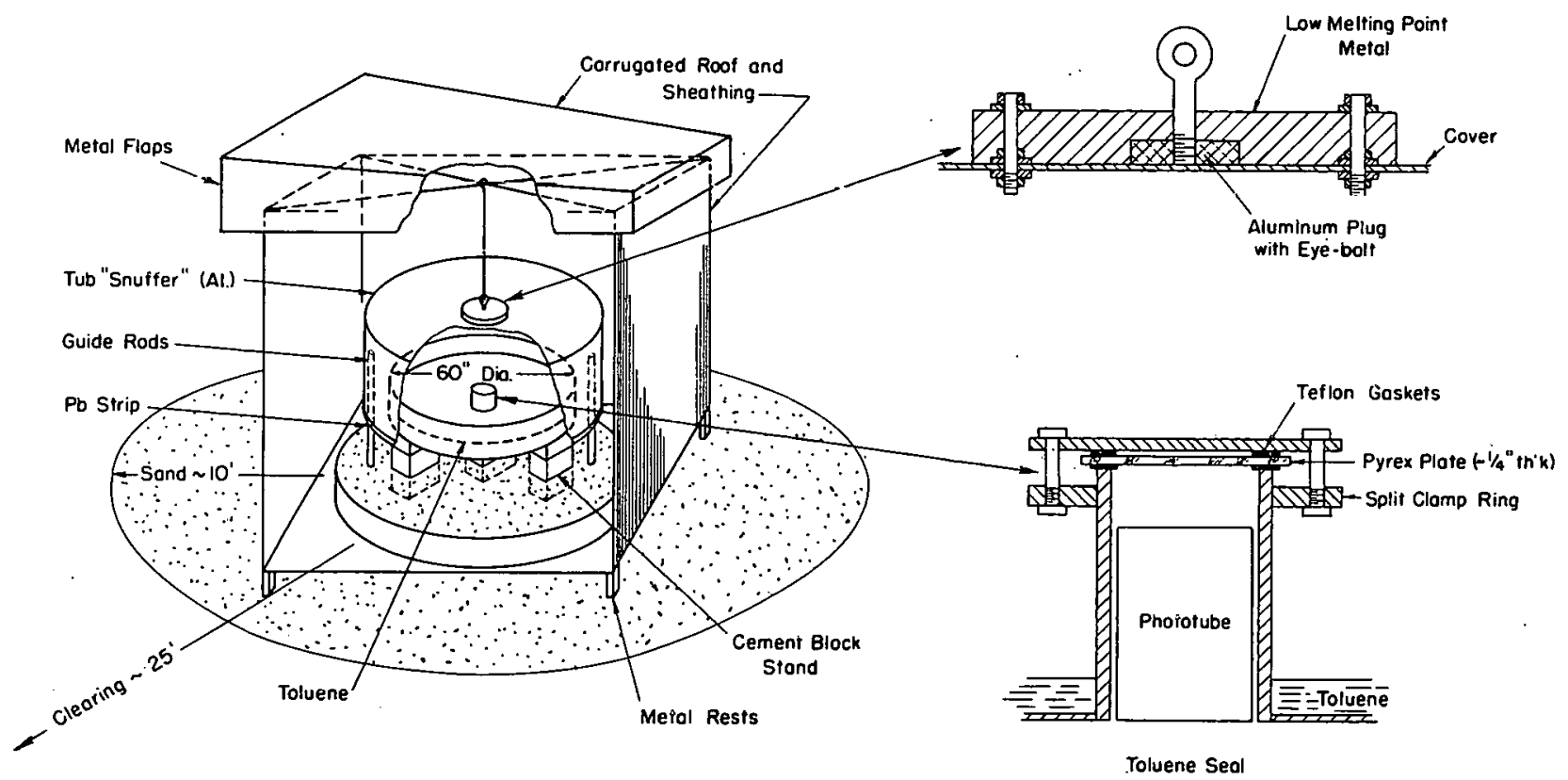

Figure 4.1

Schematic diagram (not to scale) of the eleven detectors now being used. 
and more versatile precision pulser has been completed for calibrating the multichannel oscilloscope display.

An hydraulic analogue computor has been completed with which the size and core location of a shower can be found by visual curve fitting. The effect of oblique incidence is included. A fit is searched for by hunting with a pointer over a map of the array. When a fit is achieved, the liquid levels in a series of capillary tubes, mounted side by side on a rack, fall close to a smooth curve.

The program for digital analysis of air shower data on Whirlwind II has been modified to decrease computation time and the new version has been successfully tested. Further improvements are being made; ( 1 ) to eliminate the necessity of initial estimates of the parameter values, and (2) to display the fitted curve and original data on an oscillographic output.

A process for making large plastic scintillator slabs has been worked out and successfully applied to the manufacture of disks, $16^{\prime \prime}$ in diameter and $4 "$ thick. The process consists of the rapid polymerization of styrene monomer with 1 percent terphenyl, .05 percent popop, and .03 percent Zinc Stearate in a stainless steel reactor heated in an oil bath. A large reactor is now being constructed for producing plastic slabs which will replace the liquid in the large detectors. The slabs will be cast to fit the old containers. A complete report on the production of these plastic slabs will be prepared at a later date. (B. Rossi, G. W. Clark, J. Earl, W. L. Kraushaar, J. Linsley and F. Scherb)

\section{DIRECTIONS OF AIR SHOWERS}

We have started a survey of the arrival directions of air showers in the size range from $10^{5}$ to $10^{6}$ particles using the method of timing with a square array of detectors as described in earlier progress reports. The purpose of the survey is to determine the directional dependence of the primary flux of high-energy cosmic rays which, in turn, is essential to an understanding of the local galactic magnetic environment of the earth and the distribution of cosmic ray sources in the galaxy.

Due to atmospheric calibration only a narrow band around the celestial sphere about $50^{\circ}$ wide in declination is visible from one station during the day. Therefore in order to obtain a complete survey of the sky, it will be necessary to set up stations at $50^{\circ}$ intervals from pole to pole. At present we are collaborating with Dr. Sarabhai in setting up a directional timing apparatus at Kodaikanal in India. This station is at an altitude of 7,000 feet at $9^{\circ}$ north latitude. With equipment there and at M.I.T. the survey can be extended from $65^{\circ}$ north to $15^{\circ}$ south.

For this survey we are improving and simplifying the timing equipment so as to reduce to a minimum the amount of electronic equipment to be maintained and the amount of labor involved in analysis. Plastic scintillators will replace the liquid scintillators previously used. High-gain, 14-stage photomultipliers will be used so as to eliminate the necessity for fast amplifiers. A

$310 \quad 031 \quad \underline{-29-}$


complete directional apparatus with these features will be shipped to India during February, and we expect it to be in operation by summer.

We are considering modifications in the M.I.T. timing equipment which would make possible direct recording of the timing data onto IBM cards, thereby eliminating the tedious reading of film records.

At present there is no provision in the directional apparatus for determining the sizes of individual showers other than a rough selectivity which comes from the simple requirement that one or more particles traverse each of the four detectors. We are exploring the possibility of incorporating a simple size measuring array which would allow the classification of the showers into narrower size intervals. The object of these developments is to achieve an arrangement which provides as much.information as possible about the size and arrival direction of each shower and which is simple enough so that a very large amount of data can be obtained. (G. W. Clark)

\section{N-COMPONENT CASCADES IN THE ATMOSPHERE.}

The analysis of the $\mathrm{N}$-component cascades, mentioned in previous progress reports, is being continued. At present, the results obtained for the differential intensities of $\pi$-mesons are being

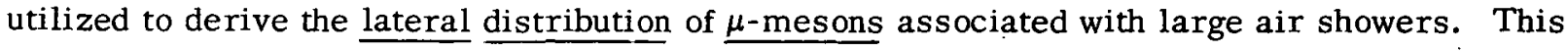
quantity is of particular interest since it recently became verifiable by experimental measurements. It is hoped that a comparison of theory and experiment will throw some light on the angular distribution of particles produced in ultra-high energy nucleon-nucleon collisions. (S. Olbert)

\section{TIME-OF-FLIGHT MEASUREMENT OF THE $\mu$-MESON-VELOCITY SPECTRUM}

The low energy region of the $\mu$-meson spectrum at sea level will be determined by a timeof-flight experiment.

The pulses from a charged particle passing through two thin scintillators placed a definite distance apart will be displayed on a fast sweep and from a measurement of the separation of the two pulses on the scope, the velocity of the particle will be determined. The particle will be required to stop in an absorber and give a delayed pulse of several microseconds, to insure that it is a $\mu$-meson.

It is hoped with this experiment to clear up recent discrepancies in the low energy portion of the $\mu$-meson spectrum.

There is also a possibility that an analysis of the diurnal charge in the $\mu$-meson spectrum may reveal the energy dependence of the temperature coefficients of $\mu$-mesons. (J. S. Strickland) 


\section{REFERENCES}

1. Bridge, Courant, DeStaebler, and Rossi, Phys. Rev. 95, 1101 (1954).

\section{ADDRESSES}

D. O. Caldwell and Y. Pal, "Photometric Mass Determination in a Multiplate Cloud Chamber", American Physical Society Meeting, University of Southern California, December 30, 1955.

\section{THESES}

Leonilda Altman, "The Mean Free Path of High Energy Nucleons in the Atmosphere", Ph. D., Department of Physics, December 1955.

B. B. Rossi

H. S. Bridge 


\section{Elementary Particle Scattering Group}

\section{LINEAR ACCELERATOR}

The bremsstrahlung spectrum produced by the analyzed beam of the linear accelerator has been measured with a proton scintillation spectrometer. The analyzed electron beam of approximately $0.2 \mu \mathrm{amps}$ and with an energy spread of $3 \%$ is passed through an $8 \mathrm{mil} \mathrm{Ta}$ target and then stopped in aluminum. A $0.75 \mathrm{~cm}^{2}$. collimated $X$-ray beam goes through a chamber filled with 6 atmospheres of deuterium. The chamber is 2.5 meters from the bremsstrahlung target. A 2.5 $\mathrm{cm}^{2}$ by $150 \mathrm{mgm} / \mathrm{cm}^{2} \mathrm{CsI}(\mathrm{Tl})$ crystal is $3 \mathrm{~cm}$. from the photon beam and can see about $4 \mathrm{~cm}$. of the beam's length in the deuterium. The crystal is coupled with $2 \pi$ light collection to a Dumont 6292 photomultiplier. After the X-ray beam passes through the chamber, it.is hardened and then goes through a Beckman ionization meter which is used as a monitor.

The CsI ( Tl) scintillator was tried after several unsuccessful attempts were made to use a thin $\mathrm{NaJ}$ ( T1) crystal. Although the light output of CsI is only about one-fourth that of $\mathrm{NaI}$, it is otherwise much more satisfactory. It is non-hygroscopic, mechanically strong, and it is more linear with energy for heavy particles than is NaI. Figure 5.1 shows some pulse-height data for the CsI. The $\alpha$-particle points were obtained with ThB and Po sources, the electron points with a $\mathrm{Na}^{22}$ source, and the proton points via $D(\gamma, p) n$. Galonsky, Johnson, and Moak ${ }^{1}$ have found that $\mathrm{CsI}(\mathrm{Tl})$ is linear for protons to less than $1 \mathrm{Mev}$ and extrapolates at zero pulse height to $0.07 \mathrm{Mev}$.

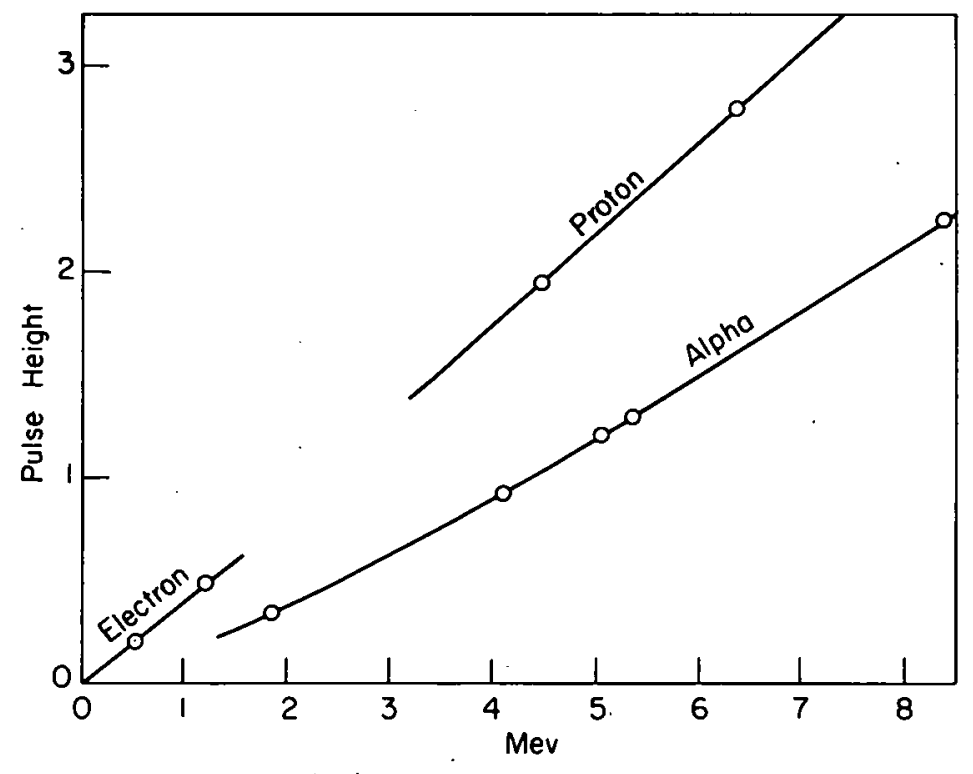

Figure 5.1

Pulse Height vs. Energy for CsI (Tl) 


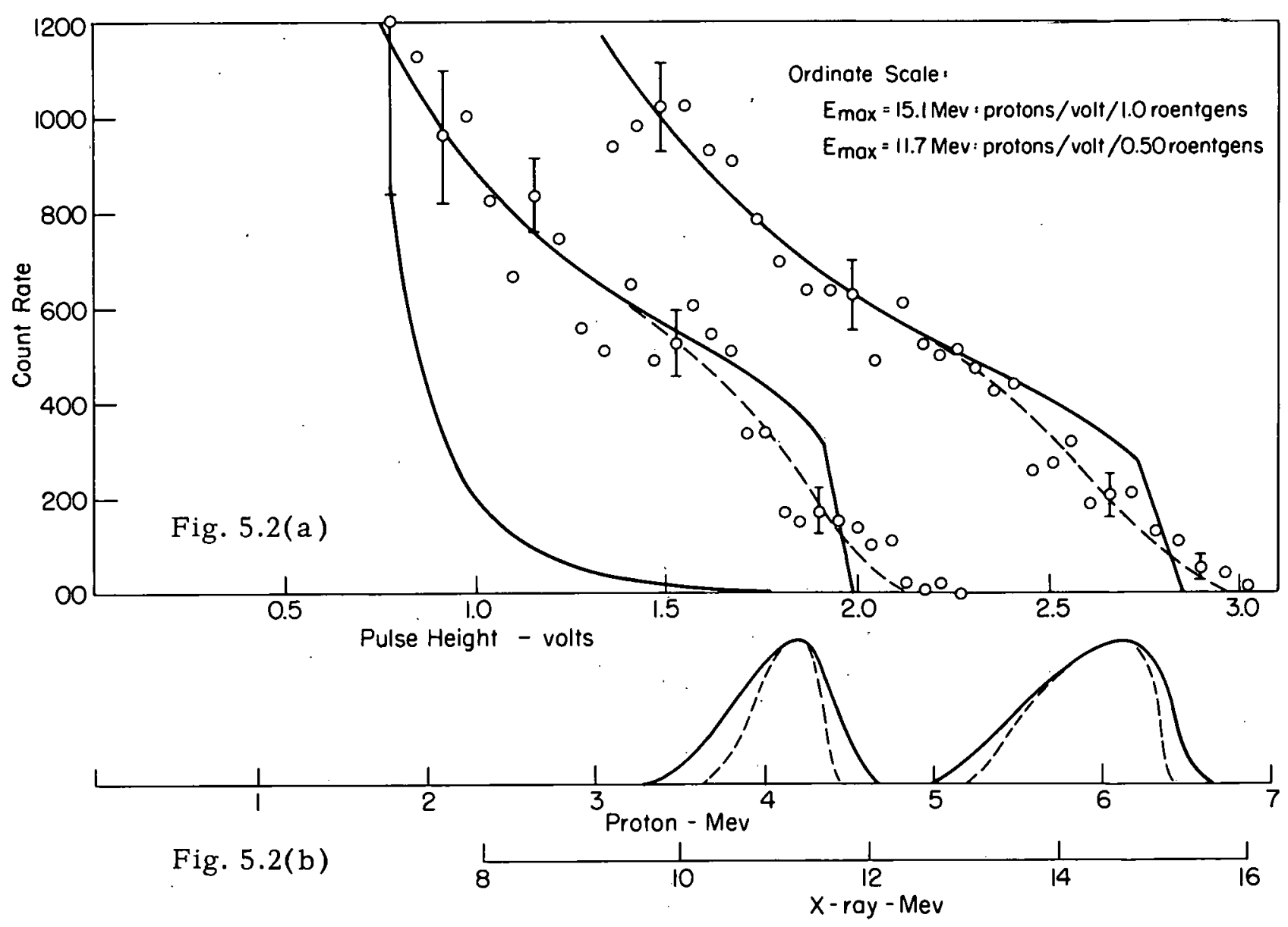

Figure $5.2(\mathrm{a})$ : Pulse height distributions of protons from $\mathrm{D}(\gamma, \mathrm{p}) \mathrm{n}$.

Figure 5.2 (b) : Resolution curves.

\section{$310 \quad 035$}


Figure 5.2(a) shows the result of two measurements of the bremsstrahlung spectrum. Each run was about five hours long. For one run $E_{\max }$, the electron energy, was $15.1 \mathrm{Mev}$, and for the other $E_{\max }=11.7 \mathrm{Mev}$. The dashed resolution curves of Figure 5.2(b) show the energy dis tribution of protons which would be observed by a detector of perfect resolution for incident monochromatic 11.2 and $14.7 \mathrm{Mev} \mathrm{X}$-rays, and the effect on resolution of reaction kinematics and geometry. The solid resolution curves show the overall resolution as an $\mathrm{X}$-ray spectrometer including the effects of the detector resolution as measured with $\alpha$-particle sources. A Po $\alpha$ source mounted inside the reaction chamber is used for calibration and to check the operation of the equipment.

In Figure 5.2(a) the dashed proton energy spectra are the result of folding the resolution curves into the solid curves, which represent an estimate of the true proton energy distributions. The curve at the left in the figure represents background pulses during the $11.7 \mathrm{Mev}$ run. The background was measured by running with hydrogen instead of deuterium in the chamber, and it has been subtracted before plotting the $11.7 \mathrm{Mev}$ points. Background was neglibible for the is.1 Mev data.

In Figure 5.3 the solid curves of Figure 5.2(a) have been translated into the incident photon spectra via the counter geometry and the $\mathrm{D}(\gamma, \mathrm{p})$ n cross-section and are plotted as a function of the fractional photon energy $\frac{h \nu}{E_{\max }}$. The counter counts 2 protons for each $10^{8}$ incident photons at $15 \mathrm{Mev}$. The normalization is per roentgen measured by the Beckman monitor. About 2.5 times as many roentgens are produced per $15.1 \mathrm{Mev}$ coulomb incident at the bremsstrahlung target as are produced per 11.7 Mev coulomb.

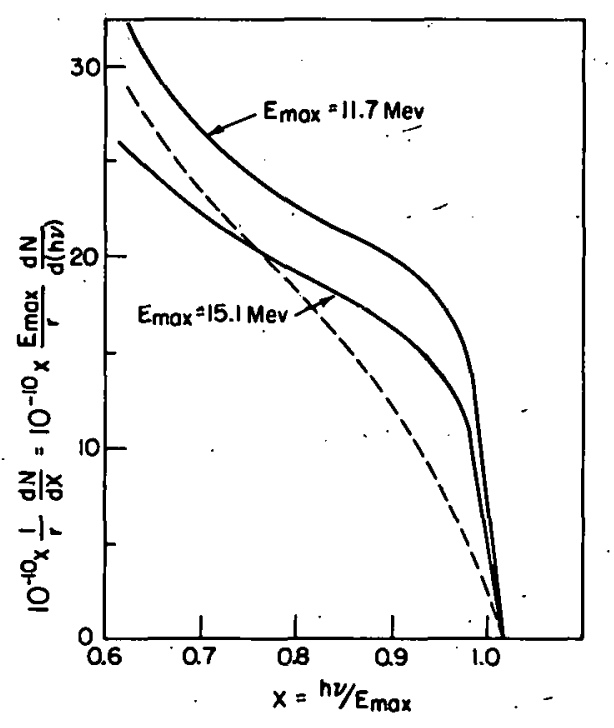

Figure 5.3

Bremsstrahlung Spectra 
The measured spectra are much flatter than the Bethe-Heitler cross sections. A BetheHeitler spectrum at $15.1 \mathrm{Mev}$ and normalized at $\mathrm{X}=0.75$ is shown by the dashed curve in Figure 5.3. At energies as low as $15 \mathrm{Mev}$ and with heavy targets, deviations from the Born approximation should be important. A run will be made using a Be target. One might expect that then the measured spectrum would be the B-H spectrum. The flatter heavy-target spectrum is more useful for studying photon-induced : reactions and additional runs will be made for better statistics and at other electron energies.

The same spectrometer is to be used to measure the energy distributions of photoprotons emitted from $\mathrm{Cu}^{63}$ and $\mathrm{Cu}^{65}$. Runs with deuterium in the chamber will be alternated with runs using foils of the separated copper isotopes. (P. T. Demos, W. Bertozzi, M. H. Wachter, F. R. Paolini, and C.: P."Sargent)

\section{PHASE SHIFT ANALYSIS OF THE $0^{16}(p, p) 0^{16}$ EXPERIMENT}

The extraction of phase shifts from the $0^{16}(\mathrm{p}, \mathrm{p}) 0^{16}$ data has proceeded on a somewhat intermittent basis during the past several months and during this period, preliminary phase shift values have been obtained in the energy region from .4 Mev to $2.25 \mathrm{Mev}$. The data used in this analysis are illustrated in Figures 5.4 and 5.5, where in Figure 5.4 the absolute differential cross section is plotted at each of the eight scattering angles as a function of proton bombarding energy and in Figure 5.5 the absolute differential cross section is plotted as a function of scattering angle at a number of selected energies in the interval of .4 Mev to $2.25 \mathrm{Mev}$.' In this energy interval

three phase shifts, $\delta_{0}, \delta_{1}, \delta_{2}^{+}$or $\delta_{0}, \delta_{1}, \delta_{2}$ (where $\delta_{l}$ is the notation used here for the case $\delta_{l}{ }^{+}=$ $\delta_{\ell}{ }^{-}=-\phi_{\ell}=\delta_{\ell}$ ) have given the most consistent fit to this data. The variation of the individual phase shifts with energy is shown in Figure 5.6, where the smooth curves represent an approximation to the extracted phase-shifts and the dotted curves, a curve drawn through each extracted point. From these latter curves there appears to be a noticeable correlation between the curves drawn for $\delta_{1}$ and $\delta_{2}^{+}$, since variations in one curve closely follow those in the other. It is believed that these variations may be possibly due to differences in the experimental uncertainties in the angular distributions used in the analysis.

The large value of $\delta_{0}$ in this energy interval is attributed to the low-lying $\mathrm{J}_{1 / 2}^{+}$level in $\mathrm{F}^{17}$; the $\mathrm{D}$-wave required to fit the data to either the $D_{5 / 2}$ ground state of $F^{17}$ or to possible effects of a higher-lying resonance; however, it is not understood at this time why such a large value of $\delta_{1}$ is required in the energy region below $1 \mathrm{Mev}$, since P-wave potential scattering based on any reasonable choice of interaction parameter should be less than a degree or so below $1 \mathrm{Mev}$ and the narrow $\mathrm{J}_{1} \overline{/}_{2}$ anomaly at $2.66 \mathrm{Mev}$ would not be expected to be effective in this region.

The results are preliminary only, since the phase shift extraction has not been completed over the entire energy range covered by the experiment, and uncertainties in phase shift values have not been established at this time. 


\section{6}

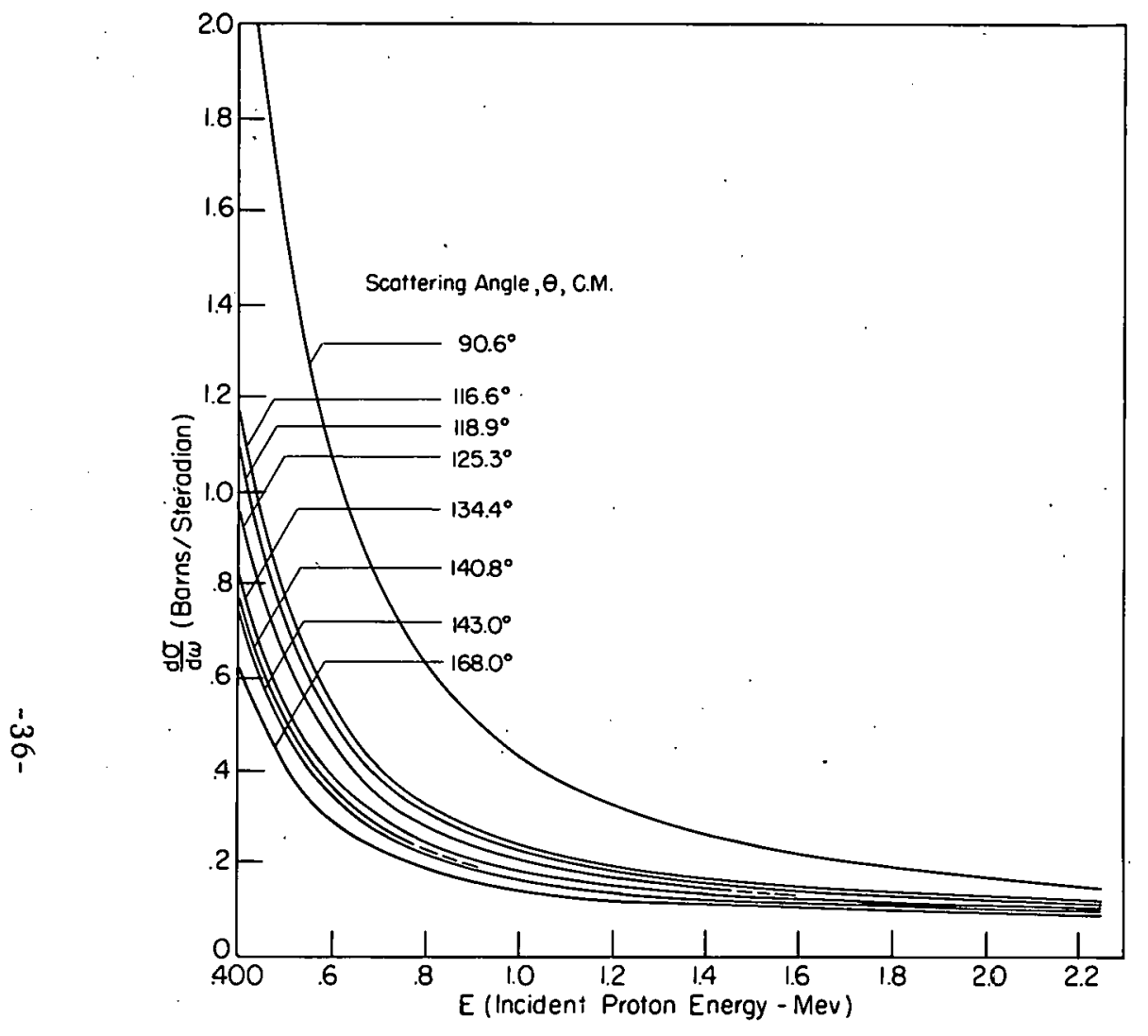

Figure 5.4

Variation of the absolute $0^{16}(\mathrm{p}, \mathrm{p}) 0^{16}$ differential cross section with energy in the interval .4 Mev to $2.25 \mathrm{Mev}$.

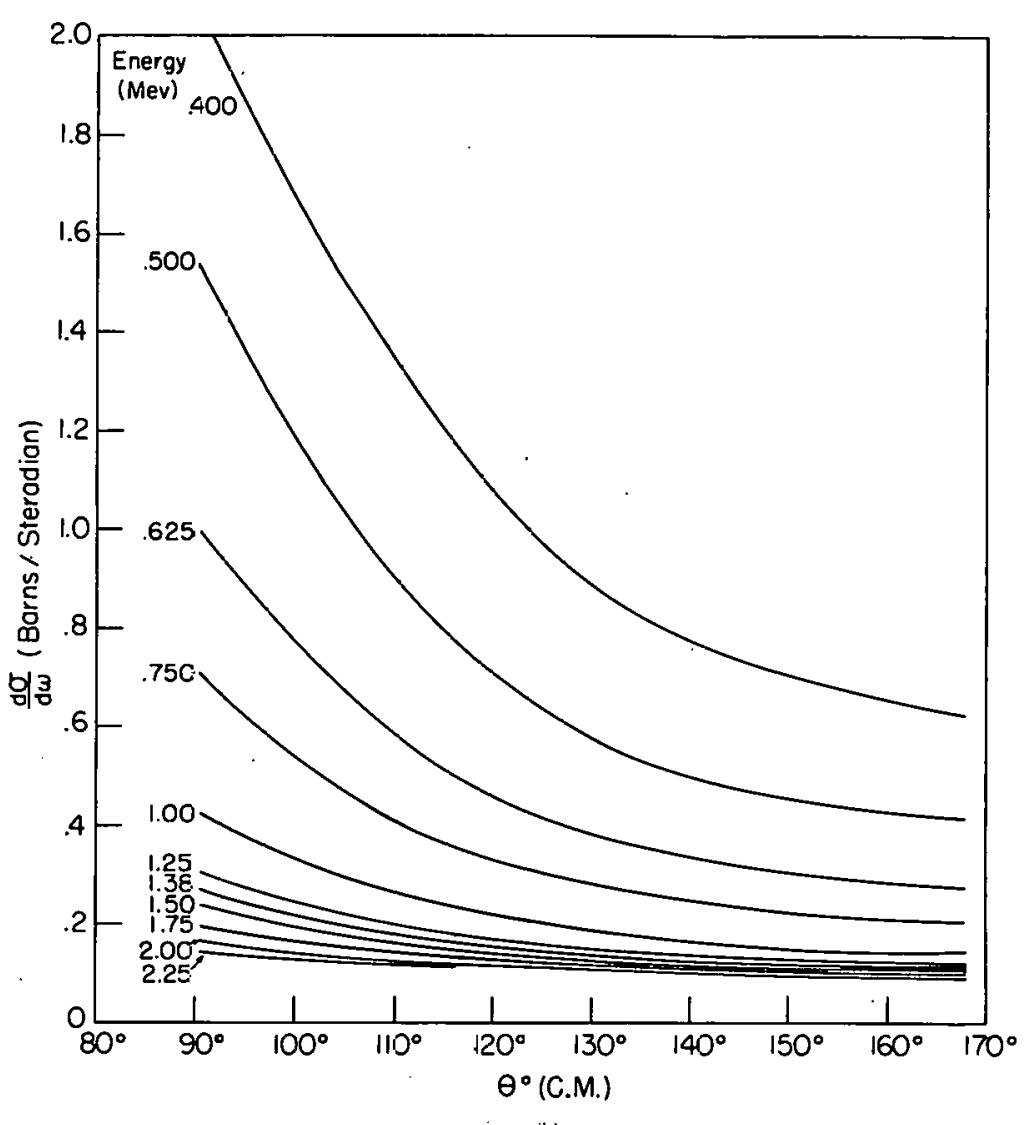

Figure 5.5

Angular distribution of the $0^{16}(\mathrm{p}, \mathrm{p}) 0^{16}$ absolute cross section at a number of selected energies. 


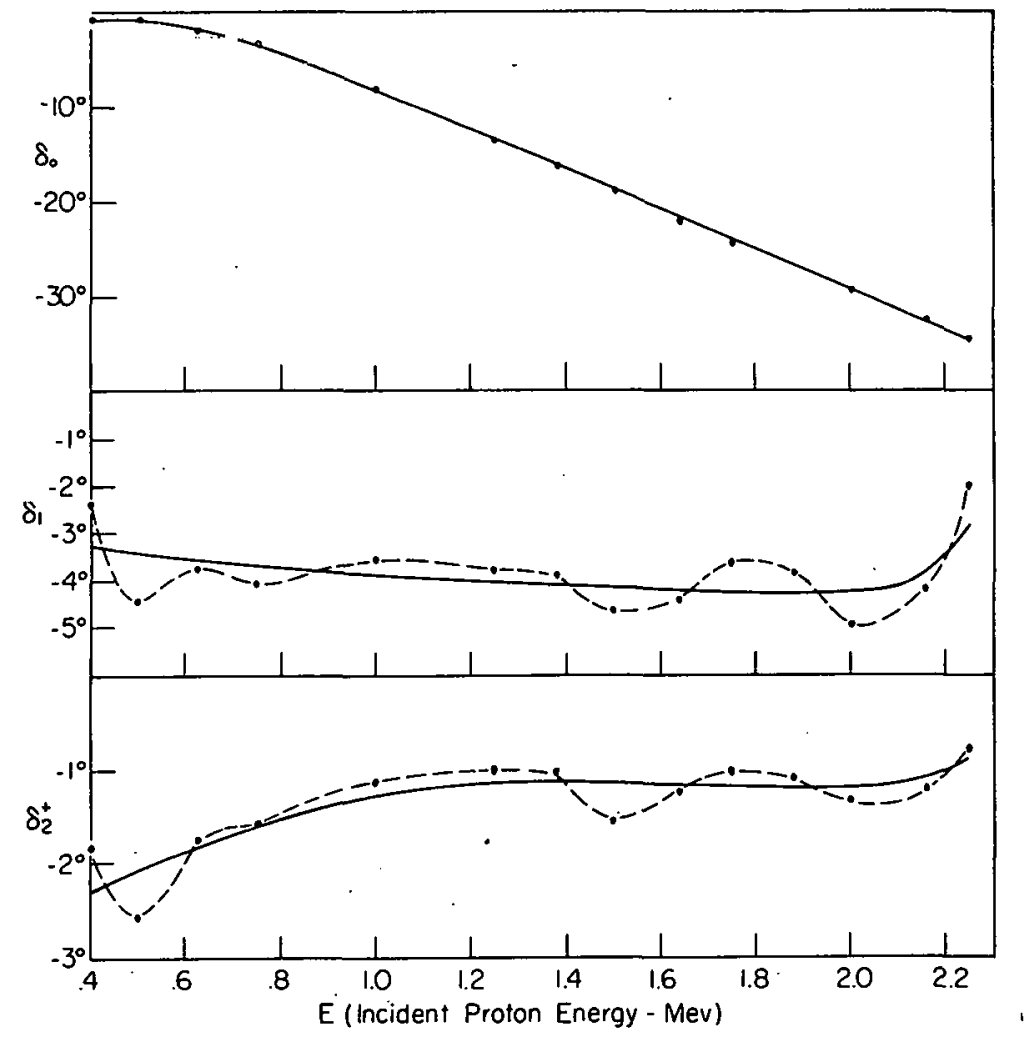

Figure 5.6

Variation of the phase shift combination, $\delta_{0}, \delta_{1}, \delta_{2}^{+}$, with energy in the interval. $4 \mathrm{Mev}$ to $2.25 \mathrm{Mev}$.

The next energy interval to be covered will contain the narrow anomaly at $2.66 \mathrm{Mev}$ (proton bombarding energy) which is believed to be $\mathrm{J}_{1 / 2}^{-}$. If this is actually the case, it is expected that one of the phase shifts, $\delta_{1}^{-}$here, will show a rapid variation through approximately $180^{\circ}$.

(F. J. Eppling)

\section{REFERENCES}

1. Galonsky, Johnson, and Moak, Rev. Sci. Inst. 27, 58 (1956).

\section{ADDRESSES}

D. M. Ritson, "Masses and Frequencies of K Mesons", Columbia University Particle Symposium, December 1955.

D. M. Ritson, "Properties of K Particles", New York American Physical Society Meeting, January 1956. 
Elementary Particle Scattering Group

D. M. Ritson, D. Fournet, and A. Pevsner, Abstract "K - Interactions", Nẹw York American Physical Society Meeting, January 1956.

\section{PUBLICATIONS}

S. Fung, A. Pevsner, D. M. Ritson, and N. Mohler, "K ${ }^{+}+{ }^{+}$Mass Difference", Phys. Rev. 101, (1956).
P. T. Demos
B. T. Feld
D. $\dot{H}_{\circ}$ Frisch 
Rockefeller Generator Group

\section{ELECTRIC EXCITATION OF NUCLEI}

The work on intensity ratios in Coulomb excitation has almost been concluded in the last three months.

In the previous report the measurement of $\frac{\mathrm{B}(\mathrm{E} 2, \mathrm{I} \rightarrow \mathrm{I}+2)}{\mathrm{B}(\mathrm{E} 2, \mathrm{I} \rightarrow \mathrm{I}+1)}$ in $\mathrm{Ta}^{181}$ has been described in detail. The same method has now been applied to $\mathrm{Re}^{187}, \mathrm{Re}^{185}, \mathrm{Hf}^{179}, \mathrm{Hf}^{177}, \mathrm{Lu}^{175}, \mathrm{Ho}^{165}, \mathrm{Eu}^{153}$.

Of all these nuclei only Ta was available in metallic form. Pressed oxide targets were used for the others and the coincidence background from the oxygen was found to be relatively low.

It was not feasible to prepare thin and measurable targets from these materials, and, therefore, targets thick to protons were used. The thin target yield was found by employing two bombarding-energies and subtracting the yields. This procedure introduces an additional error into the measurement, but since the dependence of cross section on proton energy is very similar for nuclei having approximately the same excitation energies, the consistency and reliability of this method may be checked by comparing the measured ratios of excitation (for two different proton energies) in different nuclei.

In $\mathrm{Ho}$ and $\mathrm{Eu}$ an additional difficulty was encountered in that the $\mathrm{I}+1 \rightarrow \mathrm{I}$ line in these nuclei are very close in energy to the $\mathrm{Pb}$ and $\mathrm{Au} \mathrm{KX}$-rays. Thus the $\mathrm{Pb}+\mathrm{Au}$ shield between the two counters will act to a certain degree as a reflector for the $\gamma$ rays, effectively enlarging the solid angle. The modification introduced by this effect can be estimated with an uncertainty leading to an error of a few per cent in the final result.

The values of $\frac{B(E 2, I \rightarrow I+2)}{B(E 2, I \rightarrow I+1)}$ we found are as follows:

$$
\begin{array}{ll}
\operatorname{Re}^{187} \cdot .0 .23 & \mathrm{Ta}^{181} . .0 .22 \\
\operatorname{Re}^{185} \cdot .0 .34 & \mathrm{Hf}^{179} \cdot .0 .26
\end{array}
$$

These values are believed to be correct to within $20 \%$.

The value found for $\mathrm{Hf}^{177}$ is somewhat more unreliable because of the strong cross-over transition probability in this case. "Eü and Ho data have not yet been evaluated.

To compare these values with ratios predicted by the collective motion theory, the ground state spins must be known. The information available at present is: 
Rockefeller Generator Group

$$
\begin{array}{cccc}
\mathrm{Re}^{187} \ldots .5 / 2 & \mathrm{Hf}^{179} \ldots .9 / 2 & \mathrm{Ho}^{185} \ldots .7 / 2 \\
\mathrm{Re}^{185} \ldots .5 / 2 . & \mathrm{Hf}^{177} \ldots .7 / 2 & \mathrm{Eu}^{153} \ldots .5 / 2 \\
\mathrm{Ta}^{181} \ldots .7 / 2 & \mathrm{Lu}^{175} \ldots .7 / 2 &
\end{array}
$$

The collective motion value of the ratio of the $\mathrm{B}(\mathrm{E} 2)$ 's is given below:

$$
\begin{array}{ll}
\mathrm{I} \quad \frac{\mathrm{B}(\mathrm{E} 2, \mathrm{I} \rightarrow \mathrm{I}+2)}{\mathrm{B}(\mathrm{E} 2, \mathrm{I} \rightarrow \mathrm{I}+1)} \\
3 / 2 \quad \frac{5}{9}=.555 \\
5 / 2 \quad \frac{7}{20}=.35 \\
7 / 2 \quad \frac{9}{35}=.257 \\
9 / 2 \quad \frac{11}{54}=.204 \\
11 / 2 \quad \frac{13}{77}=.169 .
\end{array}
$$

To conclude this work we intend in the next few weeks to repeat the $\gamma$-efficiency calibration measurements using sources of $\mathrm{Co}^{57}$ and $\mathrm{As}^{71}$.

\section{PUBLICATIONS}

Hans Mark and Clark Goodman, "Angular Distribution of Neutrons from $0^{18}(p, n) F^{18 ", ~ P h y s . ~ K e v . ~}$ Vol. 101 No. 2, p. 768, January 15, 1956.

Janet B. Guernsey and Clark Goodman, "Neutron Cróss Sections for Zirconium", Phys. Rev. Vol.101 No. 1, January 1, 1956.

\section{Goodman}




\section{ONR Generator Group}

\section{INTRODUUCTION}

We have continied our studies in nuclear spectroscopy. During this quarter, C. P. Browne has continued the study of the role of isotopic.spin in nuclear reactions, with particular emphasis on $\mathrm{Si}^{28}(\mathrm{~d}, \alpha) \mathrm{Al}^{26}$. In an associated study, Lts. Berger and Loper are studying the elastic scattering of deuterons from oxygen and the relation of these results to those from the $\mathrm{O}^{16}(\mathrm{~d}, \alpha) \mathrm{N}^{14}$ studies outlined in the last report. C. K. Bockelman has obtained interesting results from his analysis of the angular distributions from $\mathrm{Ca}^{40}(\mathrm{~d}, \mathrm{p})$ as has $\mathrm{H}$. A. Enge in simllar studies of the $\mathrm{Al}^{27}(\mathrm{~d}, \mathrm{p})$ reaction.

The inelastic scattering studies have been extended into the region of the rare earths. R. D. Sharp has investigated samarium, and Lts. Green and Smith are studying lanthanum. The group at the University of Utrecht has completed the analysis of plates exposed, in the broad-range spectrograph, to the proton and alpha-particle groups from chlorine targets bombarded with protons. The work at the University of Mexico on inelastic scattering from cobalt and manganese is continuing. The study of the level schemes of the iron isotopes by A. Sperduto and W. W. Buechmer has, in the past quarter, been extended to include the results from ( $d, p)$ reactions on $\mathrm{Fe}^{54}, \mathrm{Fe}^{56}, \mathrm{Fe}^{57}$, and $\mathrm{Fe}^{58}$.

The gas-target development by F. J. Eppling and D. L. Helfer has. been nearly completed, and we expect some interesting results from its use. The program of machine calculation of Qvalues, initiated by $\mathrm{H}$. A. Enge, has led to a great reduction in the time required for the analysis of the experimental data.

Quite recently, two visitors from abroad have joined the group. Dr. C. H. Paris of the Physisch Laboratorium der Rijksuniversiteit at the University of Utrecht in the Netherlands and Dr. G. L. Squires of the Cavendish Laboratory of the University of Cambridge have been appointed Visiting Fellows of the Institute, and we look forward to their collaboration in our research activities.

The following sections describe in more detail some of the work mentioned above. Of these, the first five are essentially the material submitted as abstracts of papers for the forthcoming meeting of the American Physical Society in Washington.

\section{II. $\mathrm{Al}^{27}(\mathrm{~d}, \mathrm{p}) \mathrm{Al}^{28}$ STRIPPING ANALYSIS}

Angular distribution measurements have been made on proton groups from the $\mathrm{Al}^{27}(\mathrm{~d}, \mathrm{p}) \mathrm{Al}^{28}$ reaction with a deuteron energy of $6.0 \mathrm{Mev}$ and reaction angle 5 to 60 degrees. Of the angular 
distributions for the twenty-two lowest states ${ }^{1}$ thus far plotted and analyzed, eleven show definite contributions from the stripping process. These states and the corresponding orbital angular momentum quantum numbers for the captured neutron are listed below:

$\begin{array}{ccccccc}\text { State (Mev) : } & \text { Ground } & 0.031 & 1.017 & 2.143 & 2.663 & 3.294 \\ \ell_{\mathrm{n}}= & 0 & 0 & 2.0 & 0 & 2 & 0 \\ \text { State (Mev) : } & & 3.347 & 3.461 & 3.591 & 3.669 & 3.704 \\ \ell_{\mathrm{n}}= & & 0 & 1 & 1 & 0 & 0\end{array}$

Most of the proton groups from the other eleven states are relatively weak and, within the limits of error, fairly isotropic. The possibility of $\ell_{n}=2$ or 3 stripping contributions in some of these states is being looked into. Analysis of the angular distributions from higher levels has also been initiated. (H. A. Enge, W. W. Buechner, and A. Sperduto)

\section{THE Si${ }^{28}(\mathrm{~d}, \alpha) \mathrm{Al}^{26} \mathrm{REACTION}$}

In view of the results on the violation of the isobaric spin-selection rule in the $\mathrm{O}^{16}(\mathrm{~d}, \alpha) \mathrm{N}^{14}$ reaction, reported previously, it was decided to reinvestigate the $\mathrm{Si}^{28}(\mathrm{~d}, \alpha) \mathrm{Al}^{26}$ reaction. Previous measurements ${ }^{2}$ at an observation angle of 90 degrees had shown five levels in $\mathrm{Al}^{26}$ up to $2.06-\mathrm{Mev}$ excitation with the lowest at $0.418 \mathrm{Mev}$. A state at $0.23 \mathrm{Mev}$ was known from gamma-ray measurements $^{3}$. Failure to observe an alpha group leading to this level indicated that this is the expected $\mathrm{T}=1$. state.

Alpha groups have now been measured at 30 degrees with bombarding energies from 5.5 to $7.5 \mathrm{Mev}$ and at angles from 15 to 130 degrees with $7.03-\mathrm{Mev}$ bombarding energy. The broad-range spectrograph was used to separate the alpha groups, and both nuclear track plates and a scintillation counter were used to detect the particles.

A group corresponding to a state at $0.228 \pm 0.005 \mathrm{Mev}$ was observed in addition to the previously reported groups. Identification was based on energy shift, angle shift, and change of isotopic abundance. The yields of this state, the ground state, and the 0.418-Mev state were measured at $250-\mathrm{kev}$ intervals at 30 degrees. Between 6.25 and $7.03 \mathrm{Mev}$, the ground-state yield was measured at 25-kev intervals. The results are shown in Figure 7.1. It is seen that strong resonances appear in spite of the fact that the excitation of the compound nucleus is 16 to $18 \mathrm{Mev}$. The forbidden group varies by a factor of 10 in intensity, and the ratio of this group to the groundstate group varies from 2 to 65 percent.

At 7.03-Mev bombarding energy, the ratio decreases from 62 percent at 15 degrees to 12 percent at 60 degrees. The forbidden group is not seen at greater angles.

From the figure it is evident that in order to determine the degree to which the isobaric spinselection rule holds, measurements must be made over a range of energies. In general, the forbidden group has a relatively low intensity, but at certain bombarding energies and angles of 
observation, its intensity becomes comparable to that of the allowed groups.

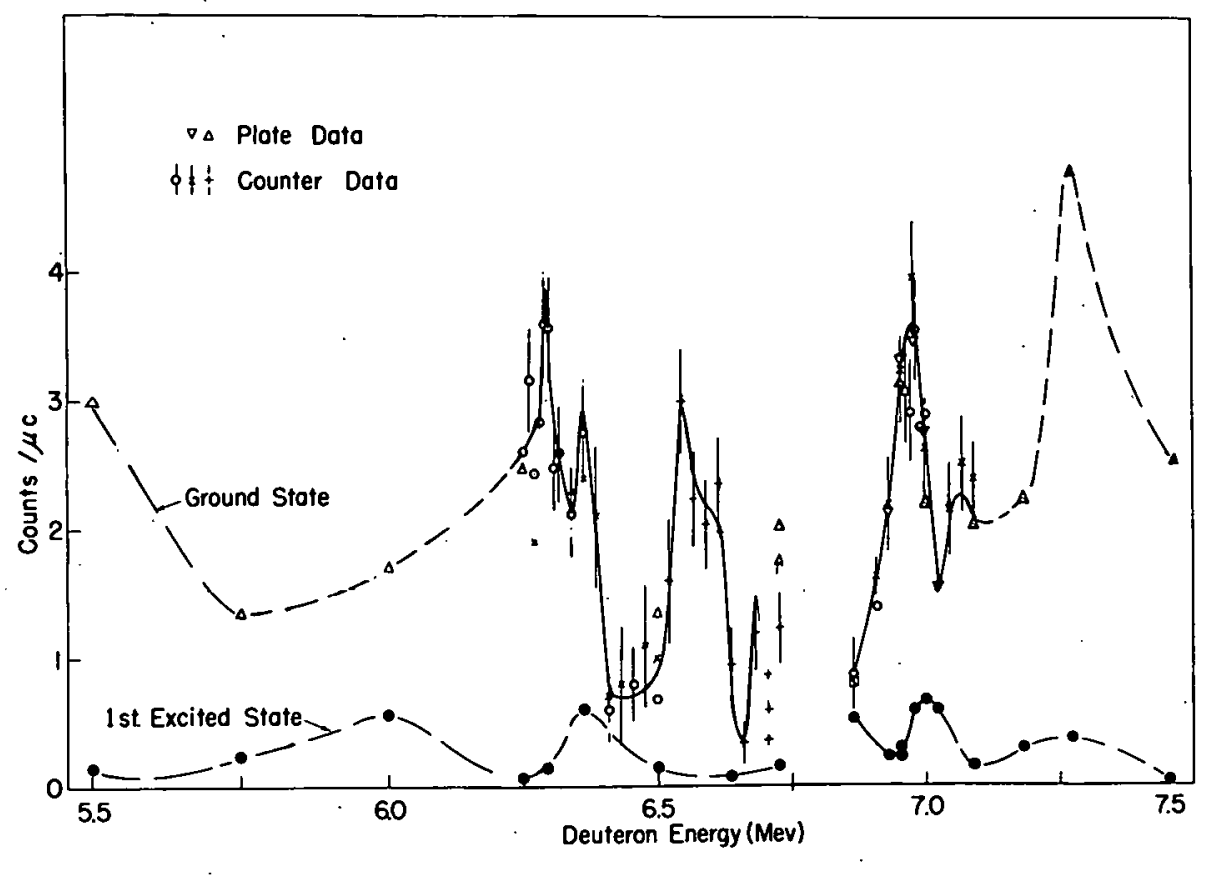

Figure 7.1

Yield curve for $\mathrm{Si}^{28}(\mathrm{~d}, \alpha) \mathrm{Al}^{26}$.

(C. P. Browne)

\section{EXCITED STATES OF $\mathrm{S}^{32}, \mathrm{~S}^{34}, \mathrm{Cl}^{35}, \mathrm{AND} \mathrm{Cl}^{37}$}

Thin barium-chloride targets have been bombarded with 7.04-Mev protons from the ONR generator, and the emerging proton and alpha-particle groups have been analyzed at 90 and 130 degrees with the broad-range spectrograph. The ground-state $Q$-values for the $\mathrm{Cl}^{35}(\mathrm{p}, \alpha) \mathrm{S}^{32}$ and the $\mathrm{Cl}^{37}(\mathrm{p}, \alpha) \mathrm{S}^{34}$ reaction were measured as $1.863 \pm 0.008$ and $3.026 \pm 0.008 \mathrm{Mev}$, respectively. From the former reaction, levels in $\mathrm{S}^{32}$ were found at $2.237,3.780 ; 4.287,4.465$, and $4.698 \mathrm{Mev}$. From the latter reaction, levels in $\mathrm{S}^{34}$ were found at $2.127,3.302,3.915,4.073,4.114,4.621$, 4.685, and $4.876 \mathrm{Mev}$. From the inelastically scattered proton groups, levels in $\mathrm{Cl}^{35}$ were observed at $1.221,1.763,2.645,2.695,3.006,3.165,4.058,4.113$, and $4.174 \mathrm{Mev}$, and in $\mathrm{Cl}^{37}$ at 0.838 and 1.728. (P. M. Endt, C. H. Paris, A. Sperduto, and W. W. Buechner)

\section{V. $\operatorname{THE~} \mathrm{Ca}^{40}(\mathrm{~d}, \mathrm{p})$ REACTION: ANGULAR DISTRIBUTIONS}

The angular distributions from 0 to 60 degrees of the protons emitted from a $\mathrm{CaO}$ target bombarded by 7.0-Mev deuterons have been obtained. The proton groups were analyzed in 
momentum by the broad-range magnetic spectrograph. While a strong proton group from the $\mathrm{C}^{12}$ $(d, p)$ reaction obscures some calcium groups at certain angles, angular distributions were obtained for most of the twenty-five levels seen by Braams ${ }^{4}$ below $4-\mathrm{Mev}$ excitation in $\mathrm{Ca}^{41}$. Where a comparison can be obtained, the agreement with the earlier measurements of Holt and Marsham 5 is good. Butler stripping curves appear to fit ten of the states measured; in other cases, the characteristic forward maximum is not evident. Most of the gamma rays emitted after neutron capture in $\mathrm{Ca}^{40}$ seen by Demidov 6 can be fitted in a scheme employing only those levels which show a stripping-type angular distribution. (C. K. Bockelman)

\section{VI. (d, p) REACTIONS OF 'I'HE IRON ISOTOPES}

Thin targets of natural iron and of iron enriched in $\mathrm{Fe}^{54}, \mathrm{Fe}^{57}$, and $\mathrm{Fe}^{58}$ have been bombarded with deuterons from the ONR generator, and the resulting proton groups have been studied with the broad-range magnetic spectrograph at angles of 10,30, and 45 degrees. Incident deuteron energies of 6.54 and $7.01 \mathrm{Mev}$ were used. The Q-values of the $(\mathrm{d}, \mathrm{p})$ reactions leading to the ground states of $\mathrm{Fe}^{55}, \mathrm{Fe}^{57}, \mathrm{Fe}^{58}$, and $\mathrm{Fe}^{59}$ were found to be 7.073, 5.418, 7.808, and $4.350 \mathrm{Mev}$, respectively. In $\mathrm{Fe}^{55}$, the first three levels found are at $0.413,0.932$, and 1.302 ; in $\mathrm{Fe}^{57}$, at $0.015,0.135$, and 0.365 ; in $\mathrm{Fe}^{58}$, at $0.799,1.644$, and 2.041 ; in $\mathrm{Fe}^{59}$, at $0.286,0.473$, and 0.728 Mev. For each of these nuclei, a large number of higher lying excited states have been measured, the regions of excitation studied being from the ground states to $7.6 \mathrm{Mev}$ in $\mathrm{Fe}^{55} ; 6.5 \mathrm{Mev}$ in $\mathrm{Fe}^{57}$; 8.3 Mev in $\mathrm{Fe}^{58}$; and 6.2 Mev in $\mathrm{Fe}^{59}$. (A. Sperduto and W. W. Buechner)

\section{INELASTIC SCATTERING IN MEDIUM-WEIGHT NUCLEI}

Additional information has been obtained on the levels previously reported in indium and cadmium, and levels have been observed in samarium.

\section{A. Indium}

Four levels had been observed in targets of natural indium at $1.08,1.14,1.30$, and $1.99 \mathrm{Mev}$ with 7-Mev incident protons, and the cross section of these levels was measured relative to the inelastic group. The absolute cross-sections calculated with the approximation of Rutherford scattering for the elastics were reported in the L. N.S. August 31, 1955 Quarterly Progress Report. The elastic group has since been experimentally related to Rutherford scattering by reducing the incident energy until the characteristic $1 / E^{2}$ behavior was observed. The intensity of the elastic group at $7.0 \mathrm{Mev}$ and 90 degrees was found to be 90 percent of the Rutherford value. Thus the reported inelastic cross-sections should be reduced by 10 percent.

An effort was made to determine whether coulomb excitation was the dominant process in the formation of these levels and, therefore, whether a quadrupole moment of the state could be 
obtained from the measured cross sections. The angular distribution of the inelastically scattered protons was measured, and preliminary results indicate that, in this energy range, the dominant process is not coulomb excitation. Further work on the interpretation of these curves is being done. An angular distribution of the elastically scattered protons was made during the course of these experiments for normalization purposes. This distribution deviates considerably from Rutherford scattering at these energies and is of some interest in itself for the determination of certain parameters in the optical model of the nucleus.

\section{B. Cadmium}

Simultaneously with these experiments, an investigation was made of levels in cadmium, also with 7.0-Mev protons. Eight levels were observed in the region between 300 and 700 kilovolts. Their cross sections, relative to the elastic group, were measured, and the elastic group was related to the Rutherford cross section as in indium. Preliminary energy values for the levels are $0.30,0.35,0.51,0.56,0.59,0.62,0.65$, and $0.66 \mathrm{Mev}$. Shifts of observation angle, incident energy and incident particle (to deuterons) were made, and the resulting variations in cross sections were compared with those expected from coulomb excitation. Four of the levels are definitely not coulomb excited; and, while the possibility cannot be excluded in the case of the other four levels, it is thought most likely that they are not either.

\section{Samarium}

In an effort to obtain larger cross sections and at the same time to shift to a region where coulomb excitation is the more likely process, an investigation of some of the rare earths is being started. Thin evaporated targets were prepared from natural samarium oxide. Two levels at approximately 80 and 120 kilovolts were observed, and their cross sections relative to the elastic group were measured. The nature of the process of the excitation of these levels is being studied, and work on other rare-earth elements is being initiated. (R. D. Sharp)

\section{REFERENCES}

1. Buechner, Mazari and Sperduto, Phys. Rev. 101, 188 (1956).

2. Bockelman, Browne, Sperduto and Buechner, Phys. Rev. 92, 665 (1953).

3. F. Ajzenberg and T. Lauritsen, Revs. Modern Phys. 27, 77 (1955).

4. C. M. Braams, Phys. Rev. to be published. Annual Laboratory for Nuclear Science Progress Report (1954).

5. J. R. Holt and T. N. Marsham, Proc. Phys. Soc. (London), A66, 565 (1953).

6. C. M. Braams, private communication. 
C. P. Browne, "Isotopic Spin-Selection Rule Violation in $\mathrm{O}^{16}(\mathrm{~d}, \alpha) \mathrm{N}^{14 ",}$ Bull. Amer. Phys. Soc. $\underline{30}$, No. 7, 26 (1955), Chicago Physical Society Meeting, November 25, 1955.

W. W. Buechner and A. Sperduto, "Inelastic Proton Scattering from Iron", Bull. Amer. Phys. Soc. 1, No. 1, 39 (1956), New York meeting, January 31, 1956.

\section{PUBLICATIONS}

C. H. Paris, W. W. Buechner, and P. M. Endt, "Energy Levels of $\mathrm{S}^{33}, \mathrm{~S}^{35}, \mathrm{Cl}^{36}, \mathrm{Cl}^{38}$, and $\mathrm{Ba}^{139}$, Phys. Rev. 100, 1317 (1955).

W. W. Buechner, C. M. Braams, and A. Sperduto, "Inelastic Proton Scattering from Vanadium, Phys. Rev. 100, 1387 (1955).

W. W. Buechner, M. M. Mazari, and A. Sperduto, "Magnetic Spectrograph Measurements on the $\mathrm{Al}^{27}(\mathrm{~d}, \mathrm{p}) \mathrm{Al}^{28}$ Reaction, Phys. Rev. $10 \mathrm{I}, 188$ (1956). 
Radioactivity Group

\section{NUCLEAR RESONANCE ABSORPTION}

Investigation of possible isotopes for the measurement of nuclear resonance $\gamma$-ray absorption has produced several possibilities. A few of these can be made into compounds which are volatile at reasonable temperatures for producing gaseous sources. One of these, $V^{48}$, has been successfully produced in the M. I. T. cyclotron, and attempts are being made to get it into the proper chemical form.

It is estimated that the resonance absorption effect with a $\mathrm{V}^{48}$ source and a $1 \mathrm{Ii}^{48}$ scatterer should be large enough that a direct absorption curve can be made. The results of this method can then be compared with the results involving a knowledge of the energy distribution of the source $\gamma$ rays as a result of the recoil of the parent nuclei. Possible errors in the second method can $\therefore$ then be evaluated. (R. C. McCall)

\section{II. $\mathrm{Al}^{26}$ DECAY SCHEME}

Work on the $\mathrm{Al}^{26}$ decay scheme is now in the final stages. It appears that the long-lived ground state decays by positron emission to the second excited state of $\mathrm{Al}^{26}$, at $1.83 \mathrm{Mev}$. This level de-excites by gamma-emission directly to the ground level, for the most part. There is . apparently some de-excitation to the first excited state, at about $1.1 \mathrm{Mev}$. This would yield two $\gamma$ rays of energies 0.7 and $1.1 \mathrm{Mev}$.

A $0.7-\mathrm{Mev} \gamma$ ray has been detected in coincidence with another $\gamma$ ray of energy greater than $0.9 \mathrm{Mev}$. Preliminary experiments indicate that this gamma has an energy of about $1.1 \mathrm{Mev}$, which checks with the mode of decay suggested above.

Note that this decay scheme differs from the one tentatively proposed in the previous progress report. The revision is due to the indications of a 1.1-Mev gamma, and the failure to definitely observe a low-energy positron spectrum. Within the limits of experimental error, the positron spectrum appears to be a simple one, with an end point of $1.14 \pm 0.05 \mathrm{Mev}$ and a forbidden shape. (J. M. Ferguson)

\section{III. $\mathrm{Co}^{57}$ DECAY SCHEME}

Only preliminary experiments have been run with our aged $\mathrm{Co}^{57}$ source. These experiments indicate that about 0.1 percent of the disintegrations in this source are $\mathrm{Co}^{58}$. Also, there are 
three unidentified $\gamma$ rays present, which could belong to $\mathrm{Co}^{57}$, but are possibly from some other cobalt isotope. These unidentified gammas are not accompanied by electronś, and so apparently follow an electron capture process. (J. M. Ferguson)

\section{MAGNETIC QUENCHING OF POSITRONIUM IN A SOLID}

The occurrence of a relatively long-lived component (approx. 3 millimicroseconds) in the annihilation of positrons in certain solids and liquids has been known for some time. Evidence has accumulated to indicate that this is connected with the formation of positronium. We have now shown that the longer life of these positrons is indeed due to the formation of a triplet state. This has been done by observing the acceleration of the decay, that is, shortening of the mean life in a magnetic field of 15,000 gauss. The present observations are consistent with the spin coupling being of the same order of magnitude as in free positronium. It will be possible from these measurements to distinguish between several possible quenching mechanisms. - For this purpose we need some additional data using a stronger magnetic field. A magnet has been built for this purpose and will be tested in the very near future. (M. Deutsch)

\section{GYROMAGNETIC RATIO OF EXCITED NUCLEAR STATE}

Preliminary measurements show the technical feasibility of measuring the magnetic moment of a low lying nuclear level excited by a coulomb interaction. Adequate counting rate, counter resolution, and electronic stability are possible.

To carry out such a precession-type experiment the angular distribution of the gamma radiation must be known. Equipment has been built for a precision measurement of the angular distributions. This will give information about quadrupole couplings, if present, in solid targets.

The equipment for the actual $g$-factor experiment has been designed and consișts of two rotating counters magnetically shielded, a 20,000 gauss magnet, and a small target chamber. Most of the electronic equipment is standard and readily available. (R. P. Scharenberg)

\section{DIRECT PRODUCTION OF MULTIPLY CHARGED IONS}

Testing facilities for a DC type ion source are being assembled. The vacuum system is available, and a gas system will be built. If the total output of the DC type ion source is satisfactory, then a magnetic analysis of the ion beam will be made. (R. P. Scharenberg)

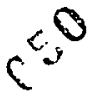




\section{MEASUREMENT OF THE LIFETIME OF POSITRONS IN GASES}

An experiment to measure the lifetime of positrons in gases has been started. At present we are engaged in building a delayed coincidence circuit in the region of $10^{-8}$ to $10^{-6} \mathrm{sec}$ that will enable measurement of the entire spectrum simultaneously. It is hoped that the experiment will lead to verification of the present theory of quenching, and further information of the effect of oxygen. (B. Gittelman)

\section{POSITRONIUM}

The behavior of positrons in gases has been studied under various conditions, by determining the relative amount of two-photon, and three-photon annihilations, using coincidence and scintillation spectrometer techniques. In commercial (welding grade) argon about 30 percent of the positrons form positronium, in freon about 40 percent. Addition of small amounts of a polyatomic gas to argon enhances formation for concentrations up to about 0.01 percent: For higher concentrations the formation decreases again, approaching the value for the pure polyatomic gas. This behavior may be explained by a model considering the cross sections for formation of positronium, for inelastic collisions, and for the annihilation of free positrons. Rough values of these cross sections deduced from the results are in agreement with corresponding cross sections for ionization and excitation by electrons. Further studies of the formation of positronium in other gases is underway.

The phenomena of the quenching of orthopositronium by addition of $\mathrm{NO}, \mathrm{O}_{2}$, or $\mathrm{Cl}_{2}$ have also been investigated. Quenching by $\mathrm{NO}$ and $\mathrm{Cl}_{2}$ is approximately proportional to the amount introduced, indicating a single mechanism effective for positronium atoms of all energies. About half of the orthopositronium is quenched by oxygen at low partial pressure ( $1 \mathrm{~mm} \mathrm{Hg}$ ), but additional oxygen is much less effective. This indicates an energy-dependent cross section for quenching. Magnetic fields enhance the quenching rates of $\mathrm{NO}$ and $\mathrm{O}_{2}$. The amount is in agreement with the assumption that after collision with these molecules, the positronium atom comes off in any one of the four possible states. Absence of magnetic-field effects in chlorine suggests capture of orthopositronium to form a metastable "compound". This is consistent with the dependence of the quenching rate on total gas pressure which indicates breakup of the compound by collisions at a rate comparable with the annihilation of the positron in the molecule. (B. Gittelman)

\section{ADDRESSES}

M. Deutsch, E. P. Dulit, and B. Gittelman, "Formation of Positronium in Gases", Am. Phys. Soc. meeting, February 3, 1956. 
Radioactivity Group

M. Deutsch, E. P. Dulit, B. Gittelman, "Quenching of Orthopositronium in Gases", Am. Phys. Soc. meeting, February 3, 1956.

\section{PUBLICATIONS}

M. Deutsch and H. W. Kendall, "Annihilation of Positrons in Flight", Phys. Rev. Second Series 101, No. 1, 20-26, January 1956.

R. D. Evans

M. Deutsch 


\section{Cyclotron Group}

\section{ELASTIC PROTON SCATTERING}

We have examined the elastic scattering of $7.5-\mathrm{Mev}$ protons from $\mathrm{Ni}, \mathrm{Cu}, \mathrm{Cd}$ and $\mathrm{In}$. Preliminary results show a strong similarity between the angular distributions of protons scattered from $\mathrm{Cu}$ and $\mathrm{Ni}$. Both of these elements show maxima in the differential cross section relative to Rutherford scattering at about $40^{\circ}$ and $110^{\circ}$ and a minimum at about $70^{\circ}$. In addition, Ni shows a second minimum at about $150^{\circ}$. The In and $\mathrm{Cd}$ relative cross sections are similar, essentially following Rutherford scattering to about $70^{\circ}$. Cadmium then shows a slight increase at about $80^{\circ}$. From $85^{\circ}$ on, both elements decrease to a minimum in the vicinity of $130^{\circ}$. The In then rises at a slightly faster rate than the $\mathrm{Cd}$.

By installing a new particle detector with a small aperture $\left(\sim 1 / 5^{\circ}\right)$ at about $10^{\prime \prime}$ from the target we have been able to extend our range of angles of observation down to approximately $6^{\circ}$. In order to fully use this angular range, it was necessary to eliminate the extreme sensitivity to slight angular errors inherent in technique of multiplying the observed counting rate by $\sin ^{4} \frac{\theta}{2}$. For example, for a substance following Rutherford scattering a $0.1^{\circ}$ error in the angle at $10^{\circ}$ would introduce a 4 percent error in $\sin ^{4} \frac{\theta}{2}$. Since the scattering from Au has been shown to be Rutherford at angles greater than about $20^{\circ}$ we have now taken our data by comparing the counting rate with the target to be investigated to that of an Au target under identical conditions. The ratio of these two counting rates should be a constant if both elements follow Rutherford scattering, allowing for center-of-mass corrections if the unknown target has an atomic weight appreciably different from the Au. (N. S. Wall and W. F. Waldorf)

\section{INSTRUMENTATION}

a) The above-mentioned particle detector, enabling small angle measurements to be made, has been installed. This detector is a 3/4" six-stage Dumont 6365 multiplier phototube mounted vertically on one of the arms of the scattering chamber at a distance of about 11 "from the center of rotation. The counter has an aperture which may be changed from a $3 / 8^{\prime \prime}$ circular opening just in front of the crystal to a $1 / 32$ " aperture, permitting small angle measurements at reasonable beam currents, without causing pile-up. Because of the vertical mounting and, therefore, nonsymmetrical light collection from the crystal with consequently poorer light collection efficiency, the resolution of this counter, with the small apexture, is only about 4 percent for $7.5-\mathrm{Mev}$ protons. With the large aperture the resolution is about 6 percent because of the fact that the light emitted by particles entering the crystal in different regions is collected differently. (N. S. Wall) 
b) The proportional counter for the particle selective counter has been rebuilt and will be tested soon. (C. E. Hunting)

\section{MAGNETIC ANAALYSIS SYSTEM DESIGN}

Preliminary designs have been made for a magnet system which will have a resolution of $\frac{E}{\Delta E}=400$. These preliminary designs call for a quadrupole focusing lens pair (strong focusing) near the cyclotron to produce an image on a target at an "optical distance" of approximately 25 feet from the cyclotron. Between the target and the quadrupole lenses will bc a uniform field sector-analyzer magnet of 25-inch radius of curvature with a pole gap of approximately one-half inch. This magnet will bend the beam about $135^{\circ}$, and is used both as a beam-analyzing magnet and a deflection magnet. The particles scattered by the target will be examined by a uniform field, oblique entry and exit, double focusing spectrometer which will deflect the scattered particles $90^{\circ}$. This magnet will also have a 25 -inch radius of curvature to enable the focusing of 35-Mev alpha particles at fields of 13.5 kilogauss which should avoid saturation difficulties. The novel feature of this spectrometer is that instead of the usual slit followed by a counter at some appropriate point in the focal plane of the spectrometer, we intend to use the particle-localization scheme, first suggested by Yuan and Poss ${ }^{1}$. This scheme essentially measures the light from a given event between two photomultipliers by the output of these tubes. The ratio of the two signals then uniquely defines the position of the event. With a crystal in the focal plane of the spectrometer the ratio signal of the two photomultipliers can then be displayed on our present 20 -channel pulseheight analyzer, and we can, therefore, essentially collect relative intensity information from 20 points in the focal plane at once rather than just a single point. This scheme will enable us to measure angular distributions of a single particle group with a high resolution $\left(\frac{E}{\Delta E}=400\right)$ set in about the same time as the present poor resolution scheme $\left(\frac{E}{\Delta E} \sim 50\right)$ of a NaI spectrometer. It may also permit us to measure angular distributions corresponding to two levels at once providing they are separated in energy by about $200 \mathrm{kev}$.

Preliminary results on such a particle localization counter indicate that we should be able to detect displacements of about $1 \mathrm{~mm}$, which would correspond to an energy interval of about 15 kev in the focal plane of the above magnet. (N. S. Wall and M. Deutsch)

\section{SHORT-LIFETIME MEASUREMENTS}

The cyclotron beam has been found to be sharply pulsed. The beam appears to come from about 7 percent of the RF cycle $(\sim 5 \mu \mathrm{sec})$. This measurement was made by using two distributed amplifiers directly driving the vertical deflection plates of a Tektronix 541 oscilloscope. The signal into these amplifiers came. from 7.5- Mev protons elastically scattered through an angle of $30^{\circ}$ and detected by a plastic phosphor on an RCA 6199 photomultiplier. The oscilloscope sweep 
was triggered using the cyclotron RF and the high frequency synchronizing control on this model oscilloscope. Measurements were also made using the RF signal directly on the horizontal plates of the oscilloscope. All measurements were made by observing the spread in time relative to a fixed level on the RF signal by visual observation of the oscilloscope.

A fast coincidence circuit, which will enable us to verify these results and actually measure the life-times of isomeric states, is under construction. (L. W. Swenson)

\section{REFERENCES}

1. L. C. L. Yuan and H. L. Poss, Rev. Sci. Instṛ. 23, 553, (1952).

\section{ADDRESSES}

Dr. H. J. Watters, "Elastic and Inelastic Scattering of 31.5-Mev Particles", Am. Phys. Soc. meeting, January 31, 1956.

M. S. Livingston 


\section{Synchrotron Group}

\section{OPERATION AND MAINTENANCE}

\section{A. Operation}

The machine has operated on a full schedule in the past quarter with about 75 percent efficiency. There were no major breakdowns.

B. Maintenance

\section{Flux Forcing Coil}

A shorted turn of copper was mounted on the inside of the betatron flux bars. The purpose was to drive the inside pole pieces harder near maximum field in an effort to get higher-energy electrons. The test resulted in the partial collapse of the coil, and it is being rebuilt to give a greater degree of mechanical strength.

\section{Van de Graaff Injector}

The injector has been delivered and tested for continuous operation at low current. We are at present testing various cathodes for high peak currents. The Philips cathode CP-1B has been run at 200 milliamps peak at a pressure of $4 \times 10^{-6} \mathrm{~mm}$. A lifetime measurement has not been done. We plan to test the Raytheon TL-10 as well.

The inflector and extra r.f. doughnut sections have been delivered, cut, and are being ground. The inflector and its mount are nearly completed. The pulsing circuit is completed but remains to be mounted. The new r.f. transmitter is in operation and is being tested.

The present schedule calls for the completion of three more experiments before shutting down to change injectors. Because of delays on the experimental side, the projected changing time will probably be around June. (R. Schluter, L.S. Osborne, D.M. Ritson, G.S. Janes, C. Strumski, W. Lobar)

\section{COHERENT PHOTOPRODUCTION OF $\pi^{\circ}$ MESONS}

We measured the angular differential cross section for photoproduction of $\pi^{\circ}$ mesons in hydrogen and deuterium from $0^{\circ}$ to $180^{\circ}$ for a gamma incident energy of $250 \mathrm{Mev}$, and for several heavier elements from $0^{\circ}$ to $90^{\circ}$. The $\gamma$ rays were produced in the synchrotron set to give a long pulse. The two meson-decay $\gamma$ rays were detected in coincidence (resolving time about $10^{-8} \mathrm{sec}$ onds) with $\gamma$ ray telescopes in a yoke arrangement. The angle between the telescopes defined the meson energy, and therefore, the energy of the incident $\gamma$ rays. Each telescope consisted of two scintillation counters and a Cerenkov counter of such size as to give uniform pulses for electrons 
produced by conversion of $\geq 100-$ Mev $\gamma$ rays, and with a cutoff of about $50 \mathrm{Mev}$.

The meson-decay $\gamma$ rays were converted in $1 / 8$ " thick lead converter, 4 " in diameter in front of the telescope ( 5 " in diameter). The background for each run was taken with the lead behind the first counter. The angular resolution is given in Figure 10.1.

The cross section for hydrogen (Figure 10.1) can be represented by $\sigma=\mathrm{A}[(1.0 \pm 0.10)-$ $\left.(0.066 \pm 0.045) \cos \theta-(0.530 \pm 0.11) \cos ^{2} \theta\right]$ (arbitrary units) in agreement with previous measurements 1,2 . The deuterium data are also shown in Figure 10.1. $\pi^{\circ}$ photoproduction is rel-. atively higher in the forward direction for deuterium than for hydrogen. This could be indicative of an elastic coherent effect, c. ${ }^{3}$.

For the heavy elements (see Figure 10.2) production near $0^{\circ}$ is consistent with an $A^{4 / 3}$ dependence. Between $0^{\circ}$ and $40^{\circ}$ each element showed a well-defined maximum. Thereafter, up to $90^{\circ}$, they decreased, with a secondary peak for copper. The finite angular resolution of our apparatus $\left(\approx 15^{\circ}\right.$ at $0^{\circ}$ ) was such that our data do not rule out a negligible cross section at $0^{\circ}$ with respect to the $\gamma$ beam. This is consistent with coherent photoproduction from complex nuclei with a $\sin ^{2} \theta$ dependence, and strong nuclear $\pi^{0}$. absorption, of the order of the known $\pi^{+}$nuclear. absorption 4, 5,6. (L. S. Osborne, R. Barringer, R. Meunier)

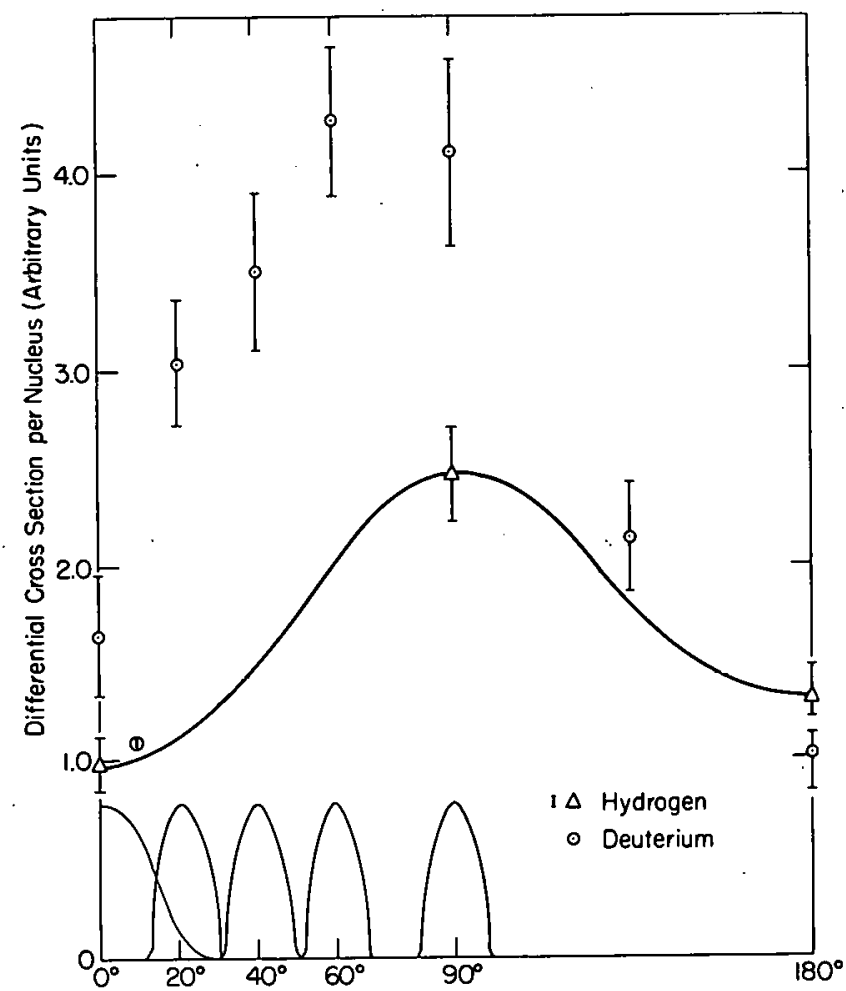

Figure 10.1

Angular distribution of $\pi^{\circ}$ photo production from hydrogen and deuterium in centimeter coordinates.

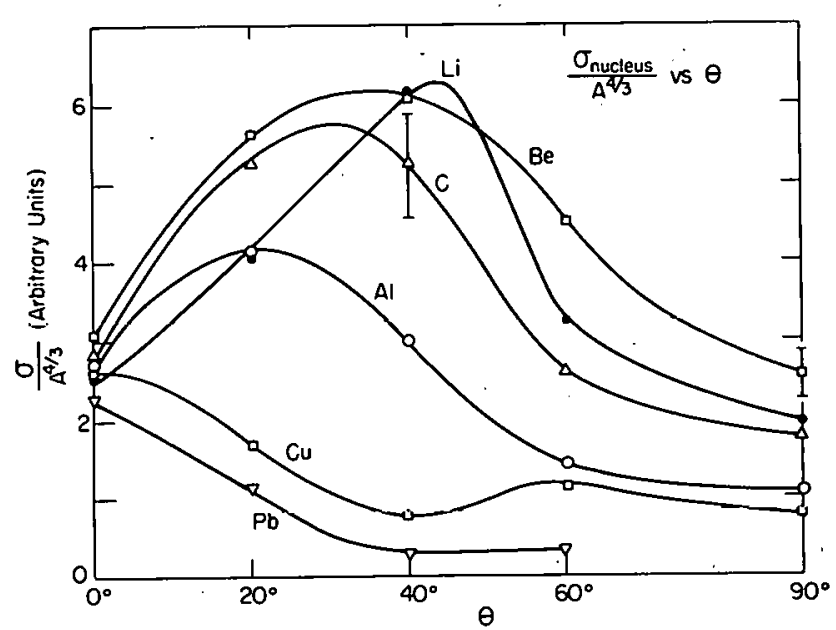

Figure 10.2

Angular distribution of $\pi^{\circ}$ photoproduction in various elements.

Typical standard deviations due to counting statistics are shown. 


\section{SEARCH FOR HIGHER MASS K-MESON}

Work on searching the plates exposed to the $\mathrm{K}$-meson mass spectrometer for masses from $1100-1450 \mathrm{~m}_{e}$ is now complete. After eliminating all $\mathrm{K}$ 's which had orientations such that they had probably scattered from the collimator walls, we could set an upper limit of $\leq 1 / 2$ percent of the intensity of the K-meson group for any high mass group present in the beam. (A. Pevsner, D. M. Ritson, J. Russell)

\section{HIGH INTENSITY PULSED MAGNET}

The use of a magnetic field to measure momentum and sign of a charged particle passing through nuclear emulsion has been attempted in cosmic rays, e.g. ${ }^{7}$. However, the method has not proved practical in cosmic ray research because of the difficulty of obtaining sufficiently high continuous magnetic fields over a volume of several cubic inches. A track curvature unambiguous in the presence of multiple scattering requires a field of the order of $10^{5}$ gauss. Such fields are attainable conveniently only in small volumes and in pulsed operation. The availability of machineproduced particles appears to make the small magnet, pulsed in synchronism with the accelerator, a useful addition to nuclear emulsion technique.

Such a magnet is under construction. It has a useful volume of about 2 cubic inches, inside diameter of $1 \mathrm{inch}$, and is designed to use a condenser bank of 10,000 mf. (45,000 joules), with which it should give 250, 000 gauss with a natural full period of 6 milliseconds, and $Q=3$ or 4 .

The design makes use of formulae compiled by Champion ${ }^{8}$. The coil spiral itself is to be cut from a solid cylinder of either copper or beryllium-copper in a manner similar to that used by Foner and Kolm (Lincoln Lab.) in making smaller coils for use at 700, 000 gauss. The coil will be contained in a stainless steel jacket designed to withstand the considerable magnetic forces tending to expand the coil. The water-cooling of this jacket is expected to permit operation with a 10-second interval at a coil temperature rise of $80^{\circ} \mathrm{C}$.

Approximately $5000 \mathrm{mf}$ of capacitor has been assembled. The next problem is the design of a switch, preferably arranged to interrupt the damped oscillation at the first current node, thereby conserving energy and reducing heat dissipation in the coil. When some experience has been gained with the coil described, others with side apertures for particle entrance will be made.

An obvious experimental possibility is the study of $\mathrm{K}^{-}$induced stars, to detect negativelycharged hyperon secondaries. (R. A. Schluter)

\section{V. "SCATTERED" K-BEAM}

In conjunction with Harvard we have set up an experiment to determine whether the particles contained in a $\mathrm{K}$-beam scatter with the same cross-section. If two components are present in the 
K-Beam with different "spin-parity" properties, we should expect. that the beam, after a scattering, would contain altered proportions of the two components.

A K-meson, strong-focussing ( $340 \mathrm{Mev} / \mathrm{c}$ ), channel was set up at Brookhaven at $120^{\circ}$ to the proton beam incident on a uranium target. At 3.0 Bev, even with $25 \mathrm{Mev}$ Fermi energy, it is impossible to directly produce $\mathrm{K}$-mesons at this angle and momentum. However, it is possible for $\mathrm{K}$-mesons to be scattered in the target nucleus into this angle.

Preliminary results give $212 \mathrm{Kl}$ to $17 \tau+\tau^{\prime}$, an identical ratio to that observed at forward angles. Thus if two components are present, they appear to scatter with very similar cross-sections.

Work is being continued to obtain more statistics and to analyze the various beam components. (D. M. Fournet, A. Pevsner, D. M. Ritson, R. A. Schluter)

\section{LIQUID HYDROGEN EMULSION STACKS}

We have initiated an investigation into the feasibility of a "club sandwich" emulsion stack in which the slices would be emulsion and the filling would be liquid hydrogen or deuterium. The purpose would be to trace tracks such as $\mathrm{K}^{-} \mathrm{s}$ through the liquid hydrogen layers and observe interactions in flight or at rest.

The type of arrangement aimed at would consist of $50 \mu$ layers or $100 \mu$ layers of emulsion separated by $50 \mu$ layers of liquid hydrogen. We have investigated the behavior of emulsions both from a physical and sensitivity point of view at liquid hydrogen temperatures. We find the emulsions remain electron-sensitive, are "wetted" by liquid hydrogen, and do not splinter if cooled slowly. Our results show stacks of this nature are definitely feasible. (D. M. Fournet, A. Pevsner, D. M. Ritson, R. A. Schluter)

\section{VII. $\mathrm{K}^{-} \cdot$ INTERACTIONS}

The emulsion study of negative $\mathrm{K}$ mesons produced at the Berkeley bevatron has been continued: The track length resulting from along-the-track scanning is 8.7 meters. This includes 128 capture stars produced by $\mathrm{K}^{-}$mesons at rest, 23 interactions in flight, and 6 decays in flight. The prong distributions of stars produced by $\mathrm{K}^{-}$mesons at rest and in flight are shown in Figure 10.3. They are seen to be very similar. The small shift toward a larger number of prongs per star for interactions in flight may be due to the additional kinetic energy. Among the interactions at rest, 20 percent of the events were zero-prong stars (all are not included in the figure). In 12 percent of the events a hyperon was emitted, in 23 percent a $\pi$ meson was emitted, and there were 7 events in which both a hyperon and a $\pi$ meson were emitted. Among the interactions in flight there were 3 zero-prong stars, 3 hyperons, and $3 \pi$ mesons. The mean-free path for 
absorption of $\mathrm{K}^{-}$mesons in flight is $37.7_{-6.5}^{+9.9} \mathrm{~cm}$. The difference in the type of interactions produced by $\mathrm{K}^{+}$and $\mathrm{K}^{-}$mesons is consistent with the Pais and Gell-Mann strangeness scheme. The typical reaction of the $\mathrm{K}^{-}$meson is its absorption by the nucleon to give a hyperon and a $\pi$ meson, whereas the $\mathrm{K}^{+}$meson undergoes only nuclear scattering. The mean lifetime calculated from the 6 decays in flight is $1.0+0.6 \times 10^{-8} \mathrm{sec}$. However, it is estimated that one or two of the 6 decays could possibly be one-prong stars in which only a minimum is emitted. (D. Fournet, A. Pevsner, D. M. Ritson)

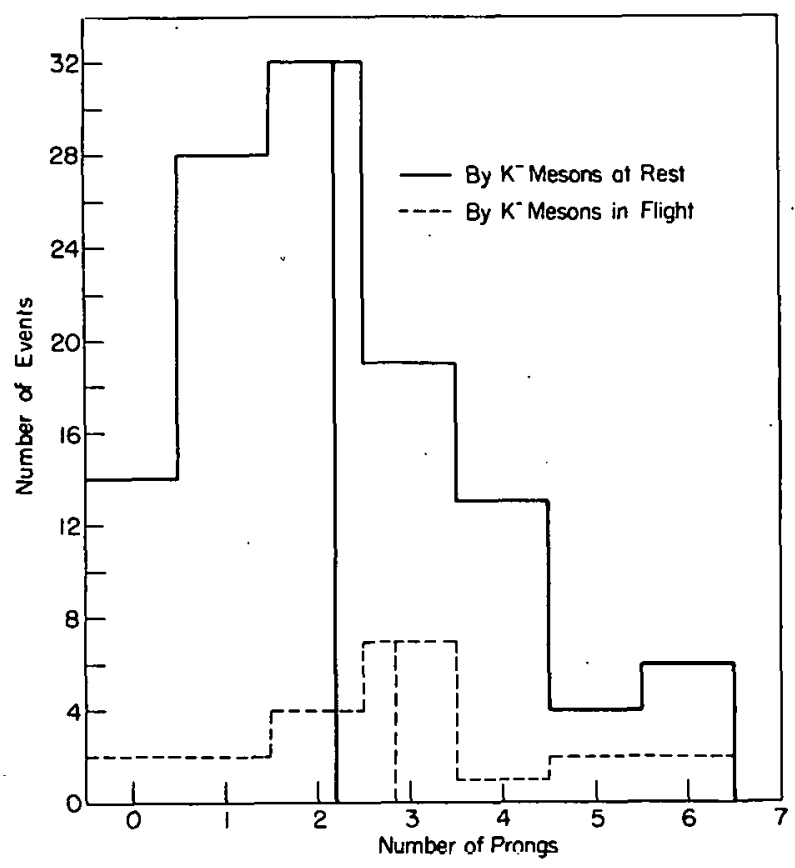

Figure 10.3

Prong distribution of stars produced by $\mathrm{K}^{-}$mesons at rest and $\mathrm{K}^{-}$mesons in flight.

\section{PHOTO-PROTON NEUTRON COINCIDENCES FROM NUCLEI}

The series of experiments on photo-proton neutron coincidences ${ }^{9}$ is being extended. New measurements will be made with an energy-sensitive neutron counter. With such a counter, it should be possible to directly measure the center-of-mass momentum of the pseudo deuterons in the nucleus.

The neutron energy is being measured by the same time-of-flight apparatus described above. However, neutrons of energy up to $100 \mathrm{Mev}$ are to be observed and hence a greater neutron path length (about 3 meters) is needed. The neutron detector described above subtends too small a solid angle at large distances, and a larger.counter has been designed. This counter, shown in figure 10.4, is broken up into small light-reflecting chambers in order to decrease the path length of the reflected light in the counter and thus decrease the uncertainty in the time of arrival of light from a given event. The counter has been built and is being tested. 


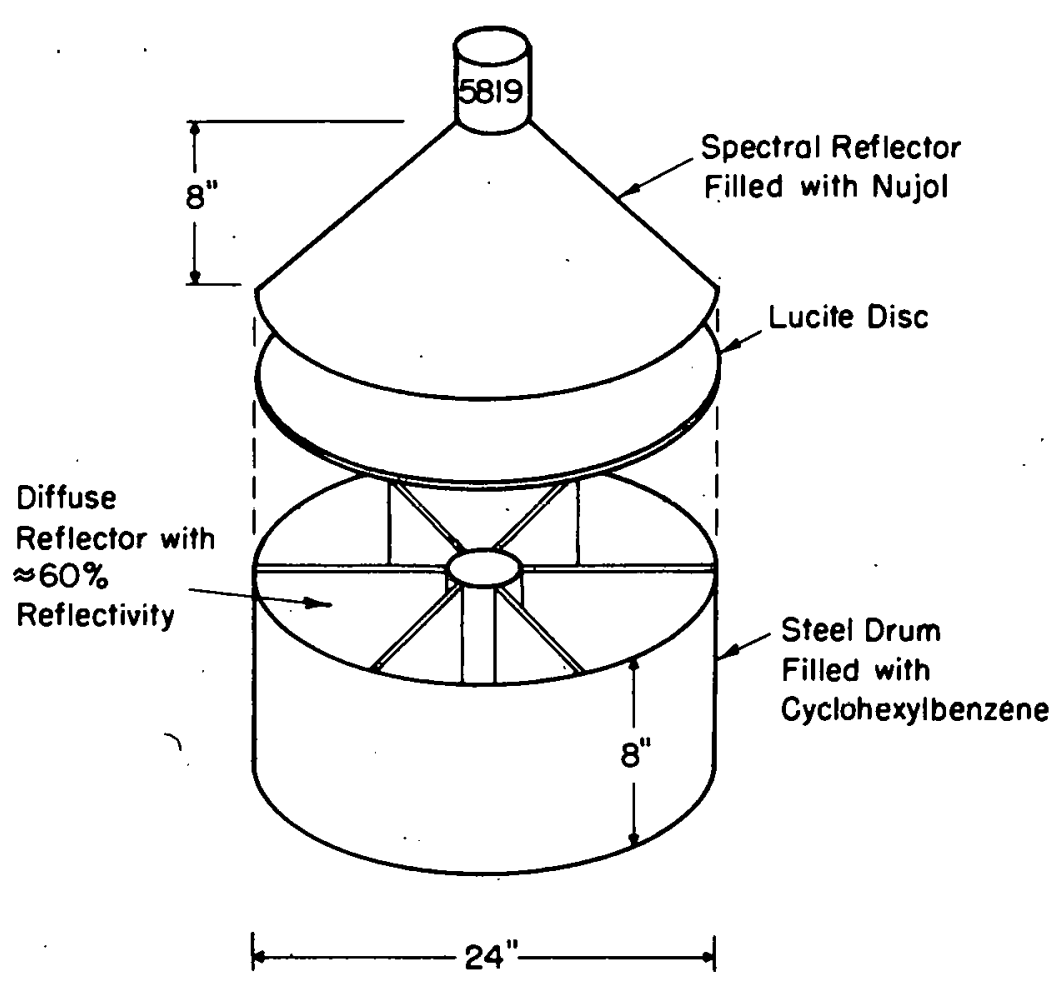

Figure 10.4

Large neutron counter for time of flight spectrometer.

(R. Weinstein, P. C. Stein, S. Ozaki)

\section{NUCLEAR EFFECTS ON PHOTOPRODUCTION OF $\pi^{+}$MESONS FROM DEUTERIUM}

An attempt is being made to measure the energies of the neutrons associated with the photoproduction of $\pi^{+}$mesons from deuterium. Such a measurement, it is hoped, will separate the contributions of spin-flip and non-spin-flip processes.

The neutron energies are being measured by a time-of-flight method, using a chronotron developed by R. Meunier and Meier Birk of this laboratory. The initiating pulse for the time interval is obtained from detection of the $\pi^{+}$meson. The $\pi$-meson detector consists of a threecounter telescope, and a fourth counter, surrounding the telescope, for the purpose of detecting the $\mu$-e decay. The neutron detector is a six-inch cylinder filled with liquid scintillator.

The time-of-flight detection method has been checked with neutron-pion coincidences from photo-meson production in hydrogen. (P. C. Stein, W. Rankin, A. Wattenherg, R. Weinstein)

\section{$310 \quad 061$}




\section{THE PHOTOPRODUCTION OF CHARGED PIONS FROM DEUTERIUM}

The following method for detecting charged pions without requiring them to stop in a crystal has been devised and constructed. The outputs of a counter telescope consisting of four thin crystals are displayed upon an oscilloscope with an artificial delay placed between them. Whenever a particle traverses the telescope, the oscilloscope sweep is triggered, and the scope display is photographed by a continuously moving camera. One thus looks at a portion of the Bragg curve.

One can identify a particle and its energy by its $\frac{d E}{d x}$ and rate of change of $\frac{d E}{d x}$ if the particle is near the end of its track. The system is calibrated by requiring positive pions to penetrate the four crystals and stop in a fifth crystal; the positive pions being identified by their subsequent $\mu$-e decay. The advantage of this method of detection is that it largely avoids the problem of stars due to negative pions which have come to rest in a crystal.

Some preliminary calibrations have been made using a carbon target and a magnet. Further calibration is needed using the liquid hydrogen target. The photoproduction of charged pions in which both nucleons are involved is to be studied in contrast to single-nucleon production - known as the "spectator process". (R. H. Land)

\section{SCATTERING OF GAMMA RAYS BY HYDROGEN AND OTHER LIGHT NUCLEI}

The six months' run reported in the L. N.S. November 30, 1955 Quarterly Progress Report has now been completely analyzed. The pulse-height response and absolute gamma-ray efficiencies for the telescope as a function of energy were computed from the electron calibration results. A second method to obtain the absolute cross-section was used which is independent of the beam. calibration and absolute efficiency of the counter; this was to observe with the counter both the direct beam and the scattered $\gamma$ rays. We estimated that our absolute cross-sections are good to 10 percent.

\section{Results}

All the data have been analyzed and the observed cross-sections were compared with the following cross-section:

$$
\sigma_{\mathrm{c}}=\mathrm{z}^{2} \mathrm{f}^{2} \dot{\sigma}_{\mathrm{T}}+\mathrm{z}\left(1-\mathrm{f}^{2}\right) \sigma_{\mathrm{KN}}
$$

where: $\mathrm{Z}=$ number of protons in the nucleus

$$
\begin{aligned}
\mathrm{f} & =\text { form factor }=\int_{0}^{\infty} \rho(\mathrm{r}) \frac{\sin \mathrm{r} \Delta \mathrm{K}}{\mathrm{r} \Delta \mathrm{K}} \mathrm{dr} \\
\sigma_{\mathrm{T}} & =\text { Thomson scattering cross-section for one proton } \\
\sigma_{\mathrm{KN}} & =\text { Klein-Nishina scattering cross-section for one proton (Dirac particle with charge e } \\
& \text { and mass } \mathrm{M}_{\mathrm{p}} \text { ) }
\end{aligned}
$$


1. Lithium, Beryllium and Carbon

In the region from 50- to $80-\mathrm{Mev}$ scattered gamma-ray energy, the cross-section at $90^{\circ}$ and $135^{\circ}$ was higher than $\sigma_{\mathrm{c}}$, reaching $2 \sigma_{\mathrm{c}}$ at $50 \mathrm{Mev}$. This is interpreted as the tail of the dipole giant resonance. At $45^{\circ}$ the yields were much higher, reaching at $50 \mathrm{Mev}$ six times the yields expected from $\sigma_{\mathrm{C}}$. This effect was carefully studied; the excess yield was proportional to $\mathrm{Z}^{2}$, to the target thickness, and roughly to $\theta^{-4}$ around $45^{\circ}$. It was also determined that it represented an inelastic process by studying its dependence on the peak energy of the bremsstrahlung. Rough estimates show that internal bremsstrahlung accompanying pair creation could be the process producing this excess yield.

In the more interesting region from $85 \mathrm{Mev}$ to $134 \mathrm{Mev}$ the cross-section at $90^{\circ}$ was essentially $\sigma_{\mathrm{C}}$; at $45^{\circ}$ it was smaller than $\sigma_{\mathrm{C}}$, dropping down to around $1 / 3 \sigma_{\mathrm{c}}$ at $120 \mathrm{Mev}$. In contrast with the behavior at $45^{\circ}$ the cross-section at $135^{\circ}$ was higher than $\sigma_{\mathrm{c}}$ reaching $2.5 \times \sigma_{\mathrm{c}}$ at $130 \mathrm{Mev}$. For these elements the statistical errors per 10-Mev interval were around \pm 5 percent for the region from $50 \mathrm{Mev}$ to $85 \mathrm{Mev}$, and \pm 15 percent for the region between $50 \mathrm{Mev}$ and $134 \mathrm{Mev}$.

Typical results for light nuclei are shown in Figure 10.5; the target in this case was Be. The ratio of the observed yield to the yield from a cross-section equal to $\sigma_{\mathrm{c}}$ has been plotted versus the scattered photon energy.

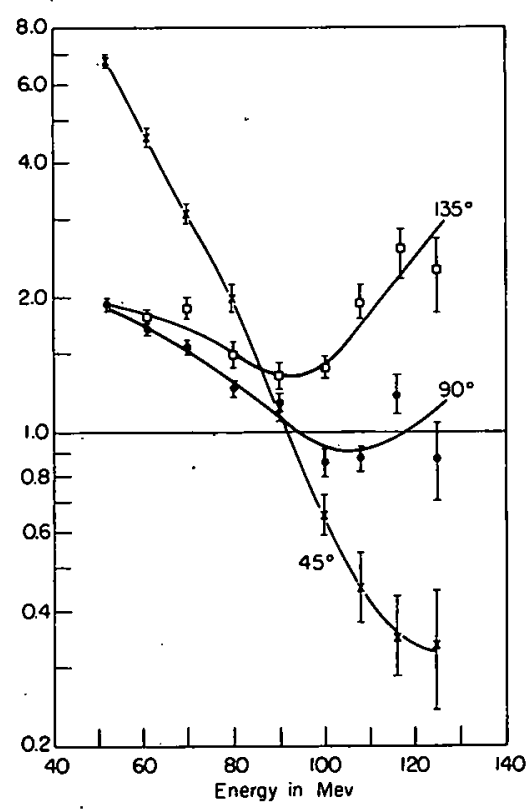

Figure 10.5

Ratio of yields from beryllium to yields from $\sigma_{c}$ (radius used $1.4 \mathrm{~A}^{\frac{1}{3}} \times 10^{-13}$ )

2. Hydrogen

Within the statistical error the $\mathrm{H}$ and the light-elements results agree fairly well in the region from 85 to $134 \mathrm{Mev}$. From $50 \mathrm{Mev}$ to $85 \mathrm{Mev}$ the cross-section follows Klein-Nishina except 
62

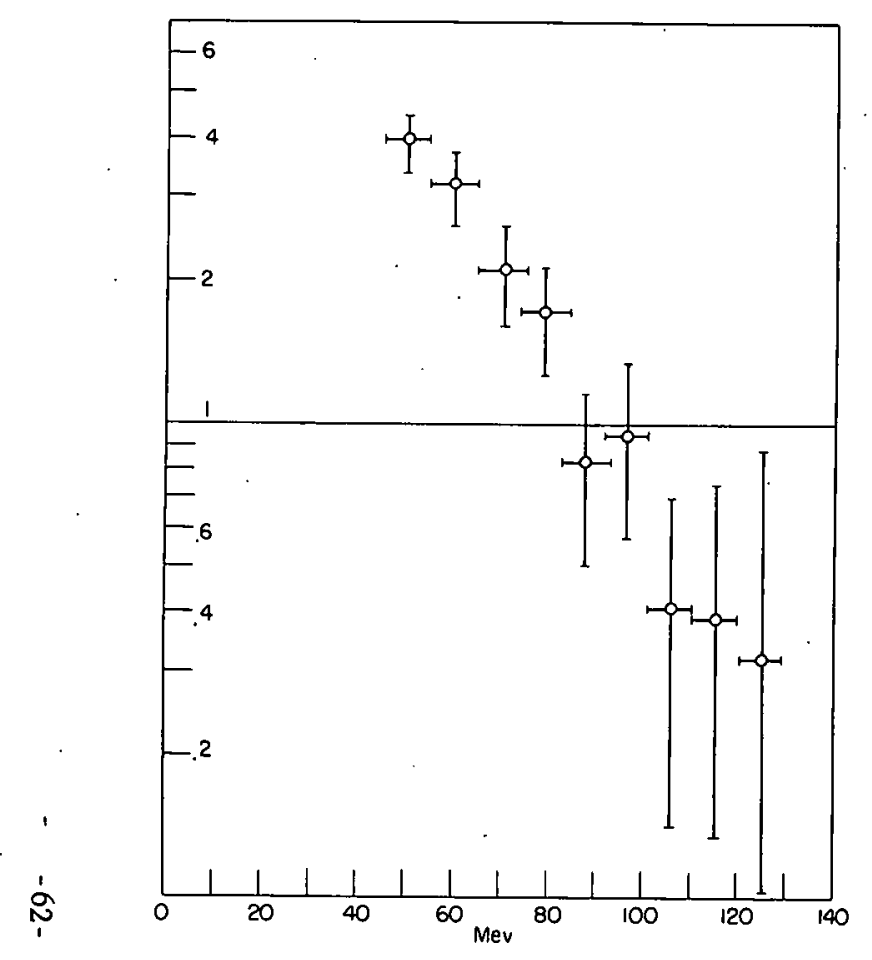

Figure 10.6

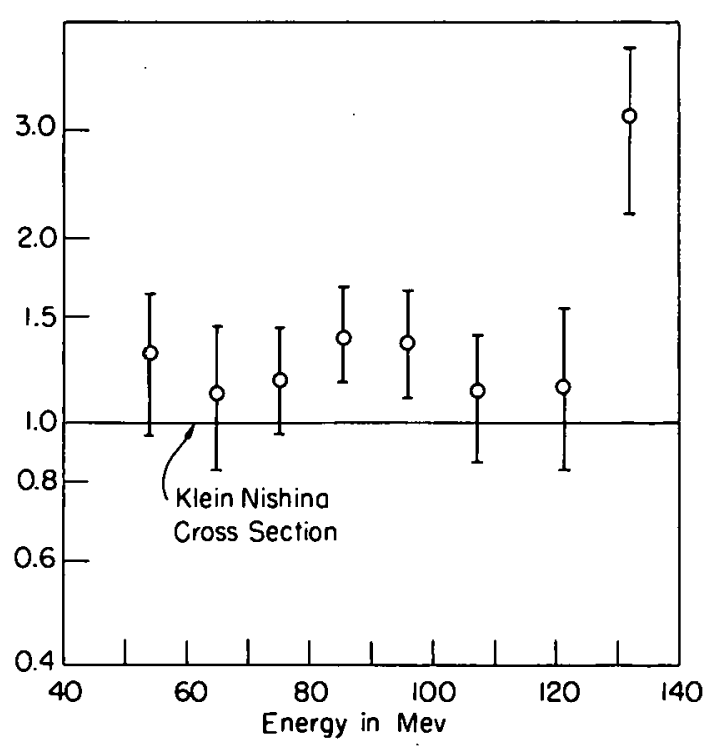

Figure 10.7

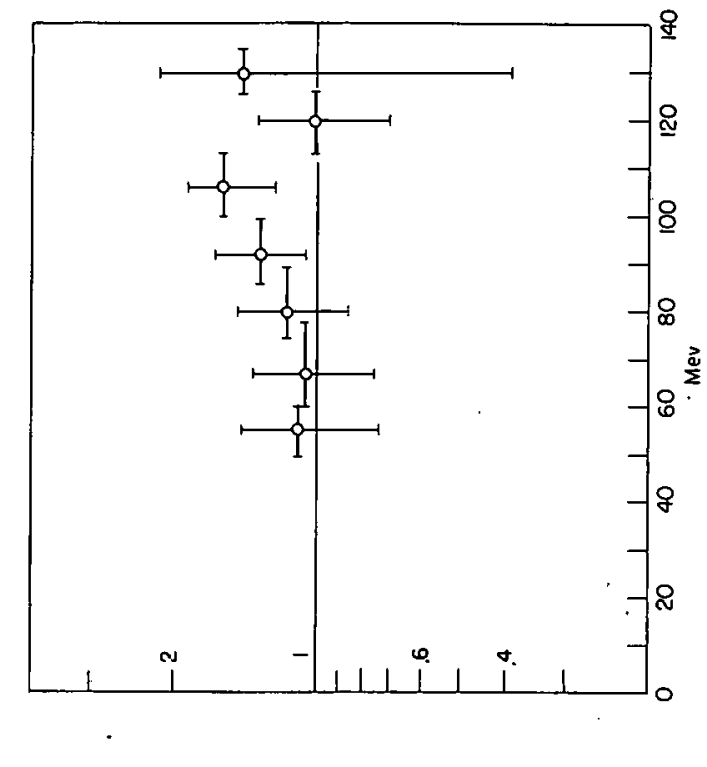

Figure 10.8

$\mathrm{H}_{2}$ cross section at $45^{\circ}$ ratio to Klein-Nishina. $\mathrm{H}_{2}$ cross section at $90^{\circ}$ ratio to Klein-Nishina. $\mathrm{H}_{2}$ cross section at $135^{\circ}$ ratio to Klein-Nishina.

总

o. 
at $45^{\circ}$ where it showed the great increase in the yield as observed in the other elements.

Figures 10.6 to 10.8 show the results from Hydrogen at $45^{\circ}, 90^{\circ}$ and 1350 in the lab system. The ratio of the observed yield to the yield from a cross-section equal to $\sigma_{\mathrm{KN}}$ has been plotted versus the incident energy of the scattered photon. (D. Frisch, R. Gomez, S. Janes and G. Pugh)

\section{REFERENCES}

1. Goldschmidt Clermont, Osborne, Scott, Phys. Rev. 97, 188-193 (1955).

2. D. C. Oakley, R. L. Walker, Phys. Rev. 97, $1283-1291$ (1955).

3. John Chappelear, Phys. Rev. 99; 254-260 (1955).

4. R. M. Littauer and D. Walker, Phys. Rev. 86, 838-846 (1952).

5. Handler, Osborne, Richter, " $\pi^{+}$.Photoproduction from Hydrogen", Laboratory for Nuclear Science Progress Report, p. 57, Auguśt 31, 1955.

6. H. A. Bethe and R. R. Wilson, Phys. Rev. $\underline{83}, 690$ (1951).

7. Dilworth et.al., Phil. Mag. 41, 1032 (1950).

8. K. S. W. Champion, Procedings of the Physical Society (London) B 63, 795 (1950).

9. Previous Laboratory for Nuclear Science Progress Reports.

L. S. Osborne 


\section{NEUTRON SCATTERING ABSORPTION BY A DIFFUSE-EDGED CLOUDY CR YSTAL BALL MODEL}

Calculations are proceeding on a nucleon-nuclear potential which has a tail rather than being sharp-edged, as was the case in previous calculations with the square well potential. In addition, the notions of effective range and scattering length are being considered as possibilities for the correlation of low-energy data. (H. Feshbach, C. E. Porter, and V. F. Weisskopf)

\section{INELASTIC SCATTERING VIA DIRECT INTERACTION}

A paper has been written, based on the ideas discussed in the last Quarterly Progress Report. The direct interaction between the incident nucleon and the nucleon is assumed to be a delta-function form with the understanding that anything of longer range will be included in the average nuclear-nucleon potential.: Calculations of this effect have shown cross sections of the order of several millibarns for a carbon target nucleus with the incident neutron of energy in the neighborhood of $5 \mathrm{Mev}$. This indicates that the most favorable place at which to observe this effect would be in between the energies at which compound nuclear resonances occur. Measurement of a direct interaction would indicate the nature of nucleon-nucleon forces inside the nucleus.

(J. LaMarsh and H. Feshbach)

\section{RELATIVISTIC WAVE MECHANICS}

A report is being written, in which we try to give a unified presentation of the relativistic wave mechanics of spin $O, \operatorname{spin} 1 / 2$ and spin 1 particles. The interpretation of the wave function will be discussed, and the connection with the quantum-field theoretical description will be established. The discussion will be elementary throughout, and we hope this report will be useful to experimentalists having to deal with relativistic particles. (H. Feshbach and F. Villars)

\section{NUCLEAR SATURATION}

An attempt is underway to generalize the Brueckner theory of nuclear saturation to finite size nuclei. The essential quantity in the Brueckner theory is the coherent scattering amplitude $t_{c}$. For a finite nucleus, $t_{c}$ is replaced by an analogous amplitude $t_{c}^{\prime}$, which is related to $t_{c}$ by a simple integral equation. Models for $t_{c}$ are now being constructed. The equation for $t_{c}^{\prime}$ has not 
as yet been solved. (F. Villars)

\section{THE BOHR-MOTTELSON MODEL.}

As reported earlier, the problem of collective motion in a nucleus is solved by using a method of canonical transformations. The resulting transformed Hamiltonian has the structure of the Hamiltonian of the. Bohr-Mottelson unified model, but with some additional terms. The collective motion is almost decoupled from the intrinsic motion. However, the residual coupling may still affect strongly the rotational level spectrum. To investigate this effect, a perturbation method is now being developed. This is a non-trivial problem, because of the subsidiary condition which the wave function has to satisfy (see previous reports). "(F. Villars)

\section{CHEW-LOW TREATMENT OF S-WAVE MESONS}

A fixed source analysis of S-wave meson scattering has been constructed along the lines of the Chew-Low Wick Formalism. A bilinear S-wave interaction of the form $\lambda_{0} \varphi^{2}+\lambda \underline{\tau} \cdot \underline{\phi} \times \underline{\pi}$ is added to the usual $\mathrm{P}$-wave coupling $\mathrm{g} \underline{\sigma} \cdot \underline{\nabla} \underline{\tau} \cdot \underline{\phi}$ : Scattering and photoproduction equations are developed in an analogous manner to that discussed by Wick ${ }^{1}$. The specific S-wave interaction assumed in this work leads to scattering equations of the same form as that obtained from the dispersion relations. 2 An approximate solution to the scattering problem in the one meson approximation is in reasonable agreement with the experimental phase shifts up to $100 \mathrm{Mev}$. An exact relation is derived between the S-wave photoproduction from the dominant $\underline{\sigma} \cdot \underline{\mathrm{A} \tau} \cdot \underline{\phi}$ term and the scattering solution. As a result of the Kroll-Ruderman theorem, rescattering of the photoproduced S-wave meson alters the Chew-Low results by only five percent. (S. D. Drell, M. H. Friedman, F. Zachariasen )

\section{PRODUCTION OF S-WAVE MESONS IN MESON-NUCLEON COLLISIONS}

The equation for the production of S-wave mesons in meson-nucleon collisions has been constructed using the Chew-Low formalism.

The cross section for the process was found to be zero if the term in the interaction Hamiltonian responsible for $S$-wave production is taken to be $\phi^{2}$.

Work is in progress on solving the equation on the assumption that the $\mathrm{S}$-wave interaction Hamiltonian contains both $\phi^{2}$ and $\tau \cdot \phi \times \pi \cdot$ (S. D. Drell and A. Bincer) 
Theoretical Group

VIII. NUCLEAR SCATTERING OF RELATIVISTIC NUCLEONS

The nuclear potential which is effective for elastic scattering of nucleons in the energy range up to several hundred Mev is larger than the "matter" or charge radius, presumably because of the range of the nucleon-nucleon interaction. The effective interaction as deduced from a (pseudo) scalar meson field theory is reduced in the large-impact parameter collisions of relativistic nucleons with nuclei by a factor

$$
\langle\beta\rangle=\left[1-\left(\mathrm{v}^{2} / \mathrm{c}^{2}\right)\right]^{\frac{1}{2}}=\mathrm{mc}^{2} / \mathrm{E}
$$

Thus, elastic or total cross sections for nucleons in the Bev range should lead to a smaller radius for the potential. (S. D. Drell, and R. W. Williams)

\section{A HIGH-ENERGY APPROXIMATION FOR RELATIVISTIC SCATTERING CROSS SECTIONS}

The short wave length approximation of Molière ${ }^{3}$ has been extended to take account of both relativistic and spin effects. The approximation is best at small angles, but still gives good agreement with exact calculations at $90^{\circ}$, even for large values of $Z$, both for Coulomb scattering and for scattering by an extended nucleus. The method should be particularly useful for calculating variations of the scattering cross section, when the form factor of the extended nucleus is varied. An extension to potentials not spherically symmetrical is discussed. (L. R. B. Elton)

\section{SCATTERING OF NUCLEONS BY NUCLEI AT ENERGIES OF ABOUT $30 \mathrm{MEV}$}

The problem has been formulated on a semi-classical basis; i.e. the beam of incident particles is refracted into the nucleus and the trajectories of individual particles are then followed through. Calculations for the scattering of $31-\mathrm{Mev}$ protons by $\mathrm{Sn}$ are in progress. It is hoped that they can eventually be tested against experiments. (L. R. B. Elton)

\section{REFERENCES}

1. G. C. Wick, Revs. Modern Phys. 27, 339 (1955).

2. M. Goldberger, private communication.

3. G. Moliere, Zeits. f. Naturf. 2A, 133 (1947). 


\title{
PUBLICATIONS
}

F. L. Friedman, and V. F. Weisskopf, "The Compound Nucleus", Niels Bohr and the Development of Physics; Pergamon Press, London, 1955.

V. F. Weisskopf, "A Model of the Nucleus", Scientific American, December, 1955.

\author{
V. F. Weisskopf
}


CAMBRIDGE ACCELERATOR PROJECT GROUP

(Harvard-M.I.T. Strong Focusing Synchrotron)

For several years staff members of the Laboratory for Nuclear Science at M. I. T. have cooperated with a similar group from the Harvard University Physics Department, in the planning and design of a high energy accelerator to serve the future research needs of scientists in the Cambridge area. Initially, the design efforts were concentrated on a protun synchrotron using alternating gradient magnetic focusing, and culminated in a L.N.S. Technical Report. ${ }^{1}$ This study was submitted as a proposal to the U.S. Atomic Energy Commission, but funds for construction of university-located accelerators were not available at that time. Subsequently, a parallel design study at the Brookhaven National Laboratory was received with favor by the A.E. C., and authorization was given for the design and construction of a 25-30 Bev proton accelerator at Brookhaven.

In April 1954, the Cambridge group renewed their design activity, directed toward an electron synchrotron of 5 to $6 \mathrm{Bev}$ energy. A preliminary proposal was submitted to the A. E. C. on August 17, 1954, followed by further memoranda on August twenty-seventh and December first, although funds for accelerators in universities were still not available within the A.E.C., this proposal (strengthened by a parallel proposal from Princeton University) prompted the inclusion of an item in the A. E. C. Research Division budget to provide such support. In letters from Dr. T. H. Johnson of the A.E. C. on July 6, and August 4, 1955, we learned of the potential availability of funds for university accelerators, and were requested to submit a proposal by January 1, 1956.

With these more favorable prospects the Cambridge Accelerator Project was revitalized. M.I.T. and Harvard administrations made funds available to employ several full-time personnel and to initiate model studies. Three physicists were employed by the project: Dr. G. Lanza, Dr. K. Robinson and Dr. R. Waniek. One laboratory technician was also employed, starting in July and August of 1955. Space was provided by M. I. T. for offices and laboratories. The facilities of the Laboratory for Nuclear Science stock-rooms, drafting office and machine shops were made available to the CAP group. Frequent meetings of the CAP design staff were held, to discuss design problems and decide on machine parameters. This effort culminated as a "Proposal for a 6-Bev Electron Accelerator", dated December 15, 1955, and submitted to the A.E.C. as a formal proposal for support.

Subsequent information from Dr. Johnson of the A. E. C. indicates that the proposal is receiving serious attention, and that we can be hopeful of favorable action in the near future. Conferences have been held with members of the A.E.C. Research Division, representatives from the New York Area office of the A.E.C. and members of the A.E.C. engineering staff, to discuss alternative proposals, contract procedures and cost estimates. These discussions have supported our hope for support for an electron accelerator of still higher energy. On February 10, 1955, an "Amendment" proposal for a 7.5-Bev accelerator was submitted to the A.E.C. Negotiations are 
still in process relative to the two alternative proposals.

In illustration of the work of the CAP group, the design parameters for an electron accelerator of $7.5 \mathrm{Bev}$ are given in Table 12.1.

\section{Stanley Livingston (Director Cambridge Accelerator Project)}
P. T. Demos
B. T. Feld
D. H. Frisch
W. L. Kraushaar
L. S. Osborne
A. Pevsner
B. Richter
D. Ritson
A. Wattenberg
R. W. Williams 
Table 12.I

Parameters

1. Magnet:

$\mathrm{R}_{\mathrm{O}}$, magnet circle radius

$\mathrm{C}$, circumference at orbit

$118.0 \quad \mathrm{ft}$

$741.0 \quad \mathrm{ft}$

$M$, number of magnet sectors

48.

$\ell_{0}$, mag. length/straight section

$3.5 \mathrm{ft}$

$\ell$, mag. length/sector

$11.94 \mathrm{ft}$

$r_{0}$, orbit radius

$L^{\prime}$, total phys. length of sectors

$91.2 \mathrm{ft}$

Area of iron magnetic circuit

$563.0 \quad \mathrm{ft}$

Weight of iron/sector

$2.53 \mathrm{ft}^{2}$

Weight of iron, total

6.73 tons

323. tons

2. Alternating Gradient Parameters:

$\mathrm{N}=\frac{1}{2} \mathrm{M}$, number of $\mathrm{AG}$ units/turn

24.

$\nu$, number of betatron wavelengths/turn

5.40

$\sigma=\frac{2 \pi \nu}{N}$, phase angle $/ A G$ unit

$1.41 \mathrm{rad}$.

n-value

116.

Pole face hyperbola

$(9.45 x) y=9.45$ in $^{2}$

$g_{\min }$, pole gap at $x=4$ in.

1.40 in

3. Magnet Coil:

$\mathrm{N}_{c}$, number of turns/sector

$A_{1}$, cross section of $\mathrm{Cu} /$ turn

8.

$\mathrm{X}_{1}$, av. length $\mathrm{Cu} /$ turn

3.25 in $^{2}$

Volume $\mathrm{Cu} /$ sector

$27.3 \mathrm{ft}$

Weight $\mathrm{Cu} /$ sector

$4.92 \mathrm{ft}^{3}$

Weight $\mathrm{Cu}$, total

1.35 tons

65.

$R_{N}$, resistance of $N$ turns

$2.70 \times 10^{-2}$ ohms

4. Magnet Bus Bars:

$A_{2}$, cross section of bus bar

$X_{2}$, length of $4 \pi R_{o}$ plus leads

$R_{2}$, resistance of bus bars

Volume of $\mathrm{Cu}$, bus bars

Weight of $\mathrm{Cu}$, bus bars

\begin{aligned} 6.0 & \multicolumn{1}{c}{ in $^{2}$} \\ 1800. & $\mathrm{ft} \\ 2.5 \times 10^{-3} &$ ohms \\ 75. & $\mathrm{ft}^{3} \\ 17.5 &$ tons \end{aligned}


Table 12.I (Cont.).

Parameters.

5. Magnet Excitation (half-dc-bias):

$\mathrm{B}_{0}$, av. field for $7.5 \mathrm{Bev}$

$\begin{aligned} 9.0 & \text { kilogauss } \\ 9.2 & \text { kilogauss } \\ 4.31 \times 10^{4} & \text { amp-turns } \\ 39.2 & \text { webers } \\ 5.40 \times 10^{3} & \text { amp } \\ 2.70 \times 10^{3} & \text { amp } \\ 58 . \quad \times 10^{-3} & \text { henries } \\ 0.85 \times 10^{6}: & \text { joules } \\ 15.0 & \text { cps } \\ 1960 . & \mu \text { farad } \\ 14.8 & \text { kilovolt } \\ 10.4 & \text { kilovolt } \\ 80.0 & \text { volts }\end{aligned}$

6. Power Supply for Magnet:

2- res. capac., $\mathrm{C}^{\prime}=2 \mathrm{C}_{0}$, each

Voltage, peak

3920. $\quad \mu \mathrm{farad}$

Stored energy, peak.

Power rating

2- chokes, $\frac{1}{2} \mathrm{~L}_{1}=0.875 \mathrm{~L}_{\mathrm{O}}$, each

Stored energy, peak

Resist. of 96-turn winding

2- capac. across chokes, C', each

Voltage, peak

Stored energy

Power rating

Resistance dc circuit, total

Voltage required, dc

Power required, dc

Power required, ac

Power for magnet, total

$7.4 \quad$ kilovolt

95. $\times 10^{3}$ joules

$8.9 \times 10^{3} \quad \mathrm{kva}$

$50.8 \times 10^{-3}$ henries

413. $\times 10^{3}$ joules

$7.0 \times 10^{-3}$ ohms

2220. $\quad \mu$ farad

7.4 kilovolts

61. $\times 10^{3}$ joules

$5.75 \times 10^{3} \quad \mathrm{kva}$

$3.09 \times 10^{-2}$ ohms

. 118 . volts

320. kilowatt

340. kilowatt

660. kilowatt

7. Injection (Linear Accelerator):

$T_{i}$, linac energy

40.0 Mev

$B_{i}$, mag. field at inject.

48.0 gauss 
Table 12.I (Cont.)

$f$, pulse repetition rate

$\mathrm{f}_{\mathrm{O}}$, orbital frequency

$\mathrm{T}_{\mathrm{o}}$, orbital period

$i_{o}$, linac peak pulse current
15. cps

1.33 Mc

$0.75 \cdot \mu \mathrm{sec}$

0.25 amp

8. Inflection: (no change)

9. Orbit Acceptance:

$\mathrm{N}_{\mathrm{o}}$; no. electrons injected/pulse

$1.0 \times 10^{12} \quad$ el/pulse

$N_{1}$, no. electrons accepted/pulse

$3.3 \times 10^{11}$ el/pulse

$\mathrm{N}_{2}$, no. electrons captured/pulse

$1.9 \times 10^{11}$ el/pulse

10. Radiofrequency Acceleration:

$\mathrm{eV}_{1}$, max. rate accel. due to $\mathrm{dB} / \mathrm{dt}$

$\begin{array}{rr}0.21 \times 10^{6} & \text { ev/turn } \\ 10.1 \times 10^{6} & \text { ev/turn }\end{array}$

$\mathrm{eV}_{2}$, radiation loss at $7.5 \mathrm{Bev}$

16.

$\mathrm{V}_{\mathrm{e}}$, rf acceleration/cavity

$0.63 \times 10^{6} \quad$ ev/cav.

$\mathrm{V}_{\text {app}}$, peak applied rf volts

$0.89 \times 10^{6} \quad \mathrm{ev} / \mathrm{cav}$.

$h$, harmonic order

346.

$\mathrm{f}^{\prime}$, applied radiofrequency

Dimensions of cavity (2-sec.)

$Q$, electrical effic. of cavity

$R^{\prime}$, shunt impedance of cavity

$i^{\prime}=\mathrm{N}_{2} \mathrm{f}_{\mathrm{o}} \mathrm{e}$, cavity beam current

460.

Mc

$1.75 \times 2.5 \quad \mathrm{ft} \times \mathrm{ft}$

$3.5 \times 10^{4}$

$1.0 \times 10^{7}$ ohms

$0.04 \mathrm{amp}$

$\mathrm{P}_{\mathrm{L}}$, beam power load, peak

$25.2 \mathrm{kw} / \mathrm{cav}$.

${ }_{\mathrm{C}}$, rf dissip. power, peak

$39.6 \mathrm{kw} / \mathrm{cav}$.

65. kw/cav.

$\mathrm{P}_{\mathrm{T}}$, peak rf power/cavity, total
$\mathrm{P}_{1}$, av. rf power/cavity (duty cycle)

$11.5 \mathrm{kw} / \mathrm{cav}$.

$\mathrm{P}_{\mathrm{av}}$, av. rf power, total

$\mathrm{P}_{\mathrm{dc}}$, dc power at $25 \mathrm{kv}$ for klystrons

$184 . \quad \mathrm{kw}$

$750 . \quad \mathrm{kw}$

11. Correcting Lenses: (no change)

12. Beam Properties:

$T_{m}$, final electron energy

$\mathrm{N}_{2}$, number electrons accel./ pulse

$\mathrm{fN}_{2}$, number electrons/sec
7.5 Bev
$1.9 \times 10^{11} \quad$ el/pulse
$2.5 \times 10^{12} \mathrm{el} / \mathrm{sec}$ 
Table 12.I (Cont.)

$\mathrm{i}_{2}$, equiv. av. beam current

Parameters

$P_{\text {rad, power radiated }}$

$0.4 \times 10^{-6}$

amp.

$-\quad \mathrm{P}_{2}$, average beam power

36.4

$3.1 \mathrm{kw}$

kw 


\section{APPENDIX}

PERSONNEL LISTING BY PROJECTS

ADMINISTRATION

$\underline{\text { Steering Committee }}$

Zacharias, Prof. J. R. (Chairman)

Harrison, G. R., Dean of School of Science

Benedict, Prof. Manson

Cope, Prof. A. C.

Frank, Prof. N. H.

\section{Headquarters}

Zacharias, Prof. J. R., Director

Demos, Dr. P. T., Assistant Director

Eppling, Dr. F. J.

Thompson, D. C.

Sargeant, J. L., Purchasing

DeAgazio, E., Electronics Shop

Tourtellotte, C. W., Drafting

Gustavson, R. H., Machine Shop

Scrima, V., General Service

\section{RESEARCH GROUPS}

Chemistry of the Fission Elements Group

$\underline{\text { Staff }}$

Hume, Prof. D. N.

Rogers, Prof. L.B.

Whiteker, Dr. R. A.

Graduate Students

Breese, R. F.

Burns, E. A.

DeGeiso, R. C.

Forman, E. J.

Hanselman, R. B.

Heintz, E. A.

Hercules, D. M.

Keily, H. J.

Lee, J. K.

Morrison, C. F.

Newman, L.

Ohnesorge, W. E.

Przybylowicz, E. P.

Reinmuth, W. H.

* Terminated
Nucleax Chemistry (Inorganic) Group

$\underline{\text { Staff }}$

Coryell, Prof. C. D.

Irvine, Prof. J. W., Jr.

Cotton, Dr. F. A.

Horne, Dr. R. A.

Schindewolf, Dr. U. L. .

Graduate Students

Alexander, J. M.

Dietz, R. J., Jr.,

Fix, R. C.

Gleit, C. E.

Freeman, D. H.

Poskanzer, A. M.

Rudzitis; E.

\section{Visitors}

Dostrovsky, Dr. Israel (Head of the Isotopes Department, Weizmann Institute of Science, Rehovoth, Israel; Member of the Israeli Atomic Energy Commission ).

Shiokawa, Prof. Takanobu * (Department of Radiochemistry, Shizuoka University, Shizuoka, Japan).

Nuclear Chemistry (Organic) Group

Staff

Greene, Prof. F. D., II

Sheehan, Prof. J. C.

Swain, Prof. C. G.

Kresge, Dr. A. J.

Graduate Students

Bader, R. F. W.

Reuwer, J. F., Jr.

Schaad, L. J.

Zanet, P. M.

Cosmic Ray Group

Staff

Rossi, Prof. B. B.

Bridge, Dr. H. S. 
Blumenfeld, Dr. H.

Caldwcll, Dr. D. O.

Clark, Prof. G. W.

Kraushaar, Prof. W. L.

Linsley, Dr. J.

Olbert, Dr. S.

Pevsner, Dr. A.

Smith, W. B.

Williams, Prof. R. W.

Graduate Students

Boldt, E. A.

Brenner, A.

D'Arcy, R.

Earl, J. A.

Pal, Y.

Sandri, G.

Scherb, F.

Stora, R.

Strickland, J. S.

$\underline{\text { Visitors }}$

Jauneau, Dr. L.

Ecole Polytechnique, Paris, France

Elementary Particle Scattering Group

Staff

Demos, Dr. P. T.

Feld, Prof. B. T.

Frisch, Prof. D. H.

Ritson, Dr. D. M.

Sargent, Dr. C. P.

Schluter, Dr. R. A.

Strumski, C. J.

Wattenberg, Dr. A.

Graduate Students

Bertozzi, W.

Paolini, F. R.

Wächter, M. H.

Rockefeller Generator Group

Staff

Goodman, Prof. C. (Absent)

Paulissen, George T.

Salomaa, Matti K.

Graduate Students

Collins, Stuart A.*

* Terminated
Visitors

Goldring, Dr. G.

Weizmann Institute; Rehovoth, Israel

Guernsey, Dr. Janet B.

Wellesley College, Wellesley, Mass.

ONR Generator Group

Staff

Buechner, Prof. W. W.

Van de Graaff, Prof. R. J.

Browne, Dr. C. P.

Enge, Dr. H. A.

Eppling, Dr. F. J.

Sperduto, A.

Graduate Students

Angleman, C. C., Lt. USN

Berger, D. W., Lt. USN

Green, J. W., Lt. USN

Helfer, D. L.

Jarrell, D. L., Lt. USN

Loper, O. J., Lt. USN

Sharp, R. D.

Smith, A. J., Lt. USN

Wahlig, M. A.

Visitors

Paris, Dr. C. H.

University of Utrecht, Utrecht, Holland

Squires, Dr. G. L.

Cavendish Laboratory, University

of Cambridge, Cambridge, England

Radioactivity and Cyclotron Group

Staff

Evans, Prof. R. D.

Deutsch, Prof. M.

Livingston, Prof. M. S.

Bulkley;' J. B.

Backofen, Elizabeth W.

Brownell, Dr. G. L.

Hine, Dr. G. J.

Kendall, Dr. H. W.

Scharenberg, Dr. R. P.

Wall, Dr. N. S.

White, E. F.

Graduate Students

Darden, C. W.

Ferguson, J. M. 
Gittelman, B.

Hunting, C. E.

McCall, R. C.

Swenson, L. W.

Waldorf, W. F.

Watters, H. J.*

$\underline{\text { Visitors }}$

Ljunggren, K.*

The Royal Institute of Technology

Stockholm, Sweden

Looney, Dr. W. B.

Natl. Institutcs of Health

Bethesda, Maryland

Synchrotron Group

$\underline{\text { Staff }}$

Osborne, Dr. L. S.

Feld, Prof. B. T.

Frisch, Prof. D. H.

Wattenberg, Dr. A.

Janes, Dr. G. S.

Lobar, W.

Pugh, Prof. G. E.

Ritson, Dr. D. M.

Schluter, Dr. R. A.

Strumski, C. J.

Weinstein, Dr. R. M.

Graduate Students

Barringer, R.

Fournet, D.

Gomez,' R.

Hyman, L.

Land, R.

Maglich, B.

Ozaki, S.

Richter, B.

Russell, J., Jr.

Stein, P. C.

Visitors

Meunier, Dr. R.

Commissariat a l'energie Atomique, France

Theoretical Group

$\underline{\text { Staff }}$

Weisskopf, Prof. V. F. Feshbach, Prof. H.
Drell, Prof. S. D.

Elton, Dr. L. R. B.

Friedman, Prof. F. L. (On leave)

t

Friedman, Prof. M. H.

Villars, Prof. F.

Zachariasen, F.

Graduate Students

Bincer, A. M.

Visitors

Beck, Dr. F.*

Fritz Haber Institut der Max Planck

Gesellschaft, Berlin-Dahlem

Germany

Zemach, Dr. C.

Harvard University

Cambridge, Mass. s. 


$$
\begin{gathered}
\text { I- II ANd } \\
1-76
\end{gathered}
$$

\section{THIS PAGE}

\section{WAS INTENTIONALLY}

LEFT BLANK 